$45 / 116595(2)$

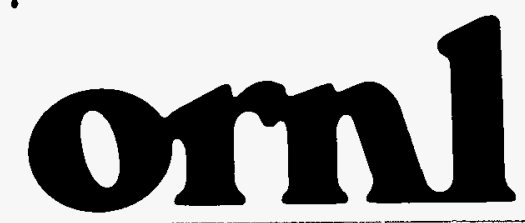

OAK RIDGE NATIONAL LABORATORY

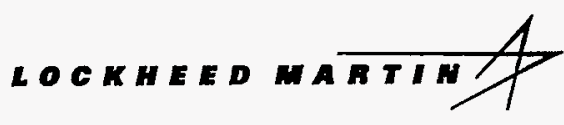

MANAGED BY

LOCKHEED MARTIN ENERGY SYSTEMS, INC.

FOR THE UNITED STATES

DEPARTMENT OF ENERGY

UCN-13673 (38 6-95)
ORNL-6875

\section{BIOLOGY DIVISION PROGRESS REPORT}

For Period of

October 1, 1993 - September 30, 1995
DISTRIBUTION OF THIS DOCUMENT IS UNLIMITED 
This report has been reproduced directly from the best available copy.

Available to DOE and DOE contractors from the Otfice of Scientific and Technical Information, P.O. Box 62, Oak Ridge, TN 37831; prices available from (615) 576-8401, FTS 626-8401.

Available to the public from the National Technical Information Service, U.S. Department of Commerce, 5285 Port Royal Rd., Springfield, VA 22161.

This report was prepared as an account of work sponsored by an agency of the United States Government. Neither the United States Government nor any agency thereof, nor any of their employees, makes any warranty, express or implied, or assumes any legal liability or responsibility for the accuracy, completeness, or usefulness of any information, apparatus, product, or process disclosed, or represents that its use would not infringe privately owned rights. Reference herein to any specific commercial product, process, or service by trade name, trademark, manufacturer, or otherwise, does not necessarily constitute or imply its endorsement, recommendation, or favoring by the United States Government or any agency thereof. The views and opinions of authors expressed herein do not necessarily state or reflect those of the United States Government or any agency thereof. 


\section{DISCLAIMER}

Portions of this document may be illegible electronic image products. Images are produced from the best available original document. 
ORNL-6875

Distribution Category UC-408

\section{BIOLOGY DIVISION PROGRESS REPORT}

For Period of October 1, 1993 - September 30, 1995

Date Published: October 1995

F. C. Hartman, Director

Section Heads

S. K. Niyogi, Molecular, Cellular, and Cancer Biology

R. P. Woychik, Mammalian Genetics and Development

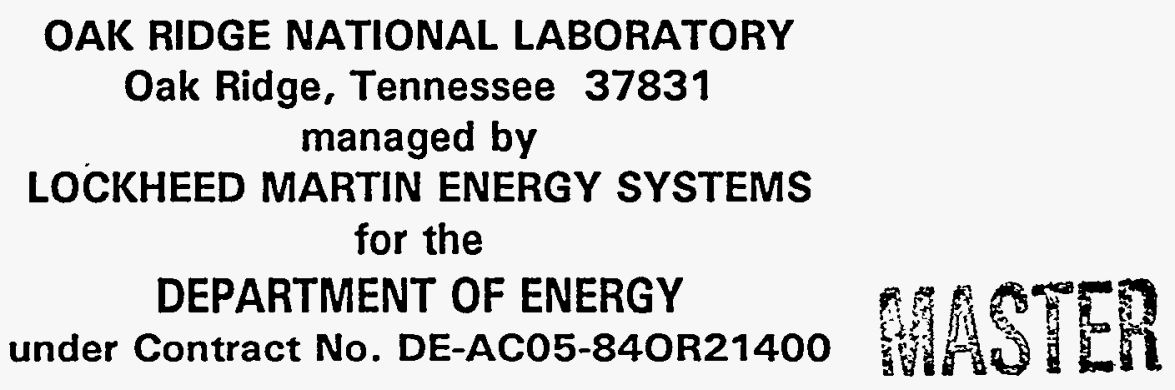


Reports previously issued in this series are as follows:

ORNL-13

ORNL-61

ORNL-150

ORNL-220

ORNL-318

ORNL-244

ORNL-457

ORNL-537

ORNL-644

ORNL-727

ORNL-807

ORNL-889

ORNL-969

ORNL-1026

ORNL-989

ORNL-1167

ORNL-1244

ORNL-1297

ORNL-1393

ORNL-1456

ORNL-1497

ORNL-1614

ORNL-1693

ORNL-1776

ORNL-1863

ORNL-1953

ORNL-2060

ORNL-2155

ORNL-2267

ORNL-2390

ORNL-2481

ORNL-2593

ORNL-2702

ORNL-2813

ORNL-2913

ORNL-2997

ORNL-3095

ORNL-3201

ORNL-3267

ORNL-3352

ORNL-3427

ORNL-3498

ORNL-3601

ORNL-3700

ORNL-3768

ORNL-3853

ORNL-3922

ORNL-3999

ORNL-4100

ORNL-4240

ORNL-4412

ORNL-4535

ORNL-4740

ORNL-4817

ORNL-4915

ORNL-4993

ORNL-5072

ORNL-5195

ORNL-5685

ORNL-5927

ORNL-6021

ORNL-6119

ORNL-6248

ORNL-6353

ORNL-6499

ORNL-6604

ORNL-6679

ORNL-6757
Period Ending February 29, 1948

Period Ending May 31, 1948

Period Ending August 31, 1948

Period Ending November 30, 1948

Period Ending February 28, 1949

Period Ending May 15, 1949

Period Ending August 15, 1949

Period Ending November 15, 1949

Period Ending February 15, 1950

Period Ending May 15, 1950

Period Ending August 15, 1950

Period Ending November 10, 1950

Period Ending February 10, 1951

Period Ending May 10, 1951

Period Ending August 10, 1951

Period Ending November 10, 1951

Period Ending February 10, 1952

Period Ending May 10, 1952

Period Ending August 10, 9152

Period Ending November 10, 1952

Period Ending February 10, 1953

Period Ending August 15, 1953

Period Ending February 15, 1954

Period Ending August 15, 1954

Period Ending February 15, 1955

Period Ending August 15, 1955

Period Ending February 15, 1956

Period Ending August 15, 1956

Period Ending February 15, 1957

Period Ending August 15, 1957

Period Ending February 15, 1958

Period Ending August 15, 1958

Period Ending February 15, 1959

Period Ending August 15, 1959

Period Ending February 15, 1960

Period Ending August 15, 1960

Period Ending February 15, 1961

Period Ending August 15, 1961

Period Ending February 15, 1962

Period Ending August 15, 1962

Period Ending February 15, 1963

Period Ending August 15, 1963

Period Ending February 15, 1964

Period Ending August 15, 1964

Period Ending February 15, 1965

Period Ending July 31, 1965

Period Ending January 31, 1966

Period Ending July 31, 1966

Period Ending January 31, 1967

Period Ending December 31, 1967

Period Ending December 31, 1968

Period Ending December 31, 1969

Period Ending June 30, 1971

Period Ending June 30, 1972

Period Ending June 30, 1973

Period Ending June 30, 1974

Period Ending June 30, 1975

Period Ending September 30, 1978

Period Ending May 31, 1980

Period Ending July 31, 1982

Period Ending September 30, 1983

Period Ending September 30, 1984

Period Ending September 30, 1985

Period Ending September 30, 1986

Period Ending September 30, 1988

Period Ending September 30, 1989

Period Ending September 30, 1991

Period Ending September 30, 1993 


\section{Table of Contents}

ORGANIZATION CHART $\ldots \ldots \ldots \ldots \ldots \ldots \ldots \ldots \ldots \ldots$

PREFACE $\ldots \ldots \ldots \ldots \ldots \ldots \ldots \ldots \ldots \ldots \ldots \ldots$ vii FOREWORD $\ldots \ldots \ldots \ldots \ldots \ldots \ldots \ldots \ldots \ldots$ ix

RESEARCH ACTIVITIES $\ldots \ldots \ldots \ldots \ldots \ldots \ldots \ldots \ldots$

MOLECULAR, CELLULAR, AND CANCER BIOLOGY SECTION . . . . . 1

Section Overview $\ldots \ldots \ldots \ldots \ldots \ldots \ldots \ldots \ldots \ldots$

Protein Engineering and Chemistry . . . . . . . . 7

RNA Metabolism . . . . . . . . . . . . . . 17

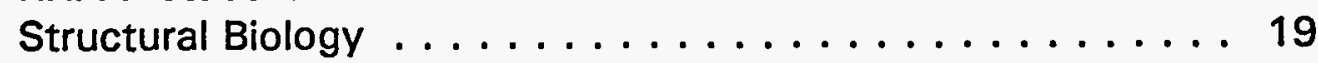

New Methods for DNA Sequencing . . . . . . . . . . 22

Genome Structure and Organization . . . . . . . . . . 25

Chromosome Chemistry ................ 28

Molecular Immunology . . . . . . . . . . . . 31

Radiation Carcinogenesis . . . . . . . . . . . . 33

Neoplastic Progression in Rat Tracheal Epithelium . . . . . . 35

Fundamental and Applied Cryobiology .......... 37

MAMMALIAN GENETICS AND DEVELOPMENT SECTION . . . . . 45

Section Overview .................... 45

Genetic Analysis and Mutagenesis Studies . . . . . . . 48

Molecular Genetics . . . . . . . . . . . . . . . 58

Organismic Effects .................66 62

Chromosomal Damage . . . . . . . . . . . . . . 65

Insertional Mutagenesis and Transgenic Mice . . . . . . 67

Targeted Mutagenesis . . . . . . . . . . . . . . . 71

Mammalian Biochemical Genetics . . . . . . . . . . 72

Genome Analysis ................... 74

GENOME MAPPING PROGRAM $\ldots \ldots \ldots \ldots \ldots \ldots \ldots$

Program Overview ................... 76

Mapping Human-Mouse Genomic Homologies . . . . . . . . 77

An Intelligent System for DNA Sequence Interpretation $\ldots .81$

Strategies for the Identification of Evolutionary-Conserved

DNA Sequences .................83 


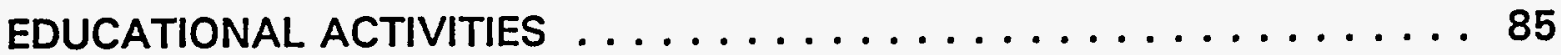

Doctoral and Postdoctoral Training Programs . . . . . . . 85

Undergraduate Training Programs . . . . . . . . . . . . 86

APPENDICES $\ldots \ldots \ldots \ldots \ldots \ldots \ldots \ldots \ldots \ldots \ldots \ldots \ldots \ldots$

Advisory Committee . . . . . . . . . . . . . . 89

Extramural Activities $\ldots \ldots \ldots \ldots \ldots \ldots \ldots \ldots \ldots \ldots$

Society Committees ................... 90

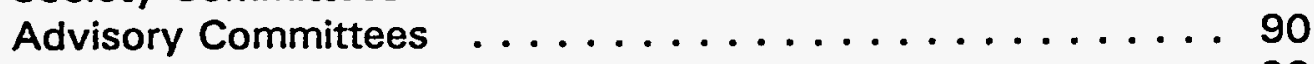

Editorial Boards . . . . . . . . . . . . . 93

Awards, Honors . . . . . . . . . . . . . . . . 93

Invited Presentations at Major Conferences . . . . . . . . . . 95

Abstracts for Technical Meetings . . . . . . . . . . . 97

Grants ............................ 109

Contracts ........................ 110

Financial Summary and Personnel Distribution . . . . . . . 111

Author Index ...................... 113 


\section{BIOLOGY DIVISION}

September 1995

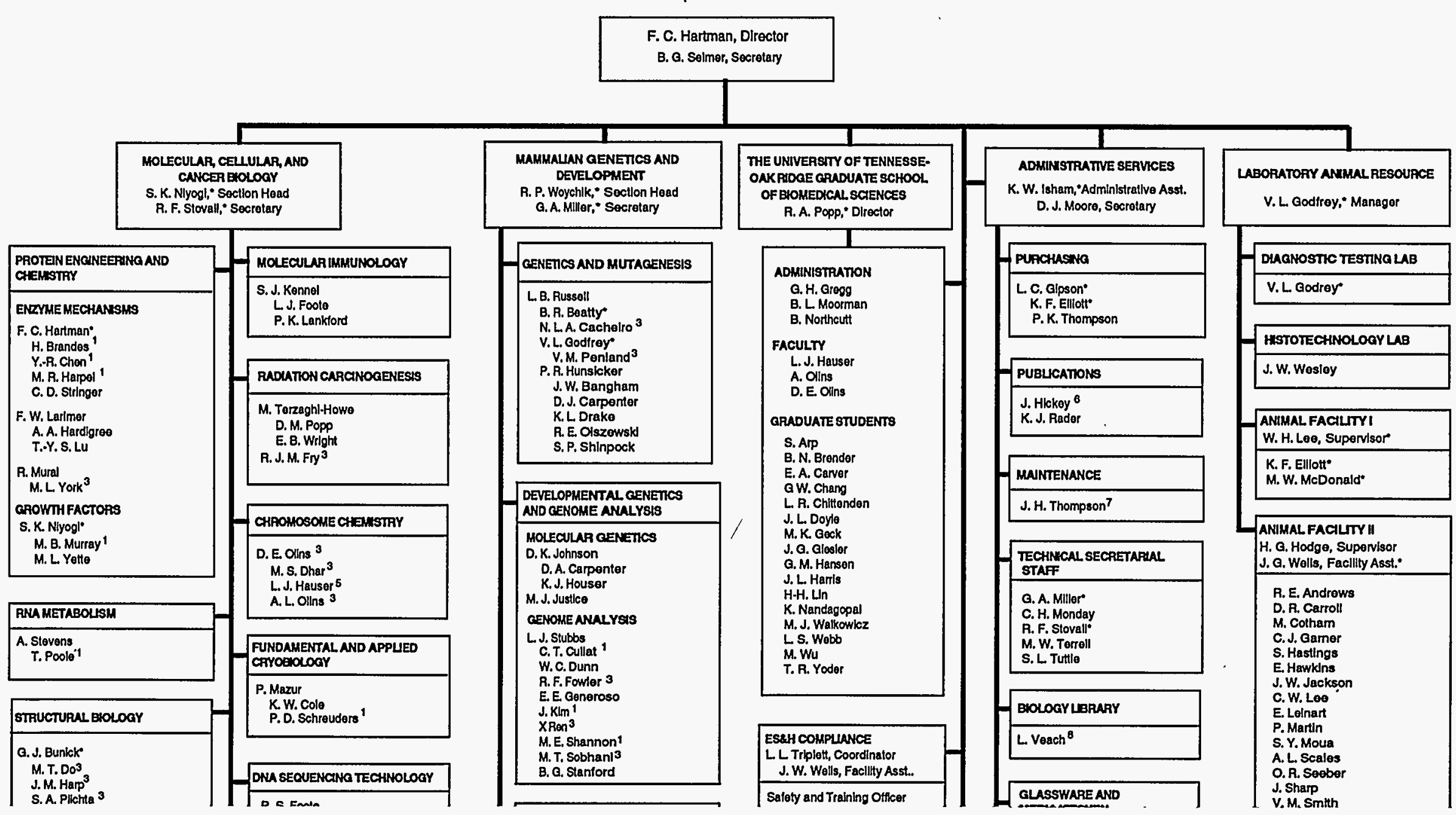




\section{PREFACE}

This Progress Report summarizes the research endeavors of the Biology Division of the Oak Ridge National Laboratory during the period October 1, 1993, through September 30, 1995. The report is structured to provide descriptions of current activities and accomplishments in each of the Division's major organizational units. Lists of information to convey the entire scope of the Division's activities are compiled at the end of the report. 


\section{FOREWORD}

The Biology Division of the Oak Ridge National Laboratory is an integral component of the Department of Energy's intramural program in life sciences. Accordingly, about $80 \%$ of the Division's total budget is derived from the Department of Energy through its Office of Health and Environmental Research. With respect to experimental biology, congressionally mandated missions of this Office are to define and acquire comprehension of energy-related health effects, to engage in underpinning basic research, and to map and ultimately sequence the entire human genome.

Within the framework of these broad missions, predominant programs of the Biology Division include mammalian genetics and mutagenesis, genomic organization and expression, and protein structure and function. Among these programs, interactions of animals, cells, and macromolecules with their respective environments reflect a unifying theme. Goals of studies concerning genetic and somatic effects of radiation and chemicals include identification and quantification of these effects and elucidation of pathways by which the effects are expressed. The Division's integrated genome program includes physical and functional gene mapping and bio-informatics. In this program, the mouse genome, because of its extensive homology to the human genome, serves as an experimental model for dissecting human gene function and thereby unraveling the basis of genetic abnormalities. Transgenic mice, constructed by either insertional or targeted mutagenesis, not only foster these studies but also provide mimics of human diseases and offer new avenues for the diagnostics and treatment of genetic disorders. Exploiting its long-standing expertise in cryobiology, the Division preserves precious mutant mouse stocks as frozen embryos.

The Division's diverse efforts in protein structure-function relationships have multifaceted goals. The integrated program in protein engineering concentrates on two types of proteins: those which are crucial to cellular growth and differentiation and hence could offer new entrees into cancer therapy, and those which control biomass yields and hence through systematic redesign might ultimately lead to more efficient plants. The X-ray crystallography group is pursuing an atomic-resolution structure of the nucleosome, the basic repeating unit of chromatin. Such a structure would have far-reaching ramifications relative to understanding regulation of replication and transcription, processes which are also studied biochemically in the Division.

Research grants and contracts from federal agencies other than DOE and from the private sector, secured through initiatives of principal investigators, 
comprise the remaining portion of the funding base for the Biology Division. Collectively, these grants augment and enhance the DOE-supported activities and provide positions for students, postdoctoral investigators, and research associates, who contribute enormously to the Division's productivity and intellectual vitality.

This Progress Report is intended to provide both broad perspectives of the Division's research programs and synopses of recent achievements. Readers are invited to contact individual principal investigators for more detailed information, including reprints of publications.

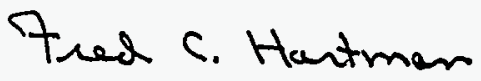


Superscripts after Staff Names

on Research Summaries

${ }^{1}$ Postdoctoral Investigator

${ }^{2}$ Consultant

${ }^{3}$ Guest Assignment

${ }^{4}$ Student, University of Tennessee-Oak Ridge Graduate School of Biomedical Sciences

${ }^{5}$ No longer at Biology Division

${ }^{8}$ Computing and Mathematical Sciences Division

${ }^{7}$ Chemistry Division

${ }^{8}$ Atom Sciences, Inc., Oak Ridge, TN

${ }^{9}$ Health Sciences Research Division

${ }^{10}$ Methodist Medical Center, Oak Ridge

${ }^{11}$ ORISE Professional Intern Program

${ }^{12}$ ORISE SEED Program

${ }^{13}$ Great Lakes Colleges Association Student

${ }^{14}$ ORISE Student Research Participant

${ }^{15}$ ORISE Faculty Research Participant

${ }^{18}$ Chemical and Analytical Sciences Division

${ }^{17}$ ORISE Science and Engineering Research Semester 


\title{
RESEARCH ACTIVITIES
}

\section{Molecular, Cellular, and Cancer Biology Section}

\author{
Section Overview - S. K. Niyogi
}

The research of this Section engages fundamental issues of macromolecular structure/function and cellular processes that relate to responses of organisms to their environments. Programs are concerned with the structure and organization of the eukaryotic genome, turnover of messenger RNA (mRNA), enzyme mechanisms, hormones and receptors, carcinogenesis, and cryobiology. Some recent findings are encapsulated here to portray their inherent scientific significance and their relevance to missions of DOE.

\section{Structure/Function Relationships of Biologically Important Proteins}

Many genes are being implicated in various human diseases. However, apart from the mapping, isolation, and sequencing of a gene, the elucidation and understanding of its true biological function necessitates thorough characterization of the gene product. The Protein Engineering and Chemistry Group is the largest unified cohort in the Section that seeks to address biological function with studies of a variety of important proteins. Its members utilize sitedirected mutagenesis and other sophisticated genetic, biochemical, and chemical techniques to explore structure/function relationships of proteins of both plant and animal origin. Although the proteins form a diverse group, they each reflect the programmatic missions of the DOE. The proteins under study include (1) ribulosebisphosphate carboxylase/oxygenase (Rubisco) and phosphoribulokinase (PRK), enzymes that regulate photosynthetic carbon assimilation and thereby biomass yield, with additional relevance to the global $\mathrm{CO}_{2}$ problem (greenhouse effect); (2) thioredoxins, redox proteins that modulate the activities of target enzymes via thiol-disulfide exchanges; (3) epidermal growth factor (EGF) and its receptor, proteins that regulate cell growth and are therefore of importance to cancer biology.

With the three-dimensional structure of Rubisco now available, mechanistic studies of the enzyme have taken on added significance. Many of the Protein Engineering and Chemistry Group's findings that predated a high-resolution structure have now been validated, and additional sophisticated issues regarding biological and physicochemical aspects of Rubisco can be addressed systematically.

By use of chemical modification (both covalent and noncovalent) to restore activity to catalytically impaired mutants, the Group has been able to decipher 
precise catalytic roles of certain active-site residues. Another noteworthy advance is the validation of the long-standing postulate that the key reaction intermediate in the enzyme's energy-wasteful oxygenation pathway is a peroxyketone. This conclusion was based on the generation of novel $\mathrm{O}_{2}$-dependent products from the turnover of ribulose bisphosphate by site-directed mutants. Concurrent identification of specificity determinants provides prerequisite information to gauging prospects for increased plant yield by judicious genetic manipulations of Rubisco - a long-sought goal of plant biologists.

Another plant protein under intensive study is the light-regulated enzyme PRK which catalyzes the production of ribulosebisphosphate, the obligatory substrate for $\mathrm{CO}_{2}$ fixation. Various aspects of the catalytic and regulatory mechanisms of this important enzyme are being elucidated utilizing both sitedirected mutagenesis and protein chemistry. Recent achievements include pinpointing of the regulatory cysteines, discerning the basis of catalytic incompetence of the oxidized form of the enzyme, and defining interactions between PRK and thioredoxin (the in vivo regulator).

Growth factors and their specific cell-surface receptors, acting in harmony, play key roles in regulating cell growth. Moreover, many receptors are also protooncogenes, and either overexpression or mutation to oncogenes leads to various growth abnormalities including cancer. The Protein Engineering and Chemistry Group is studying EGF, a prototypical growth factor that initiates cell proliferation by the stimulation of the tyrosine kinase activity of its receptor. The last two years have seen considerable progress in the identification and characterization of the receptor-binding residues of the EGF ligand. Most of these residues are hydrophobic with the exception of a highly conserved electrostatic residue (arginine 41 ) which is nestled between two hydrophobic domains. A highly significant observation is that the receptor-binding residues act independently of one another with multiple mutations leading to cumulative effects on receptor binding affinity. It therefore becomes feasible to develop EGF superagonists that could be useful in clinical applications, for example, wound healing, treatment of burns, ulcers, and cataracts. On the other hand, identification of the EGF residues critical for receptor binding and activation makes it feasible to design EGF mutants that could act as growth inhibitors with potential for cancer therapy.

\section{Messenger RNA Turnover in Eukaryotes}

Regulation of the stability of mRNAs is a major control mechanism that modulates mRNA levels in eukaryotic and prokaryotic systems. The mechanism of posttranscriptional RNA processing and turnover represents a major challenge for molecular biologists and biochemists. The RNA Metabolism Group has been studying various aspects of eukaryotic mRNA turnover, focusing on several 
enzymes including two $5^{\prime}-3^{\prime}$ exoribonucleases that degrade decapped mRNA, the latter arising from the action of a decapping enzyme. All of these enzymes were discovered by the RNA Metabolism Group. The $5^{\prime} \rightarrow 3^{\prime}$ exoribonuclease 1 (XRN1) from yeast has been cloned and sequenced, and the disrupted gene introduced into cells to analyze the physiological consequences. The studies indicate that this enzyme and the mRNA decapping enzyme, in concert, catalyze mRNA turnover. Exoribonuclease 2 (XRN2) is coded by an essential gene in yeast and is therefore of great interest. Understanding how these enzymes regulate mRNA processing is important because, as an example, some cancers are believed to develop from increased stability of certain oncogene mRNAs. On the other hand, manipulation of the activity of these key enzymes so as to stabilize other mRNAs could prove beneficial.

\section{Crystallographic Analysis of Nucleosomes and Proteins}

The Structural Biology Group has analyzed in detail their $8 \AA$ crystallographic structure of the nucleosome core particle and now has obtained crystals that diffract to $<3 \AA$ resolution. For this purpose they have reconstituted preparations of precisely positioned nucleosomes that are each homogeneous in their histone composition and in the associated DNA sequence, and they have shown that the reconstitutions conform to theoretical predictions. The use of palindromic DNA sequences further enhances crystal homogeneity. The DNA wrapping around the protein core of the nucleosome does not form a smoothly curved superhelix but at several locations makes sharp histone-induced bends related to the primary DNA sequence at those points. These are putative binding sites for DNA binding proteins. The analysis has the promise of establishing the structural basis for the regulation of transcription and other DNA-dependent functions of the cell. This group is also investigating the crystal structure of pyrophosphatase and, in collaboration with the Protein Engineering and Chemistry Group, has initiated a study of the crystal structure of human epidermal growth factor. The Structural Biology Group is also spearheading, in concert with the Solid State Division, the establishment of the Neutron Resource Center and the User Facility for Structural Biology at ORNL.

\section{DNA Sequencing Technology}

In genome-related studies, several new methods for sequencing are being developed or explored by the DNA Sequencing Technology Group, including the use of stable isotopes as DNA labels, sequencing by hybridization, scanning probe microscopy for mapping single DNA molecules, and analysis by laser desorption mass spectrometry. The activities of this group include multidisciplinary collaborations with several Divisions of ORNL. A major accomplishment in this reporting period has been the development of photosensitive reagents for the synthesis of microchip arrays of oligonucleotides for use in sequencing by hybridization. 


\section{DNA and Chromatin Structure/Function}

The group studying Genome Structure and Organization has extended their analysis of the relation of DNA primary sequences in their model system la complex satellite of a crustacean) to mutation hotspots, showing that regions of sequence-dependent distortion of the helix are regions of high mutation frequency. The satellite sequence is transcribed in specific organs at specific growth stages, a fact that has been demonstrated both biochemically and histologically by cytological hybridization. The regulation of such transcription is under current investigation. The extent of DNA methylation appears to be a significant factor in establishing which sequences are transcribed. The group has recently improved the PCR amplification of $G+C$-rich DNAs (a long standing challenge) by use of chaotropes.

In recent studies, multigene families for $\alpha$-tubulin and actin isoforms of $G$. lateralis have been found. The proteins are expressed at the highest rate during mitosis and lowest during atrophy. Glycosylation patterns of crustacean exoskeletal proteins are also being investigated.

Alternative approaches to exploring the structure of chromatin have been adopted by the Chromosome Chemistry Group. They have been examining the structure as well as the transcription and replication characteristics of short linear DNA molecules, possibly one gene per fragment, which exist in the macronucleus of a ciliated protozoan. In addition, they have continued their development of electron microscope tomography and its application to resolving three-dimensional structures, focusing on the Balbiani rings engaged in RNA synthesis in the polytene chromosomes of the insect Chironomus. Using an electron-dense stain developed in their laboratory, they have been visualizing the mRNA synthesized on the giant chromosome puffs. These studies are expected to lead to a better understanding of the packaging, replication, and transcription of DNA in eukaryotic chromosomes.

Receptors, Carcinomas, and Cell Targeting with Antibodies

Underlining the importance of the role of specific receptors in pathogenesis, the Molecular Immunology Group has been investigating the integrin $\alpha 6 \beta 4$, found on the cell surface in a number of carcinomas. The group is focusing on its tissue distribution, molecular characterization, and attempts to identify its specific ligand. Other studies concentrate on monoclonal antibodies that are specific to endothelial cell-surface glycoproteins in the lung. They have demonstrated that a major lung endothelium-specific antigen is thrombomodulin, a protein that plays a significant role in the prevention of intravascular clotting. A goal of this group is to develop a system utilizing antibody-containing liposomes that will be targeted 
to lung and other tissues and thus will be potentially useful in tissue-specific drug delivery. This group has provided monoclonal antibodies to over $\mathbf{4 0 0}$ laboratories worldwide.

Monoclonal antibodies for targeting drugs to tumors are being developed. Model studies indicate that targeting in the vascular space is much more efficient than to solid tumors.

\section{Radiation-Induced Cell Transformation}

The Radiation Carcinogenesis Group studies the mechanisms and role of chromosome aberrations in leukemia induced by radiation either occupationally, environmentally, or during diagnosis and therapy. Various models of doseresponse and time-dose relationships have been developed. Recent results relate to studies of the effects of dose rate and fractionation of low-LET radiation on the induction of myeloid leukemia, total cancers, and life shortening. The carcinogenic effects of neutrons, radon, and heavy charged particles are also being investigated.

A major effort of the Radiation Carcinogenesis Group has been an integrated study of myeloid leukemia in RFM mice (prone to myeloid leukemia) at the molecular, chromosomal, and whole-animal levels, as well as skin carcinogenesis by both ionizing and non-ionizing radiation. Neoplastic progression in rat tracheal epithelium is also being studied by this group, using an in vivo/in vitro model that they have developed. Their studies focus on identifying the critical target cells for carcinogens, including various types of radiation, and the influence on progression of cell-cell interactions mediated by diffusible growth factors. In the Radon Program, a recent finding of particular interest is that $\alpha$ particles, which may be lethal to cells they penetrate, do not of themselves cause transformation to precancerous cells, but they interact strongly and synergistically with $\beta$ and $\gamma$ radiations to induce cell transformation. This finding takes on special significance in view of the fact that radon is not only an $\alpha$ emitter, but it and its daughters also emit both $\beta$ and $\gamma$ radiation. The Environmental Protection Agency has cited radon as the second leading etiological agent in lung cancer in the United States.

\section{Cryobiology: Basic Studies and Practical Applications}

The Fundamental and Applied Cryobiology Group has continued basic studies on the cryobiology of human and mouse sperm and applied studies in freezing of embryonic mice and Drosophila for the cost-efficient, long-term banking of mutant stocks with the benefit of avoiding genetic drift that accompanies continuous breeding. Although human sperm has been successfully cryopreserved for decades, the methods have been based on trial-and-error techniques with little being known about the underlying mechanisms. In contrast, 
mouse sperm resists cryopreservation, but cryopreservation would be a major aid in maintaining the large number of transgenic stocks that are being developed worldwide. The group has succeeded in preserving Drosophila embiyos with $25 \%$ recovery of viable, fertile organisms, an achievement that has been recognized with an R\&D 100 award, a citation for the 100 most significant technological achievements in research and development. The cost of maintaining the flies by continuous breeding in all Drosophila laboratories has been estimated as upwards of $\$ 6 \mathrm{M}$, underscoring the potential economic significance of this accomplishment. Cryobiology has been applied to the Anopheles mosquito that harbor the malaria parasite. A collaboration is ongoing with $\mathrm{NIH}$. A great amount of basic research is helping establish conditions for cryopreservation of Anopheles embryos - an achievement of enormous benefit to combat malaria that is still a scourge for millions of people.

\section{Collaborative Endeavors}

It is important to stress that the various research groups in the Molecular, Cellullar, and Cancer Biology Section are not islands of individualized activity, but rather they represent intellectual and research endeavors that span not only the Division but extend into the scientific community at large. A few examples of such activity with the outside community are given below.

The Protein Engineering and Chemistry Group has extensive interactions with DuPont, Michigan State University, Rutgers University, The University of Tennessee, Massachusetts Institute of Technology, Chiron Corporation, the University of Southampton, England, and other institutions. Clones of Rubisco, PRK, and EGF have been made available to investigators in both the public and private domains. The RNA Metabolism Group is collaborating with investigators at the University of North Carolina and the University of Arizona. In addition to providing antibodies in response to hundreds of requests, the Molecular Immunology Group interacts, on a regular basis, with scientists at the University of Pittsburgh, the University of Texas at Galveston, and the University of Rome. Extensive collaborations between the Fundamental and Applied Cryobiology Group and geneticists at the University of Chicago have led to joint research proposals funded by NSF, and similarly, collaborations with the University of Oregon and the University of Indiana have led to grants funded by $\mathrm{NIH}$. The Radiation Carcinogenesis Group has collaborations at NIEHS, New York University, and Colorado State University. 


\section{PROTEIN ENGINEERING AND CHEMISTRY}
F. C. Hartman
S. R. Campion ${ }^{1,5}$
M. R. Harpel
K. Nandagopal ${ }^{4}$
F. W. Larimer
Y.-R. Chen ${ }^{1}$
E. Larson ${ }^{1,5}$
C. D. Stringer
S. K. Niyogi
M. K. Geck ${ }^{4}$
T-Y.S. LU
D. K. Tadaki ${ }^{4,5}$
H. K. Brandes ${ }^{1}$
A. A. Hardigree
M. B. Murray ${ }^{1}$
M. L. Yette

The unifying theme in this group is the use of site-directed mutagenesis and chemical approaches to elucidate structure/function correlations of proteins. Investigations focus on five proteins with quite diverse functions: ribulose bisphosphate carboxylase/oxygenase, an enzyme whose activity is a major determinant of biomass yield; phosphoribulokinase, a photosynthetic enzyme whose activity is regulated by light; thioredoxin, a key regulatory protein; epidermal growth factor, a hormone that regulates cellular growth and differentiation; and epidermal growth factor receptor, a cell surface glycoprotein having tyrosine kinase activity that mediates the growth promoting properties of epidermal growth factor.

Ribulose Bisphosphate Carboxylase/Oxygenase (Rubisco)

\section{Introduction}

Ubiquitous among photosynthetic organisms, Rubisco is essential for net conversion of atmospheric $\mathrm{CO}_{2}$ into carbohydrates. Thus, this enzyme, a major cornerstone of life processes, is crucial to biomass yield and is also relevant to the global $\mathrm{CO}_{2}$ issue (i.e., the greenhouse phenomenon). The enzyme is bifunctional: in addition to catalyzing the carboxylation of D-ribulose-1,5-bisphosphate (RuBP) to yield two molar equivalents of D-3-phosphoglycerate (the $\mathrm{CO}_{2}$-fixation reaction), it also catalyzes the oxidation of RuBP by molecular oxygen to yield one molar equivalent each of phosphoglycolate and 3-phosphoglycerate. Although multiple substrate specificities among enzymes are not unusual, the bifunctionality of Rubisco is perhaps unprecedented in that the two reactions catalyzed are the initial steps in competing metabolic pathways - photosynthetic assimilation of $\mathrm{CO}_{2}$ and photorespiration, the latter an energy-wasteful process which results in the release of previously fixed $\mathrm{CO}_{2}$.

Our goals are (a) to understand the mechanism of this complex enzyme, especially the precise catalytic roles of active-site residues, and (b) to evaluate the feasibility of improving the carboxylase/oxygenase activity ratio and thereby providing an approach to enhancing biomass yields.

In contrast to Rubisco from higher plants, which is comprised of two gene products (eight large and eight small subunits per molecule of enzyme), the 
functionally analogous enzyme from the purple, non-sulfur photosynthetic bacterium Rhodospirillum rubrum is a homodimer and the product of a single gene. This enzyme has thus been used for many of our mutagenesis studies.

The three-dimensional structure of Rubisco with a bound substrate analogue has been published by several crystallography laboratories, thereby revealing intricate details of the active site and subunit-subunit interactions. This structure validates many of our conclusions concerning structure-function relationships derived collectively from affinity labeling, chemical cross-linking, comparative sequence analyses, and site-directed mutagenesis.

\section{Chemical Rescue of Site-Directed Mutants of Rubisco}

Despite its revolutionary impact on enzymology, site-directed mutagenesis, as a means for altering structure, is generally restricted to the 20 amino acids normally occurring in proteins. Thus, reliance on homologous series of compounds to establish structure-reactivity correlations, a hallmark of mechanistic studies with non-enzymic catalysts, has not been possible with enzymes. This limitation is partially overcome by the demonstration by Professor Jack Kirsch and colleagues at Berkeley that an enzyme, crippled because of an active-site substitution, can be partially rehabilitated ("rescued") merely by the addition of exogenous organic compounds that mimic the missing side chain.

Chemical rescue of deficient site-directed mutants can also be achieved through covalent chemical modification as pioneered in our laboratories, thereby expanding the diversity and subtlety of structural changes that can be effected through mutagenesis. Examples include substitution of lysyl with aminoethylcysteinyl residues (net replacement of the $\gamma$-methylene group with a sulfur atom), substitution of glutamyl with carboxymethylcysteinyl residues (net insertion of a sulfur atom between the $\beta$ - and $\gamma$-methylene groups with lengthening of the side chain by $\sim 1 \AA$ ), and substitution of arginyl with homoarginyl residues (net insertion of a methylene group with lengthening of the side chain by $\sim 1 \AA$ ).

We are utilizing both covalent and noncovalent chemical rescue to address a number of structure/function issues of the carboxylase. One issue entails the significance of intersubunit, electrostatic interactions at the active site between Glu48 and Lys329 found only in the activated form of the enzyme. Our studies have shown that even conservative amino acid replacement of these residues leads to virtual abolishment of carboxylase activity. Furthermore, we have been able to assign the catalytic involvement of Lys 329 and Glu48 to the carboxylation step in the overall reaction; i.e., the mutants retain catalytic competence in the first step (enolization of RuBP) and in the terminal steps (processing of the carboxylated intermediate). 
Loop 6 (which includes Lys329) and the $\mathrm{NH}_{2}$-terminal segment (which includes Glu48) of the active site, due to their positioning and flexibility, would appear to be involved in controlling ligand access to the active site and in precluding dissociation of reaction intermediates from the active site. Recent findings that support such postulates follow:

(i) Substitution of Glu48 by Gin (i.e., mere replacement of the oxyanion of a carboxylate sidechain by $\mathrm{NH}_{2}$ ) dramatically decreases the $\tau$-value (the $\mathrm{CO}_{2}: \mathrm{O}_{2}$ specificity factor) from 11 to 0.3 . Thus, the negative charge provided by Glu 48 and/or its salt bridge to Lys 329 greatly influences the relative reactivity of the enediol intermediate in favor of $\mathrm{CO}_{2}$.

(ii) E480 exhibits a far greater propensity than wild-type enzyme to misprotonate the enediol intermediate, with the consequent formation of xylulose-1,5-bisphosphate. Thus, the active site of the mutant enzyme is more accessible to bulk solvent due to destabilization of subunit-subunit interactions at the entry into the crevice for ligand anchoring.

(iii) Treatment of $\mathrm{K} 329 \mathrm{C}$ with 2-bromoethylamine partially restores enzyme activity as a consequence of selective aminoethylation of the introduced thiol group. The catalytic constant $\left(k_{\text {cat }}\right)$ of this novel carboxylase, which contains a sulfur atom in place of a specific lysyl $\gamma$-methylene group, is 4.5 -fold lower than that of the wild-type enzyme. This detrimental effect by such a modest structural change underscores the stringent requirement for a lysyl side chain at position 329. Moreover, the partitioning between the carboxylation and oxygenation pathway is reduced 2-fold relative to that of wild-type enzyme. Precise placement of the requisite amine group is critical, as further evidenced by the 20 -fold reduced $k_{\text {cat }}$ and 3.5-fold reduced specificity exhibited by aminopropylated K329C.

(iv) The virtually inactive K329A is subject to noncovalent chemical rescue by aliphatic amines. Comparison of the efficiencies of various amines as rescuers indicates that the amines bind to the site voided by the mutation and yields a Brønsted relationship with a $\beta$ of 1 , implying complete protonation of amine in the rescued transition state. Although significant rescue of carboxylation activity is observed (85-fold for ethylamine), normal specificity is only partially restored (2-fold for ethylamine), again indicating the exquisite requirements for positioning of the amino group at position $\mathbf{3 2 9}$ for proper transition-state stabilization.

(v) Truncation of loop 6 by cassette mutagenesis eliminates carboxylase activity, but allows retention of activity in partial reactions preceding and following the $\mathrm{CO}_{2}$-addition step. Loop 6 as a whole, apart from the contribution of Lys329, is clearly critical to transition-state stabilization and contributes at least 10 -fold to the total rate enhancement achieved by Rubisco. 
Thus, a variety of structural changes and chemical manipulations focused on the Glu48---Lys329 intersubunit salt bridge and flexible loop 6 render major alterations in ligand accessibility and gaseous substrate specificity. This work defines both specific regions of the polypeptide chain and structural features for future microsurgery in pursuit of understanding specificity determinants and ultimately of designing a catalytically superior enzyme.

\section{Novel Side Products and the Oxygenase Pathway}

Enzymatic side reactions, which depart from the normal reaction coordinate, can provide insight into the nature of enzymatic reaction intermediates and transition states. Furthermore, enhanced formation of side products, relativë to wild-type enzyme, by site-directed mutants provides a means of linking specific amino-acid side chains with the stabilization of specific intermediates.

Crystallographic models suggest that five residues (Thr53, Asn54, Gly370, Gly393, and Gly394) of $R$. rubrum Rubisco are positioned to serve as hydrogen-bond donors for the C1-phosphate of RuBP and thereby constrain conformational flexibility of reaction intermediates. We have used site-directed mutagenesis to test this postulate. Individual alanyl replacement of these residues leads to nominal diminution of carboxylase activity (with even lesser impact on enolization activity), increase in $K_{m}(R u B P)$, and decrease in carboxylation/oxygenation selectivity. However, these mutants catalyze enhanced $\beta$-elimination of the $\mathrm{C} 1$ phosphate from both the initial enediol intermediate and the terminal carbanion intermediate of phosphoglycerate to form the novel side products, 1-deoxy-D-g/ycero-2,3-pentodiulose 5-phosphate and pyruvate, respectively. Whereas certain mutants favor dicarbonyl formation, others favor pyruvate formation. Production of these side products demonstrates the requirement for precise positioning of those side chains interacting with the C1-phosphate group and provides evidence for active-site conformational changes during catalysis.

Another set of novel side products generated by Rubisco mutants has provided an entree into deciphering the mechanism of the Rubisco oxygenase reaction. Although Rubisco's oxygenase side reaction has long been recognized, mechanistic details are lacking. In particular, an $\alpha$-peroxy ketone has been postulated, but never proven, as the key intermediate. We have now characterized two novel $\mathrm{O}_{2}$-dependent side products, $\mathrm{D}$-g/ycero-2,3-pentodiulose 1,5-bisphosphate (dicarbonyl bisphosphate) and 2-carboxytetritol 1,4-bisphosphate (CTBP), produced by the E480 and K329A mutants. Chemical structures for these compounds were assigned by chemical, NMR, and MS analyses. Because formation of the dicarbonyl bisphosphate, formally an oxidized form of RuBP, is accompanied by $\mathrm{H}_{2} \mathrm{O}_{2}$ production, it must derive from a peroxy adduct of RuBP, the putative oxygenase intermediate. CTBP is formed by 
rearrangement of the dicarbonyl bisphosphate, as catalyzed by K329A. Thus, these novel products prove the nature of the oxygenase intermediate and provide signatures for the misprocessing of this intermediate.

\section{Phosphoribulokinase (PRK) and Thioredoxin (Trx)}

Our interest in PRK derives from two considerations: this enzyme catalyzes the formation of RuBP (from ribulose-5-P and ATP), the requisite $\mathrm{CO}_{2}$ acceptor in photoautotrophs, and is regulated by light via the ferredoxin-thioredoxin electron transfer chain. Thus, our studies focus on mechanisms of both catalysis and regulation. Our efforts to unravel the structure-function relationships of PRK and its interactions with Trx have been hampered by the modest availability of the recombinant enzyme. Prior attempts to express the gene for spinach PRK in Escherichia coli have been only marginally successful, yielding PRK as $<0.5 \%$ of the total soluble protein. Furthermore, Western blotting of electrophoretic gels of crude extracts of transformed cells indicates extensive degradation of PRK. In contrast, expression of the PRK gene in the yeast Pichia pastoris yields PRK as $>5 \%$ of total soluble protein, and degradation of the recombinant enzyme is not observed. The expression cassette consists of the PRK coding sequence spliced immediately behind the alcohol oxidase promoter $(A O X 1)$ of $P$. pastoris; consequently, PRK expression is methanol-responsive. The cassette is stably integrated by transplacement of the chromosomal $A O X 1$ gene. Recombinant PRK from $P$. pastoris, purified to homogeneity by successive anion-exchange and affinity chromatography, is redox sensitive and'exhibits kinetic parameters indistinguishable from those of the native spinach enzyme. Site-specific replacement of the regulatory cysteinyl residues (positions 16 and 55), located at the active site, confirm the lack of any catalytic role for Cys16 and only a modest facilitative role for Cys55. In fact, the construct devoid of all four cysteinyl residues found in wild-type enzyme exhibits $\sim 20 \%$ of wild-type activity.

Structure-function analyses of PRK would be incomplete without defining its interaction with chloroplastic $\operatorname{Trx} f$. Thioredoxins $(\sim 12,000 \mathrm{kDa})$ are members of a large class of ubiquitous redox proteins [which includes glutaredoxin, protein disulfide isomerase, and dsbA (a procaryotic, periplasmic protein disulfide isomerase)] that generally function to mediate thiol-disulfide exchange with target proteins. The common structural feature of thioredoxins, crucial to function, is an active site that contains two proximal cysteines (-Trp-Cys-Gly-Pro-Cys-). One of the two active-site sulfhydryls attacks the disulfide on the target protein to form a protein-protein mixed disulfide. By intramolecular attack by the second sulfhydryl of thioredoxin, reduced enzyme and oxidized thioredoxin will be formed. In vivo, the oxidized thioredoxin can be reduced by ferredoxin or NADPH as catalyzed by a specific thioredoxin reductase, so that only catalytic amounts of thioredoxin are required. Heretofore, structural and biochemical characterization of the protein-protein complex has not been feasible, because the equilibrium in the oxidation/reduction process greatly favors the non-complexed 
proteins; i.e., the putative mixed disulfide coupling PRK and thioredoxin is destabilized by the thermodynamically favored intrasubunit disulfide (represented by either oxidized PRK or oxidized thioredoxin). The lack of biochemical characterization extends to the identity of the primary nucleophile (i.e. the sulfhydryl group of the redox protein that attacks the regulatory disulfide of the target protein) which has not been directly established for any thioredoxin or thioredoxin-like protein. In collaboration with Peter Schürmann of Neuchâtel, Switzerland, we approached this question with appropriate site-directed mutants of spinach Trx $f$ (the regulatory cysteinyl residues are located at positions 46 and 49 ) in conjunction with the target protein chloroplastic fructose-1,6-bisphosphatase (FBPase). We chose this target protein, rather than PRK, because the original recombinant $\operatorname{Trx} f$ was obtained as a fusion protein (a 3-residue appendage at the amino terminus) which lacked normal redox activity against PRK despite the normal redox activity when assayed with FBPase. The C49S mutant retains the capacity to activate FBPase, while the C46S mutant is totally lacking in this regard. Based on kinetics of FBPase activation, wild-type and C49S exhibit half-saturation values of $0.9 \mu \mathrm{M}$ and $4 \mu \mathrm{M}$, respectively. Lack of activation by C46S is not because of failure to interact with FBPase, for it exhibits a $K_{\mathrm{i}}$ of $5 \mu \mathrm{M}$ in competition with wild-type. Therefore, in the normal thioredoxin-catalyzed reduction pathway, Cys 46 is the nucleophile required to attack the disulfide of the substrate, and Cys 49 serves to cleave the mixed disulfide intermediate, thus allowing for the release of oxidized thioredoxin and the reduced target enzyme.

In a continuation of these studies, we wish to identify the sulfhydryl of PRK that engages the C46 sulfhydryl of Trx. Whether in the presence of dissolved air, dehydroascorbate, or oxidized glutathione, incubations of the C49S mutant of Trx with either C16S or C55S mutants of PRK do not lead to formation of a stable mixed disulfide. Therefore, an alternate strategy is in progress in which the candidate sulfhydryl of the mutant protein is activated prior to mixing with the other single-site mutant protein. Based on preliminary analysis by gel electrophoresis, this strategy appears promising.

Besides modulating the redox status of PRK, Trx $f$ similarly regulates chloroplastic fructose-1,6-bisphosphatase (FBPase), glyceraldehyde-3-phosphate dehydrogenase, and sedoheptulose-1,7-bisphosphatase. Trx $m$, homologous with $\operatorname{Trx} f$ and also a substrate for thioredoxin reductase, is more active as a redox protein toward chloroplastic NADP-malate dehydrogenase (MDH) and glucose 6-phosphate dehydrogenase. The necessity for higher plants to elaborate two such similar redox proteins, within the same organelle, that preferentially mediate identical redox chemistry of different sets of target enzymes is not understood. As a prerequisite to addressing this question, we are exploring the structural determinants of target specificity of $\operatorname{Trx} f$. Based upon amino acid sequence 
alignments and the NMR structure of reduced $E$. colf Trx, residues of $\operatorname{Trx} f$ potentially involved in interactions with target enzymes were investigated by replacements with residues found at corresponding positions of Trx $m$. The following site-directed mutants of spinach Trx $f$ were generated and purified: K58E, Q75D, N74D, and deletions of Asn74 and Asn77. Initial rates of target protein activation by wild type $\operatorname{Trx} f$, wild type $\operatorname{Trx} m$, and the $\operatorname{Trx} f$ mutants were obtained through spectrophotometric assays with oxidized recombinant sorghum leaf MDH and oxidized spinach FBPase. The affinity of Trx $f$ (wild type and mutants) for NADP-MDH is too weak to measure kinetically. However, the rate of activation of NADP-MDH by the Trx $f$ mutants can exceed that effected by wild type $\operatorname{Trx} m$. In addition, all of the mutants are less efficient than the wild type Trx $f$ in activating FBPase. In conclusion, Lys58, Asn74, Gln75, and Asn77 of Trx $f$ contribute to its interaction with target enzymes and influence target protein selectivity.

\section{Epidermal Growth Factor (EGF)}

\section{Background}

Because of their crucial role in the regulation of growth and differentiation and the abnormalities resulting from their malfunction, growth factors have attracted considerable interest. EGF, a 6-kDa protein with three internal disulfide bonds, exhibits high-affinity binding to its specific cell surface receptor. Upon binding EGF, the receptor undergoes autophosphorylation on tyrosine residues by its intrinsic protein-tyrosine kinase activity, which also phosphorylates endogenous substrates. Tyrosine phosphorylation triggers a cascade of biochemical events including increased glycolysis and protein synthesis and increased transcription of specific genes, which ultimately leads to a stimulation of DNA replication and cell proliferation.

\section{Research Goals and Approach}

The major objective of our research is the elucidation of structure/function correlations of human EGF (hEGF) by protein engineering. Utilizing the hEGF gene, cloned in this laboratory as a bacterial secretory protein, targeted amino acid residues were substituted by oligonucleotide-directed mutagenesis. The selection of amino acid residues for mutagenesis was based on (a) their interspecies homologies; (b) published solution structures of mouse and human EGFs, which are based on 2D-NMR and computer modeling; and (c) previous studies of EGF structure/function in our laboratory. Mutant proteins were purified to homogeneity and tested for (a) specific binding to the EGF receptor by a radioreceptor competition assay, (b) stimulation of the protein-tyrosine kinase activity of the EGF receptor as a measure of agonist activity, (c) stimulation of DNA synthesis and growth of mammalian cells in culture, and (d) possible structural alterations as determined by NMR spectroscopy. 
Functional Residues of EGF

(i) Hydrophobic Residues. Our studies have indicated the importance of several hydrophobic residues in EGF for binding to its receptor. These include Tyr13, lle23, and Leu26 in the N-terminal domain, and Leu47 in the C-terminal domain. Replacement of any of these residues led to drastic reduction in EGF's biological activity. The most severe losses in receptor affinity occurred upon replacement by electrostatic residues, indicating the importance of hydrophobic "bonding" in EGF-receptor interaction. The role of these hydrophobic residues in serving as possible contact points with the receptor is further underscored by the fact that substitutions at these positions led to very minor alterations in the native structure of EGF that could not account for the drastic reduction in receptor affinity.

(ii) Leucine 15. The biological importance of Leu15 was suggested by its conservation through evolution, its critical location in the domain-domain interface of EGF, as well as its close proximity to Arg41, a residue that we found to be crucial for receptor binding and activation. The relative receptor binding affinities of the position 15 hEGF variants were as follows: wildtype $>$ L15F $>$ L15W $>$ L15V $>$ L15A $>$ L15R $>$ L15E. The relative agonist activities, as measured by receptor tyrosine kinase stimulation assays, generally followed a similar trend. The results indicate that both the size and hydrophobicity of the $\gamma$-branched aliphatic side-chain of Leu15 play an important role in receptor binding and activation. Structural analyses of three hEGF mutants, L15R, L15A, and L15W, by NMR spectroscopy showed only minor alterations that were not sufficient to account for the dramatic losses in activity. Overall, the results indicate that the Leu15 side-chain plays a critical role as a "contact residue" in the high-affinity binding of EGF to the receptor by contributing to hydrophobic ligandreceptor interactions.

(iii) Histidine 10. The amino acid residue at position 10 of EGF is conserved as a histidine or tyrosine. NMR analyses suggest that His 10 of hEGF is located in a hydrophobic cluster that includes Tyr13, Try22, and Tyr29. To examine the possible role of His 10 in receptor recognition, site-directed mutants were characterized by radioreceptor competition and receptor tyrosine kinase stimulation assays. The relative binding affinities of aromatic (Tyr, Phe) or hydrophobic (Leu) variants were similar to wild-type, whereas reduced hydrophobicity (Ala) or a polar substitution (GIn, Lys or Ser) diminished receptor affinities $\sim 5$-fold. Introduction of a negative charge (Glu) weakened binding affinity to only $5 \%$ of wild-type. Receptor tyrosine kinase activation by the mutants paralleled binding efficiencies. Structural analyses of hEGF mutants, $\mathrm{H} 10 \mathrm{~A}$ and $\mathrm{H} 10 \mathrm{E}$, by NMR spectroscopy indicate minor alterations in the native structure that could not account for the loss in activity. Our results suggest that His 10 plays a functional role in receptor binding by contributing toward hydrophobic interactions between the ligand and receptor. 
(iv) Asparagine 32. The highly conserved asparagine residue at position 32 (Asn32) in the "hingen region of EGF separates the $\mathrm{N}$ - and $\mathrm{C}$-terminal structural motifs of the EGF molecule, and is therefore an appropriate target for structurefunction studies. Analogues of hEGF were generated in which Asn32 was substituted with aspartate, glycine, isoleucine, lysine, proline, and tryptophan. A wide range of receptor affinities was observed depending on the amino acid substitution. N32K and N32W mutants had relatively high receptor affinity, while N32G and N32D showed decreased affinity, 35\% and 25\%, respectively, relative to wild-type hEGF. However, no binding of N32P was detected by radioreceptor competition assay. The N32P mutant displayed an NMR spectrum significantly different from that of native wild-type hEGF, indicating gross structural perturbation. In contrast, N32K and N32D exhibited spectra similar to that of native wild-type hEGF. Genetically combining N32K with a species having either the mutation L26G in the $\mathrm{N}$-terminal region or L47A in the C-terminal region, generated double mutants which had relative affinities essentially equal to the product of the relative affinities of the parent hEGF mutants, indicating functionally independent changes in ligand-receptor interaction. These studies indicate the requirement for $\mathrm{H}$-bond donor functionality in the side chain of residue number 32 in forming a fully competent receptor-binding epitope.

(v) Tyrosines 22 and 29. Aromatic character is conserved at positions 22 and 29 in the $\mathrm{N}$-terminal major $\beta$-sheet of EGF. Extensive structure/function studies by protein engineering of Tyr22 and Tyr29 in hEGF revealed that these residues are not directly involved in receptor binding but are important for the structural integrity of EGF. Molecular modeling, based on NMR data, and sequence conservation analysis suggested a divalent metal-ion binding site comprising several acidic residues (Asp3, Glu5, and Glu24) and Tyr29 of hEGF. Indeed, this could be confirmed by electron paramagnetic resonance (EPR) measurements. Scatchard analysis of the EPR data indicated positive cooperativity in the metal binding. A Hill plot of the same data shows a Hill coefficient of 1.8 suggesting more than one binding site, and extrapolation of the plateau reveals an apparent $K_{d}$ value for the high-affinity site(s) of $\sim 60 \mu \mathrm{M}$. This indicates a fairly strong affinity for divalent metal ion that is similar to that of other proteins containing EGF-like sequences. Such metal binding proteins include blood coagulation factors IX and $X$. The metal-ion binding characteristics of hEGF are currently being studied by NMR spectroscopy and equilibrium dialysis.

(vi) Histidine 16. The amino-acid residue at position 16 is conserved as either an histidine or an asparagine. NMR studies suggest that His 16 or Asn16 may be one of the residues in the ligand that contributes to the receptor-binding epitope. Site-directed variants of hEGF (H16L, H16Y, H16N, and H16O) were characterized with respect to radioreceptor competition binding and receptor tyrosine kinase stimulation with $\left(\mathrm{Glu}_{4}, \mathrm{Tyr}_{1}\right)_{\mathrm{n}}$ as the substrate. The decreased receptor affinity of the $\mathrm{H16L}$ mutant reveals that hydrophobicity per se is not 
critical at this position in the hEGF molecule. Biochemical properties of the $\mathrm{H} 16 \mathrm{Y}$ analogue were similar to wild-type hEGF, suggesting a possible role for the aromaticity and/or the hydrogen-bonding potential of His 16 in receptor binding. The considerably higher receptor affinities of the $\mathrm{H} 16 \mathrm{~N}$ and $\mathrm{H} 16 \mathrm{O}$ variants were translated into 3- to 4-fold lower $\mathrm{Km}$ values for receptor kinase stimulation. The results indicate that aromaticity of His 16 is not essential for receptor binding and activation; rather, hydrogen-bonding via the imidazole nitrogen(s) may play a critical role in these processes. The design of "superagonists" of hEGF also appears to be feasible by protein engineering at the His 16 site.

1. Brandes, H. K.,F. W. Larimer, M. K. Geck, C. D. Stringer, P. Schürmann, and F. C. Hartman. Direct identification of the primary nucleophile of thioredoxin $f$. J. Biol. Chem. 268: 18411-18414, 1993.

2. Campion, S. R., C. Biamonti, G. T. Montelione, and S. K. Niyogi. The role of asparagine-32 in forming the receptor-binding epitope of human epidermal growth factor. Protein Eng. 6: 651-659, 1993.

3. Campion, S. R., and S. K. Niyogi. Interaction of epidermal growth factor with its receptor. In: Prog. Nucleic Acid Res. Mol. Biol., vol. 49, ed. by W. E. Cohn and K. Moldave. Academic Press, New York, 1994, pp. 353-383.

4. Chen, Y.-R., and F. C. Hartman. A signature of the oxygenase intermediate in catalysis by ribulose-bisphosphate carboxylase/oxygenase as provided by a site-directed mutant. J. Biol. Chem. 270: 11741-11744, 1995.

5. French, A. R., D. K. Tadaki, S. K. Niyogi, and D. A. Lauffenburger. Intracellular trafficking of epidermal growth factor family ligands is directly influenced by the $\mathrm{pH}$ sensitivity of the receptor/ligand interaction. J. Biol. Chem. 270: 4334-4340, 1995.

6. Ghiron, C. A., M. R. Eftink, D. A. Engler, and S. K. Niyogi. Fluorescence studies with human epidermal growth factor. Photochem. Photobiol. 55: 29-34, 1992.

7. Harpel, M. R., and F. C. Hartman. Chemical rescue by exogenous amines of a site-directed mutant of ribulose 1,5-bisphosphate carboxylase/oxygenase that lacks a key lysyl residue. Biochemistry 33: 5553-5561, 1994.

8. Harpel, M. R., F. W. Larimer, E. H. Lee, R. J. Mural, H. B. Smith, T. S. Soper, and F. C. Hartman. Partial reactions and chemical rescue of site-directed mutants of Rubisco as mechanistic probes. In: Nobel Jubilee Series $\mathrm{CO}_{2}$-Fixation and $\mathrm{CO}_{2}$-Reduction in Biological and Model Systems, ed. by C-I. Brändén and G. Schneider. Oxford University Press, Oxford, England, 1994, pp. 19-35.

9. Harpel, M. R., E. H. Serpersu, and F. C. Hartman, Utilization of partial reactions, side reactions, and chemical rescue to analyze site-directed 
mutants of ribulose 1,5-bisphosphate carboxylase/oxygenase (Rubisco). In: Techniques in Protein Chemistry, Vol. VI, ed. by J. W. Crabb. Academic Press, San Diego, California, 1995, pp. 357-364.

10. Harpel, M. R., E. H. Serpersu, J. A. Lamerdin, Z.-H. Huang, D. A. Gage, and F. C. Hartman. The oxygenation mechanism of ribulose-bisphosphate carboxylase-oxygenase. Structure and origin of 2-carboxytetritol 1,4-bisphosphate, a novel $\mathrm{O}_{2}$-dependent side product generated by a site-directed mutant. Biochemistry (in press).

11. Hartman, F. C., and M. R. Harpel. Structure, function, regulation, and assembly of D-ribulose-1,5-bisphosphate carboxylase/oxygenase. Ann. Rev. Biochem. 63: 197-234, 1994.

12. Larimer, F. W., M. R. Harpel, and F. C. Hartman. B-Elimination of phosphate from reaction intermediates by site-directed mutants of ribulose-bisphosphate carboxylase/oxygenase. J. Biol. Chem. 269: 11114-11120, 1994.

13. Larson, E. M., F. W. Larimer, and F. C. Hartman. Mechanistic insights provided by deletion of a flexible loop at the active site of ribulose-1,5-bisphosphate carboxylase/oxygenase. Biochemistry 34: 4531-4537, 1995.

14. Lee, E. H., M. R. Harpel, Y.-R. Chen, and F. C. Hartman. Perturbation of reaction intermediate partitioning by a site-directed mutant of ribulosebisphosphate carboxylase/oxygenase. J. Biol. Chem. 268: 26583-26591, 1993.

15. Lorimer, G. H., Y.-R. Chen, and F. C. Hartman. A role for the $\epsilon$-amino group of lysine-334 of ribulose-1,5-bisphosphate carboxylase in the addition of carbon dioxide to the 2,3-enediol(ate) of ribulose1,5-bisphosphate. Biochemistry 32: 9018-9024, 1993.

16. Tadaki, D. K., and S. K. Niyogi. Epidermal growth factor: Cellular and molecular function. In: Growth Factors and Cytokines in Health and Disease, ed. by D. LeRoith and C. Bondy. Jai Press, Inc., Greenwich, Connecticut (in press).

\section{RNA METABOLISM}

\section{A. Stevens T. L. Poole ${ }^{1}$}

Regulation of the cytoplasmic stability of mRNAs has been found to be a major control mechanism which modulates mRNA levels in a variety of eukaryotic and prokaryotic systems. An important part of unraveling the mystery of mRNA turnover is to analyze in detail the enzymes that may be involved. RNA processing reactions which convert precursor RNA species to mature RNA molecules also involve unique ribonucleases. Studies of ribonucleases, two $5^{\prime} \rightarrow 3^{\prime}$ exoribonucleases and an mRNA decapping enzyme(s), and their possible role in mRNA turnover and processing have been continued in this laboratory. 


\section{Analysis of the Metabolic Role of $5^{\prime} \rightarrow 3^{\prime}$ Exoribonuclease-1 of Saccharomyces Cerevisiae: Poly(A) and Cap Structure-deficient mRNAs}

Analysis of the slowed turnover rates of short-lived mRNA species and the higher cellular levels of some of these mRNAs in yeast cells lacking $5^{\prime} \rightarrow 3^{\prime}$ exonuclease-1(XRN1) showed the accumulation of essentially full-length mRNAs that do not bind to oligo(dT)-cellulose. Quite high levels (50\% or more) of the mRNAs of $x r n 1$ cells are poly(A) deficient. Examination of the cap structure status of the accumulated poly(A)-deficient mRNAs in $x r n 1$ cells by measurements of $m^{7} G$ content of total poly(A)- RNA showed that this RNA fraction contains only slightly more cap structure than the same fraction from wild-type (wt) cells. The rate of XRN1 hydrolysis of specific full-length mRNA species also showed that approximately $50 \%$ of the $x r n 1$ poly $(A)$-deficient mRNAs lack the cap structure since they are susceptible to XRN1 hydrolysis. The enzyme hydrolyzes capped mRNA poorly, if at all. No hydrolysis of wt poly(A)-deficient mRNA species was found, as was also true of both wt and $x r n 1$ poly $(A)^{+}$mRNA species.

Primer extension analysis of the 5'-terminus of RP51A mRNA of wt and $x r n 1$ cells was carried out to determine if the chains of $x r n 1$ poly(A) $)^{-}$mRNAs were further modified (shortened) at the 5 '-terminus. The results showed that $30-40 \%$ of the $x r n 1$ poly(A)-deficient RP51A mRNA molecules are slightly shortened (predominantly 3-4 nt) at the $5^{\prime}$ end. The accumulation of poly(A)-deficient mRNA species (especially the short-lived mRNAs) modified at the $5^{\prime}$-termini, together with the restriction of the rate of their turnover in cells lacking the enzyme, suggest a role for XRN1 in the turnover process. That such mRNAs could be formed due to processing defects does not appear likely because the polysome distribution of mRNA species in the $x r n 1$ cells is very similar to that in wt cells. Also, pulse-labeling of cells shows that long poly $(A)$ chains are formed in $x r n 1$ cells as in wt cells.

5'-Exonuclease-2 of Saccharomyces Cerevisiae: Purification and Features of Ribonuclease Activity with Comparison to 5'-Exonuclease-1

$5^{\prime}$-exonuclease- 2 has been purified 17,000-fold from whole cell extracts of Saccharomyces cerevisiae. A 116-kDa polypeptide parallels the enzyme activity when the purified protein is examined by polyacrylamide gel electrophoresis in sodium dodecyl sulfate. Amino-terminal sequencing of the $116-\mathrm{kDa}$ protein shows that the sequence agrees with that encoded by the HKE1gene, previously reported to encode exonuclease-2. A 45-kDa polypeptide also parallels the enzyme activity upon purification, and Sephacryl S-200 molecular sieve chromatography of the purified enzyme shows a parallel elution of most of the 116-kDa and $45-\mathrm{kDa}$ polypeptides, suggesting a close association of the two. Enzyme instability has precluded a more detailed analysis of their associative properties. The enzyme hydrolyzes RNA substrates to $5^{\prime}$-mononucleotides in a processive manner. Measurements of its substrate 
specificity and mode of action are compared with 5'-exonuclease-1. Restrictioncut single-stranded T7 DNA is hydrolyzed at approximately $5-7 \%$ of the rate of $18 S$ rRNA of yeast by both enzymes. That $5^{\prime}$-exonuclease- 2 hydrolyzes in a processive manner and lacks endonuclease activity is shown by the finding that [5'-32P]GMP is the only product of its hydrolysis of $\left[\alpha{ }^{32} \mathrm{P}\right]$ GTP-labeled synthetic RNAs. That the enzyme hydrolyzes by a $5^{\prime}-3^{\prime}$ mode is shown by (1) its poor hydrolysis of both $5^{\prime}$-capped and triphosphate-ended RNA substrates; (2) the products of its hydrolysis of $\left[5^{\prime}-{ }^{32} \mathrm{P},{ }^{3} \mathrm{H}\right](\mathrm{pA})_{4} ;$ and $(3)$ the accumulation of $3^{\prime}$-stall fragments when a strong artificial RNA secondary structure is present in synthetic RNAs. 5'-exonuclease-1 hydrolyzes the synthetic RNAs and $(p A)_{4}$ in an identical manner.

1. Hsu, C. L., and A. Stevens. Yeast cells lacking $5^{\prime}-3^{\prime}$ exoribonuclease 1 contain mRNA species that are poly(A)-deficient and partially lack the $5^{\prime}$ cap structure. Mol. Cell. Biol. 13: 4826-4835, 1993.

2. Stevens, A., and T. L. Poole. 5'-Exonuclease-2 of Saccharomyces cerevisiae: Purification and features of ribonuclease activity with comparison to 5'-exonuclease-1. J. Biol. Chem. (in press).

\section{STRUCTURAL BIOLOGY}
G. J. Bunick
J. M. Harp ${ }^{3}$
S. A. Plichta ${ }^{3}$
M. T. Do ${ }^{3}$
S. J. Henderson 5
M. L. York ${ }^{3}$
A. Gewiess ${ }^{3}$
E. L. Palmer ${ }^{3}$

This laboratory is investigating the three-dimensional structures of several biological macromolecules. One major objective is to determine the structural organization of genomic DNA and associated histone proteins by pursuing a medium resolution $X$-ray crystal structure of the nucleosome core particle. Several other proteins are also being studied, including chicken erythrocyte histone octamer, epidermal growth factor, and scorpion neurotoxin II.

\section{Macromolecular Crystallography}

\section{Nucleosome Core Particle Crystal Structure}

The nucleosome core particle structure has been determined to a resolution of $8 \AA$ by $X$-ray crystallographic methods. Features present in this structure include the histone organization, the double helical DNA structure, numerous protein-DNA interactions, and distortions in the path of the DNA around the protein core. 
Nucleosomes reconstituted from homogeneous histone octamers and cloned specific-sequence DNA are necessary in order to determine a higher resolution $(\sim 3 \AA$ A ) crystal structure. Several DNAs that form precisely positioned nucleosomes have been developed. We are currently concentrating on a $146 \mathrm{bp}$ palindrome that has been engineered based on one-half of the human $\alpha$-Satellite sequence. A source of disorder in the crystals occurs because two possible orientations, related by a $180^{\circ}$ rotation about the nucleosome's dyad axis, exist for hucleosomes to be incorporated into the crystal lattice. Non-palindromic DNA does not have true dyad symmetry at the base level, whereas palindromic DNA makes the two halves of the nucleosome precisely equivalent and thus removes the two-fold disorder.

Nucleosomes containing the $\alpha$-Satellite palindrome sequence have been prepared by salt gradient dialysis reconstitution and have been crystallized. The crystals have dimensions of approximately $4.5 \times 0.35 \times 0.25 \mathrm{~mm}$. Diffraction experiments show reflections between 3.0 and $2.8 \AA$ in the c-axis direction, while the resolution limit is approximately $3.2 \AA$ in the general direction of the $a$ and $b$ axes, respectively. The method of cryo-crystallography (flash cooling) has been developed for data collection. Ground-based crystallization experiments using the diffusion controlled apparatus for micro-gravity (DCAM) are serving as controls for micro-gravity crystallization experiments. Data collection is planned on beam line $\mathrm{X}-12 \mathrm{C}$ at the National Synchrotron Light Source.

\section{Histone Octamer}

Determination of a low temperature chicken erythrocyte histone octamer structure is underway in the laboratory. The structure will be used in molecular replacement phasing of the nucleosome core particle data. Crystallization and flash cooling methods $\left(-160^{\circ} \mathrm{C}\right)$ have been developed. Several low temperature data sets have been collected to $3 \AA$ resolution with an overall Rsym of $4.1 \%$. Heavy atom derivative preparation and data collection are in progress using the mercury cluster compound tetrakis(acetoxymercuri)-methane (TAMM). The low temperature histone octamer structure will enhance our knowledge of nucleosome and chromatin structure.

\section{Epidermal Growth Factor (EGF)}

Epidermal growth factor (EGF) is a $6 \mathrm{kDa}$ protein consisting of 53 amino acids with 3 internal disulfide bonds. EGF has been crystallized in monoclinic and tetragonal space groups. Data collected on the tetragonal form indicate cell constants of $a=b=53.7 \AA, c=182.5 \AA$ with 6 molecules per asymmetric unit. Several milligrams of EGF that contain seleno-methionine in place of methionine have been prepared for use as an intrinsic heavy atom derivative. 


\section{Scorpion Toxin-variant /I (CsEv2)}

The venom of the bark scorpion, Centruroides sculpturatus Ewing, contains a series of closely related small basic proteins. Each of the neurotoxins possesses a compact structure stabilized by four disulfide bonds. The activity of the neurotoxins is eliminated by reducing any one of the four disulfide bonds. The proteins are about $7 \mathrm{kDa}$ with 65-70 amino acid residues. Although the proteins are quite similar in composition, their biological activities vary dramatically. A single crystal structure has been solved for variant 3 neurotoxin from C. sculpturatus, CsEv3, and NMR structures are available for it and variant 1, CsEv1. Variants 1 through 6, as well as CsE-V, are $\alpha$-toxins and work to slow the inactivation of sodium channels. We have been able to obtain small crystals of variant 2, CsEv2 and are currently working to improve the size of the crystals using macro seeding techniques.

\section{Small Molecule Crystallography}

A collaboration was initiated with the Chemical Separations Group (CSG) at ORNL for structural elucidation of organic compounds that form crystals too small for X-ray structural determination using CSG instrumentation. Two of the structures solved were the crown ethers dibenzo-24-crown-8 $\left(B_{2} 24 C 8\right)$ and tetrabenzo-24-crown-8 $\left(\mathrm{B}_{4} 24 \mathrm{C} 8\right)$. These compounds are of interest because $\mathrm{B}_{4} 24 \mathrm{C} 8$ shows the highest ability to extract $\mathrm{Cs}^{+}$, and $\mathrm{B}_{2} 24 \mathrm{C} 8$ exhibits the highest selectivity for $\mathrm{Cs}^{+}$when mixed with other alkali metal ions.

The crystal structures of bis(triptyceno-24-crown-6) $\left(T_{2} 24 C 6\right)$ and bis(triptyceno-32-crown-8) $\left(\mathrm{T}_{2} 32 \mathrm{C} 8\right)$ were also determined. These compounds are also potential $\mathrm{Cs}^{+}$selective extraction agents. Nano-technology researchers are interested in $\mathrm{T}_{2} 32 \mathrm{C} 8$ as perhaps the first molecular "gear". Extensive NMR data has been collected on the molecular $\mathrm{T}_{2} 32 \mathrm{C} 8$. The X-ray determination adds conclusive proof as to its structure, giving us a snapshot of the gear, and also revealing the presence of a reasonably sized cavity for the coordination of metal ions. Several additional compounds await data collection and structure elucidation.

\section{Neutron Resource Center and the User Program for Structural Biology}

A User Program for Structural Biology has been established within the Neutron Resource Center, matrixed from the Divisions of Biology, Chemical and Analytical Sciences, and Solid State. This program recognizes the scientific value of neutron scattering facilities at the Oak Ridge National Laboratory and builds on recent funding by the ORNL Laboratory Directed Research and Development (LDRD) program. The User Program provides continuity and access to state-of-the-art neutron diffraction and scattering opportunities for scientists worldwide. The User Program is guided by an external Advisory Board, as well 
as by a Users' Group which provides input through workshops and timely meetings. Externally reviewed proposals remain the basis for beam time allocations.

1. Affholter, K. A., S. J. Henderson, G. D. Wignall, G. J. Bunick, R. E. Haufler, and R. N. Compton. Structural characterization of $\mathrm{C}_{60}$ and $C_{70}$ fullerenes by small-angle neutron scattering. J. Chem. Phys. 99: 9224-9229, 1993.

2. Harp, J. M., E. L. Palmer, M. C. Davis, A. Gewiess, M. L. York, and G. J. Bunick. Preparative separation of nucleosome core particles containing defined-sequence DNA in multiple translational phases. Electrophoresis (in press).

3. Harp, J. M., E. C. Uberbacher, A. E. Roberson, A. Gewiess, and G. J. Bunick. Crystallization of twofold symmetric nucleosome core particles containing a 146 bp DNA palindrome. Acta Cryst. (in press).

4. Henderson, S. J., E. H. Serpersu, B. S. Gerhardt, and G. J. Bunick. Conformational changes in yeast phosphoglycerate kinase upon substrate binding. Biophys. Chem. 53: 95-104, 1994.

5. Henderson, S. J. Window materials for small-angle X-ray scattering: An improved beryllium window. J. Appl. Cryst. (in press).

6. Henderson, S. J. Modification of standard x-ray glass capillaries to improve data for small-angle scattering. J. Appl. Cryst. 27: 1067, 1994.

7. Knott, R., S. Hansen, and S. J. Henderson. A small-angle X-ray scattering study of the binding of cyclosporin-A to calmodulin. J. Struct. Biol. 112: 192-198, 1994.

\section{NEW METHODS FOR DNA SEQUENCING}
R. S. Foote
M. J. Doktycz ${ }^{9}$
F. V. Sloop ${ }^{16}$
K. B. Jacobson ${ }^{9}$
A. Hasan ${ }^{1,5}$
K. P. Stengele 1,5
H. Arlinghaus ${ }^{8}$
F. W. Larimer
R. J. Warmack ${ }^{7}$
C. H. Chen ${ }^{9}$
J. M: Ramsey ${ }^{7}$
R. P. Woychik

Mapping and sequencing a genome is a slow process at present. To develop faster and more accurate methods for sequence determination, several different approaches are being pursued.

One approach is to utilize stable isotopes as DNA labels and to detect them on electrophoresis gels by resonance ionization spectroscopy, a method that is very selective and very sensitive. Eight stable isotopes of tin have been incorporated into triethylstannylpropanoic acid and attached to oligodeoxynucleotides that have, in turn, been used as primers for the Sanger sequencing procedure and also to produce PCR products. A cage compound for 
rare earth elements has also been synthesized and attached to DNAs; there are $\sim 50$ isotopes that could be used as DNA labels from this set of elements. Multiple isotopes are advantageous since each can be assigned to a different DNA and multiple DNAs can be assayed simultaneously. The gel electrophoresis procedure itself has also been modified, by making thinner, open-faced gels and by using discontinuous buffers; both modifications shorten the time needed for DNA analysis. Resonance ionization spectroscopy has been shown to detect two different tin isotopes that were on DNAs that had been separated by gel electrophoresis. Tin-labeled DNAs produced in the Sanger sequencing and polymerase chain reaction procedures have also been successfully detected after gel electrophoresis.

In a second approach, sequencing-by-hybridization derives the DNA sequence by determining the ability of the DNA to hybridize to a set of oligonucleotides, e.g., 8-mers, in which all possible sequences of interest are represented. Methods have been developed to synthesize that set of oligonucleotides directly on a glass surface by a reaction scheme that greatly reduces the number of chemical steps needed to prepare the oligonucleotide matrix. At the same time, in collaboration with Dr. K. L. Beattie of the Houston Advanced Research Center, the matrix is also being constructed from presynthesized oligonucleotides. In collaboration with Dr. A. Mirzabekov (Moscow) the matrix is constructed on a $10 \mu \mathrm{m}$ film of polyacrylamide to produce higher concentration of the oligonucleotide in a stationary phase. Studies on the accuracy of hybridization have been carried out both in solution and in arrays.

The use of microfabricated devices for rapid DNA analysis is being investigated in collaboration with J. M. Ramsey of the Chemical and Analytical Sciences Division. These devices are created by photolithographic etching of microchannels in a planar glass surface followed by bonding to a coverplate. Both enzyme digestion and electrophoresis steps have been carried out on the same device for restriction analysis of DNA. Separated DNA fragments were detected in the electrophoresis channel using a fluorescent intercalating dye. The integration of primer extension and electrophoresis steps on a single device is being explored for use in DNA sequencing. Covalent attachment of oligonucleotide probes to channel walls is also being used to detect target DNA sequences by hybridization. A low-temperature method for bonding coverplates to the etched substrate has been developed to allow pre-attachment of multiple oligonucleotide probes to discrete sites in the open channels.

Scanning probe microscopy is being explored as a means of mapping single DNA molecules in collaboration with R. J. Warmack of the Health Sciences Research Division. Short DNAs and proteins that bind to specific sequences in the DNA molecule are being examined to detect their positions on the DNA after 
binding. In this manner a map of significant sequences in a single DNA molecule may be obtained. The binding of site-specific endonucleases to DNA has been imaged using atomic force microscopy.

Finally, the characterization of DNA sized accurately by mass spectrometry could replace gel electrophoresis for this measurement since the results could be obtained far more quickly. In collaboration with $\mathrm{C}$. $\mathrm{H}$. Chen of the Health Sciences Research Division, a tunable vacuum ultraviolet ionizer has been introduced into a time-of-flight mass spectrometer. This new instrument has proved effective in analyzing oligonucleotides by the process of matrix-assisted laser desorption mass spectrometry. Oligonucleotides as long as 500-mers have been detected. Labeling the DNAs with ferrocene, a DNA label developed in the gel electrophoresis stable isotope project above, may increase the range of DNA sizes and the sensitivity of the method.

1. Allison, D. P., M. J. Doktycz, T. Thundat, K. B. Jacobson, G. M. Brown, and R. J. Warmack. Scanning probe microscopy of immobilized DNA. Polymer Preprints 34: 332-333, 1993.

2. Allison, D. P., T. Thundat, K. B. Jacobson, L. A. Bottomley, and R. J. Warmack. Imaging entire genetically functional DNA molecules with the scanning tunneling microscope, J. Vac. Sci. Technol. A11 (4): 816-819, 1993.

3. Allison, D. P., T. G. Thundat, P. Modrich, R. J. Isfort, M. J. Doktycz, P. S. Kerper, and R. J. Warmack. Mapping site-specific endonuclease binding to DNA by direct imaging with atomic force microscopy. In: SPIE Volume 2386: Proceedings, Ultrasensitive Instrumentation of DNA Sequencing and Biochemical Diagnostics, ed. by G. E. Cohn, J. M. Lerner, K. J. Liddanc, A. Scheeline, and S. A. Soper. Society of Photo-Optical Instrumentation Engineers, Bellingham, Washington, 1995, pp. 24-29.

4. Doktycz, M. J. Discontinuous electrophoresis of DNA: Adjusting DNA mobility by trailing ion net mobility. Anal. Biochem. 213: 400-406, 1993.

5. Doktycz, M. J., K. B. Jacobson, K. L. Beattie, and R. S. Foote. Optical melting as a tool for optimizing sequencing by hybridization analysis of DNA. In: SPIE Volume 2386: Proceedings, Ultrasensitive Instrumentation for DNA Sequencing and Biochemical Diagnostics, ed. by G. E. Cohn, J. M. Lerner, K. J. Liddane, A. Scheeline, S. A. Soper. Society of Photo-Optical Instrumentation Engineers, Bellingham, Washington, 1995, pp. 30-34.

6. Doktycz, M. J., M. D. Morris, S. J. Dormady, K. L. Beattie, and K. B. Jacobson. Optical melting of 128 octamer DNA duplexes: Effects of base pair location and nearest neighbors on thermal stability. J. Biol. Chem. 270: 8439-8445, 1995.

7. Jacobson, K. B., H. F. Arlinghaus, M. J. Doktycz, R. A. Sachleben, G. M. Brown, and F. W. Larimer. Development of resonance ionization 
spectroscopy for genome mapping and DNA sequencing using stable isotopes as DNA labels. In: SPIE Volume 1891: Proceedings of Advances in DNA Sequencing Technology, ed. by R. A. Keller. Society of Photo-Optical Instrumentation Engineer, Bellingham, Washington, 1993, pp. 27-36.

8. Lumetta, V. J., and M. J. Doktycz. Electrophoresis for under five dollars. J. Coll. Sci. Teachers, March/April: 314-316, 1994.

9. Sloop, F. V., G. M. Brown, R. A. Sachleben, K. B. Jacobson, M. L. Garrity, and J. E. Elbert. Metalloorganic labels for DNA sequencing and mapping. New J. Chem. 18: 317-326, 1994.

10. Sloop, F. V., G. M. Brown, R. S. Foote, K. B. Jacobson, and R. A. Sachleben. Synthesis of 3-(triethylstannyl)propanoic acid: an organotin mass label for DNA. Bioconjugate Chem. 4: 406-409, 1993.

11. Tang, K., N. I. Taranenko, S. L. Allman, C. H. Chen, L. Y. Chang, and K. B. Jacobson. Picolinic acid as a matrix for laser mass spectrometry of nucleic acid and proteins. Rapid Comm. Mass Spec. 8: 673-677, 1994.

12. Thundat, T., D. P. Allison, R. J. Warmack, M. J. Doktycz, K. B. Jacobson, and G. M. Brown. Atomic force microsocpy of single- and double-stranded deoxyribonucleic acid. J. Vac. Sci. Technol. A11 (4): 824-828, 1993.

13. Thundat, T., R. J. Warmack, D. P. Allison, and K. B. Jacobson. Critical point mounting of kinetoplast DNA form atomic force microscopy. Scanning Microsc. 8: 23-30, 1994.

14. Thundat, T., R. J. Warmack, D. P. Allison, K. B. Jacobson, and P. T. Englund. Atomic force microscopy of kinetoplast DNA adsorbed on mica. Ultramicroscopy (in press).

\section{GENOME STRUCTURE AND ORGANIZATION}
D. M. Skinner
S. S. Kumari ${ }^{1,5}$
K. Varadaraj ${ }^{1,5}$

We are defining the organization and function of very highly repeated yet complex DNAs in the genomes of higher eukaryotes. Our model system is the genome of the Bermuda land crab, Gecarcinus lateralis, with emphasis on its $\mathrm{G}+\mathrm{C}$-rich satellite DNA, which has the most complex satellite sequence known. The satellite $(16,000$ copies per genome) has a repeat unit of $2.1 \mathrm{~kb}$ comprised of conserved domains of $85-96 \%$ identity, ranging in size from 50-670 bp, interspersed with divergent domains that are mutation hotspots. A set of related projects aims to establish the molecular biology of growth and development in the model organism whose genome provides this unique group of repeated DNAs. In the past several years, these two approaches have come together in our finding that crustacean tubulins and actins are both encoded in multigene families, the members of which are expressed at specific points in the growth cycle and 
in specific tissues. These findings enable us to pinpoint the growth-related expression of specific genes with identified products and thus have substantially sharpened our precise definition of these growth processes.

\section{Improving PCR Amplification of G + C-rich DNAs}

With the extraordinary amplification potential of PCR as a result of nonspecific priming, undesirable multiple bands may occur, especially when a $G+C$-rich DNA with its high melting temperature is used as template. In addition, secondary structures in the template DNA may hinder extension of the primers by the polymerase. The EcoRl 368 bp fragment of the crab stDNA contains $57 \%$ $G+C$ residues. In order to optimize conditions for the amplification of this segment, we tested two genetically engineered enzymes: AmpliTaq DNA polymerase $(94 \mathrm{kDa})$ and AmpliTaq DNA polymerase, Stoffel fragment (61 kDa). PCR was performed with or without chaotropes to destabilize the $G+C$-rich stDNA. Increasing the denaturation temperature from 94 to $96^{\circ} \mathrm{C}$ did not improve amplification. Addition of specific chaotropes to the PCR mixture, however, significantly improved amplification. The two enzymes showed specific responses that were concentration dependent and interdependent. In brief, the most propitious combination of DNA polymerase and detergents/cosolvents must be determined empirically. In our system, Stoffel fragment was the more efficient and specific, and glycerol and DMSO produced the most specific product and resulted in the greatest enhancement of amplification. Our results should be generally applicable to the PCR amplification of G+C-rich DNAs.

\section{Cytoplasmic Distribution of RNA Transcripts of the G+C-rich Crab stDNA}

Previous biochemical analyses showed that there is growth cycle stagespecific, tissue-specific, and strand-specific transcription of segments of crab stDNA. We selected a $368 \mathrm{bp}$ segment from one of the six highly conserved domains as a probe to identify transcripts in tissue sections. The probe was labeled by biotinylation during PCR and detected by peroxidase-bound avidin. The data show that the stDNA transcripts leave the nucleus and enter the cytoplasm, as expected if transcripts are to be translated. Testis revealed very few transcript signals. In ovary, signals were heavy around the periphery of the nuclei of oocytes. Sections of mouse pancreas were used as a control for specificity; no signals were detected. This is the first demonstration of stDNA transcripts in cytoplasm.

Multigene Families for $\alpha$-Tubulin and Actin Isoforms of $G$. lateralis

Tubulins. We have sequenced the cDNAs for a number of $\alpha$-tubulins from G. lateralis. Two of the sequences contain complete coding regions and two are partial. They code for 451 amino acid $(55 \mathrm{kDa})$ proteins. DNA sequences of all 
four clones showed highest homology to $\alpha$-tubulin genes of an insect (Drosophila melanogaster), while the predicted amino acid sequences of the clones were most highly homologous to an $\alpha$-tubulin of a mammal (Rattus norvegicus). There are a total of 5 to $7 \alpha$-tubulin genes encoded in the $G$. lateralis genome. The transcription of mRNAs for the $\alpha$-tubulins precedes, as expected, the expression of the proteins. Expression of the proteins is at its highest when the mitotic activity (cell proliferation) is greatest. The proteins are at a minimum in those tissues (late proecdysial claw muscle) which are undergoing atrophy. $\beta$-tubulin sequences have not yet been isolated from $G$. lateralis. Immunomicroscopy shows the innermost (membranous) layer of the acellular exoskeleton to be rich in tubulins secreted by the underlying epithelium. Tubulin secretion, which has not previously been observed, may be a widespread phenomenon in arthropods.

Actins. There are three distinct groups of actins, $\alpha, \beta$ and $\gamma$. $\beta$ - and $\gamma$ actins are usually present in the cytoplasm. Invertebrate muscle contains $\beta$-actin. We have isolated cDNA clones coding for two actin gene isoforms of $G$. lateralis. The two were very similar in their coding sequences, much less so in their $3^{\prime}$ untranslated regions. Codon usage is strongly biased toward $C$ or $G$ in the third position. The total umber of actin genes encoded in the $G$. lateralis genome is 7 to 11 . The inferred number of amino acid residues and calculated molecular weights for Act1 were 376 and $48.74 \mathrm{kDa}$, respectively. The nucleotide sequences of $G$. lateralis showed the highest homology to insect (D. melanogaster) actin genes. The predicted amino acid sequence of Act1 was highly homologous to muscle actins of Bombyx mori (silkworm) and $D$. melanogaster. Evolutionary conservation of the actin sequence is evident from the close relationship of a crab actin to the human cytoplasmic (non-muscle) $\beta$-actin $(87.8 \%)$. These observations strengthen the view of a common protist ancestor for all metazoans. In late proecdysis claw muscle atrophies prior to ecdysis when the muscle mass must be withdrawn through the small basiischial joint and a very large fraction of the muscle actin is lost at that time. It will be interesting to correlate the recovery of actin isoforms with claw muscle replacement during metecdysis, i.e., during the recovery from atrophy.

Phenomenology and Control of the Crustacean Molt Cycle

Little is known about the proteins of crustacean exoskeletons, their distribution within the four layers of the exoskeleton, and their evolutionary relationships to those of other arthropods. We have developed methods for physically separating the four exoskeletal layers and extracting their proteins.

Glycosylation of crustacean exoskeletal proteins. The glycosylation of crustacean exoskeleton proteins suggests that sugars play an important role in exoskeletal structure. We have used lectin binding as a bioassay for glycosylation; specificities were ascertained by inhibition with cognate sugars. Con A showed the strongest binding to many exoskeletal proteins, indicating 
mannosylation. Strong binding by soybean agglutinin but poor binding of Dolichos biflorus agglutinin and little or no binding of Ricinus communis or peanut agglutinins indicated $\beta$-linked $\mathrm{N}$-acetylgalactosamine. The presence of fucose residues was identified by the binding with Ulex europeus agglutinin. The glycosylation patterns differed in the four exoskeletal layers indicating differential glycosylation during the intermolt cycle.

Amino terminal sequences of exoskeletal proteins. We have demonstrated the antigenic similarities of a number of exoskeletal proteins to cuticular proteins of insects. From 15 to $30 \mathrm{~N}$-terminal amino acids of ten isolated (major) proteins have been analyzed by C. D. Stringer of the Protein Engineering Group. The sequences were compared to sequences in three data bases, with emphasis on cuticular or other structural protein sequences of insects. The searches showed that some stretches of amino acid sequences had from 32 to $41 \%$ identity to cuticular proteins from insects such as $B$. mori, Locusta migratoria, D. melanogaster, Manduca sexta, Hyalophora cecropia, as well as to oothecin, a structural protein from the ootheca of Periplaneta americana. These identities strengthen the probability of common ancestry of the members of these two classes of Arthropoda.

1. Kumari. S. S., and D. M. Skinner. Proteins of crustacean exoskeleton III: Glycoproteins in the Bermuda land crab Gecarcinus lateralis. J. Exp. Zool. 271: 413-424, 1995.

2. Kumari, S. S., and D. M. Skinner. Proteins of crustacean exoskeleton IV: Partial amino acid sequences of exoskeletal proteins of the Bermuda land crab Gecarcinus lateralis and their similarities to certain insect structural proteins. J. Exp. Zool. (in press).

3. O'Brien, J. J., S. S. Kumari, and D. M. Skinner. Differential localization of specific proteins in the exoskeleton of the Bermuda land crab. In: The Crustacean Integument: Morphology and Biochemistry, ed. by M. N. Horst and J. Freeman. CRC Press, Boca Raton, Florida, 1994, pp. 79-111.

\section{CHROMOSOME CHEMISTRY}
D. E. Olins ${ }^{3}$
M. S. Dhar ${ }^{1}$
H. A. Levy
A. L. Olins ${ }^{3}$
L. J. Hauser ${ }^{1,5}$
L. H. Cacheiro ${ }^{3}$
A. L. Herrmann ${ }^{3,5}$
V. N. OIman ${ }^{3,5}$

The major goal of this group is to analyze and understand the macromolecular structure of eukaryotic chromosomes and their relation to DNA 
packaging, transcription, and replication. Our laboratory employs a wide range of biophysical, biochemical, and ultrastructural techniques to work towards detailed macromolecular models.

\section{Chromatin Structure in a Hypotrichous Ciliated Protozoan}

Ciliated protozoa exhibit nuclear dimorphism, i.e., the existence of a transcriptionally-active macronucleus (MAC) in the same cytoplasm with an inactive micronucleus. Hypotrichous ciliates (e.g., Euplotes eurystomus) possess features that distinguish them from other ciliates: (1) MACs consist of a "bag" of highly polyploid (ca. 104-fold), short (ca. 2-3 kbp), linear DNA molecules each fragment corresponding to an individual structural gene, regulating and nontranscribed flanking sequences, and telomeric sequences; (2) MAC DNA replication is localized in a Replication Band (RB) that migrates along the nucleus during $S$ phase. Several MAC genes of Euplotes have been cloned and sequenced. The list includes eight genes: 5 S RNA; polyubiquitin; two versions of HSP 70 (heat shock proteins); two versions of histone $\mathrm{H} 3$; one histone $\mathrm{H} 4$ and the sole histone $\mathrm{H} 1$. In situ hybridization studies have shown that DNA replication within RBs does not appear to initiate with any particular genes, but rather progresses through the MAC, synthesizing whatever DNA lies within its path. Considerable research effort has attempted to define the properties of chromatin within the RB. Several facts are known: (1) many phosphorylated proteins are present within RBs, including phosphorylated histone $\mathrm{H}$; ; (2) acetylated histone $\mathrm{H} 4$ is enhanced within RBs; (3) exposed telomere-binding protein is enhanced within RBs; (4) replicating DNA molecules are associated to a nuclear protein matrix within RBs. Because of the large size of RBs (ca. $5 \times 15 \mu \mathrm{m})$ and the high amount of replicating DNA within this nuclear region, RBs are good models for the chromatin biochemical changes that occur in replication foci of higher eukaryotic nuclei.

\section{Chromatin Structure in the Cellular Slime Mold}

Starting in 1992, we initiated research with a new biological system, the cellular slime mold Dictyostelium discoideum. This organism has many advantages for problems of chromosome structure and function, primarily arising from the ease of molecular genetic techniques available. We have cloned and sequenced the Dictyostelium $\mathrm{H} 1$ gene. There appears to be only one type of histone $\mathrm{H} 1$ existing as a single-copy gene. This discovery suggests that knockout experiments, site-directed mutagenesis and anti-sense mutations are feasible and potentially very informative about $\mathrm{H} 1$ function. In a second project, the seven mitotic chromosomes were visualized in the electron microscope (EM) after specific staining for DNA, employing a stain developed in our laboratory. In a third series of experiments, in situ hybridization studies demonstrated that active nucleolar genes (i.e., rDNA genes) are associated into a "necklace" structure reminiscent of higher eukaryotic nucleoli. This observation was surprising, since 
Dictyostelium rDNA molecules are not tandem repeats, like in higher eukaryotes. Rather, they exist as extra-chromosomal amplified DNA fragments, much like the macronuclear genes of ciliated protozoa, described earlier. Thus, nuclear higher-order structure does not require tandem repetition of the rDNA genes.

Three-Dimensional Reconstruction by Electron Microscope Tomography (EMT)

We have been interested in the 3-D reconstruction of ası/mmetric organelles, specifically of chromosomal structures during transcription, replication, and higher-order packaging. Most attention has been focused upon a chromosomal region of RNA synthesis, the Balbiani Rings (BR) of the insect Chironomus tentans, enlarged within salivary gland cells. This gene is present on highly polytene chromosomes (ca. $10^{4}$ endoreplicated), and, when active, generates a "puffed" region in the chromosome body. In the electron microscope, electron-dense nascent ribonucleoprotein granules (RNP) can be observed surrounding the chromatin axis. Recent studies have emphasized analysis of the folded 3-D structure of the $37 \mathrm{~kb}$ mRNA within the BR granule. This has been accomplished by combining three new techniques: (1) specific nucleic acid staining by osmium ammine $B$, a stain developed in our laboratory; (2) energy-filtered imaging of the stained sections on a Zeiss EM902; and (3) reconstruction by EMT. By employing these procedures, seven BR granules have been reconstructed. These calculated structures were displayed on a Silicon Graphics workstation and volume-rendered using a software package, "VoxelView." The reconstructed BR granules were analyzed by a procedure called "seeding," which simplifies the amount of volume data. This permitted us to rotate the seven BR granules into a common 3-D orientation and to conclude that the mRNA is concentrated into about a dozen "RNA-rich" particles, rather than smeared uniformly throughout the entire volume of the BR granule.

1. Hauser, L. J., M. S. Dhar, and D. E. Olins. Dictyostelium discoideum contains a single-copy gene encoding a unique subtype of histone $\mathrm{H} 1$. Gene 154: 119-122, 1995.

2. Hauser, L. J., M. L. Treat, and D. E. Olins. Cloning and analysis of the macronuclear gene for histone $\mathrm{H} 1$ from Euplotes eurystomus. Nucl. Acids Res. 21: 3586, 1993.

3. Olins, A. L. Application of a DNA specific stain, osmium ammine $\mathrm{B}$, to cellular specimens. In: Procedures in Electron Microscopy, Vol. 5, ed. by A. W. Robards and A. J. Wilson. John Wiley \& Sons, Chichester, England, 1993, pp. 642-645.

4. Olins, A. L., L. H. Cacheiro, A. L. Herrmann, M. S. Dhar, and D. E. Olins. Inaccessibility of the Euplotes telomere binding protein. Chromosoma 102: 700-711, 1993. 
5. Olins, A. L., and D. E. Olins. Stereo-electron microscopy of DNA-stained mitotic chromosomes from Dictyostelium discoideum. Cell Biol. Int. 17: 941-944, 1993.

6. Olins, A. L., D. E. Olins, V. Olman, H. A. Levy, and D. P. Bazett-Jones. Modeling the 3-D RNA distribution in the Balbiani ring granule. Chromosoma 103: 302-310, 1994.

7. Olins, D. E., L. H. Cacheiro, and A. L. Herrmann. The replication band of Euplotes is enriched with phosphoproteins. Biol. Cell 81: 237-246, 1994.

8. Olins, D. E., and A. L. Olins. Inhibition of DNA synthesis in the macronuclear replication band of Euplotes eurystomus. J. Euk. Microbiol. 40: 459-467, 1993.

9. Olins, D. E., and A. L. Olins. The replication band of ciliated protozoa. Int. Rev. Cytol. 153: 137-170, 1994.

10. Simon, I. and D. E. Olins. Higher-order association of extrachromosomal rDNA genes in Dictyostelium discoideum. Cell Biol. Int. 18: 1091-1094, 1994.

\section{MOLECULAR IMMUNOLOGY}
S. J. Kennel
V. A. Ford ${ }^{4,5}$
J. B. Boroughs $s^{4,5}$
P. K. Lankford
L. J. Foote
S. D. Robertson ${ }^{3,5}$

Basic Carcinogenesis

Cell surface proteins mediate interaction between cells and their environment. In addition to uptake of nutrients, cells receive specific stimuli from hormone and growth factor-receptor interactions at the cell surface and specific attachment to the extracellular matrix. The expression of these molecules can be altered in tumor cells and the alteration may affect growth and metastatic characteristics of the cells. Molecules involved in tumor angiogenesis are of specific interest.

\section{Monoclonal Antibodies to Lung Endothelium}

MAbs to normal mouse lung cells have been developed to study the role of normal cells as precursors of different types of lung cancer and to probe the interaction among cells during metastasis to the lung. Rat MAbs to mouse lung macrophages, Type I and Type II alveolar cells and endothelial cells have been identified and characterized. The most remarkable of these are two antibodies that recognize different epitopes on a $112 \mathrm{kDa}$ glycoprotein (P112) expressed extensively on lung endothelial cells. This is the first demonstration that endothelial cells in the lung are different from those in other organs in that they express a unique surface glycoprotein. The target protein has been identified as 
thrombomodulin by amino acid sequence, cDNA sequence, and enzymatic activity.

The MAb to thromobomodulin mày be useful for organ-specific drug delivery, for studying the interaction between tumor cells and endothelial cells, and for "negative imaging" of tumors for diagnosis. Recent studies using liposomes targeted with these MAbs have shown for the first time that liposomes can be localized efficiently in vivo. Liposomes of optimal lipid composition and antibody concentration have been formulated and tested. Growth of lung tumors can be retarded by targeting isotope or cytotoxic drugs to the lung. In addition, immunohistochemical staining of sections of mouse embryos indicates that thrombomodulin may play an important role in embryogenesis.

\section{Monoclonal Antibodies for Drug Targeting}

Targeting of drugs to tumors as a specific means of chemotherapy has long been an appealing idea. Development of tumor-selective MAbs in the 1980's kindled enthusiasm for this approach. Unfortunately, localization of MAbs in solid human tumors has been inefficient. In the best of studies, less than $0.1 \%$ of the injected dose accumulates in tumor. Model studies in our laboratory and elsewhere have shown that targeting in the vascular space is much more efficient. Efforts are under way to produce MAbs that bind selectively to tumor blood vessels. Studies involve both human renal cell carcinomas and a model rat tracheal cell carincoma. It is anticipated that identification of specific, or at least selective, MAb for tumor endothelium may increase targeting efficiencies more than tenfold.

1. Falcioni, R., L. Cimino, M. P. Gentileschi, I. D'Agnano, G. Zupi, S. J. Kennel, and A. Sacchi. Expression of $\beta_{1}, \beta_{3}, \beta_{4}$ and $\beta_{5}$ integrins by human lung carcinoma cells of different histotype. Exp. Cell Res. 210: 113-122, 1994.

2. Ford, V. A., J. E. Wilkinson, and S. J. Kennel. Thrombomodulin distribution during murine development. Roux's Arch. Dev. Biol. 202: 364-370, 1993.

3. Goto, T., S. J. Kennel, M. Abe, M. Takishita, M. Kosaka, A. Solomon, and S. Sairo. A novel membrane antigen selectively expressed on terminally differentiated human $\beta$ cells. Blood 84: 1922-1930, 1994.

4. Kennel, S. J., L. J. Foote, L. Cimino, M. G. Rizzo, L. -Y. Chang, and A. Sacchi. Sequence of cDNA for the $\beta_{4}$ subunit of murine integrin. Gene 130: 209-216, 1993.

5. Masahiro, A., T. Goto, S. J. Kennel, O. Wolfenbarger, S. Macy, D. T. Weiss, and A. Solomon. Production and immunodiagnostic applications of anti-human light chain monoclonal antibodies. Am. J. Clin. Pathol. 100: 67-74, 1993. 
6. Maruyama, K., T. Takizaqa, T. Yuda, S. J. Kennel, L. Huang, and M. Iwatsuru. Targetability of novel immunoliposomes modified with amphipathic polyethyleneglycols conjugated at their distal terminals to monoclonal antibodies. Biochim. Biophys. Acta. 1234: 74-80, 1995.

7. Mori, A., S. J.'Kennel, and L. Huang. Immunotargeting of liposomes containing lipophilic antitumor prodrugs. Pharm. Res. 10: 507-514, 1993.

8. Mori, A., S. J. Kennel, M. van Borssum Waalkes, G. L. Scherphof, and L. Huang. Targeted delivery of 3',5'-0-dipalmitoyl-5-fluoro-2'-deoxyuridine with organ-specific immunoliposomes for thearpy of mouse lung-metastasis metastases. Cancer Chemother. Pharmacol. 35: 447-456, 1995

9. Roy, R., S. Shiota, S. J. Kennel, R. Raha, M. von Wronski, T. P. Brent, and S. Mitra. A comparative study of the biochemical properties of human and mouse recombinant $O^{6}$-Methylguanine-DNA methyltransferases. Carcinogenesis 16: 405-411, 1995.

\title{
RADIATION CARCINOGENESIS
}

\author{
R. J. M. Fry ${ }^{2}$
}

The major concern about the risks of radiation effects is excess cancer resulting from exposures that are incurred occupationally, environmentally or as a result of diagnostic and therapeutic procedures. In the case of occupational and environmental exposures, the doses are low and protracted over long periods of time. The estimation of the risk of possible carcinogenic effects under such exposure conditions is extremely difficult. The problems of risk estimation have been discussed in "Effects of low doses of radiation," R. J. M. Fry, Health Physics, in press. The human experience provides estimates with such broad confidence limits that the important differences between the effects of protracted low doses and those at high doses and high dose rates are obscured.

The long-term research carried out by the Radiation Carcinogenesis group has dealt with not only aspects of the mechanisms, such as the role of chromosome aberrations in leukemia and the ability of tissues to suppress expression of the initial events in carcinogenesis, but also the validation of models of dose-response relationships and time-dose relationships.

The recent results relate to studies of the effects of dose rate and fractionation of low-LET radiation on the induction of myeloid leukemia, total cancers and life shortening. Either lowering the dose rate or splitting the total dose into small fractions reduces the induction of myeloid leukemia and solid cancers by an amount consistent with a linear-quadratic dose-response model. Of considerable interest is the finding that the reduction of the size of the dose fraction required to have the same effect as the reduction of dose rate varies 
markedly between tissues. The conclusion from this result is that the number or size, or both, of the targets involved in cancer induction in different cell types are markedly different, for example, between breast cancer and lung tumors.

There are no data for the carcinogenic effects in humans of neutrons, to which workers are exposed, or the heavy ions that are encountered on space missions, and therefore information about mechanisms and risks must come from experimental work. In the study of the life-shortening effect of neutrons, we have reported (Storer and Fry, Radiat. Environ. Biophys. 34: 21-27, 1995) data that in the case of high-LET radiation the initial slope of the dose-response, and thus the effect of very low doses, can be determined using multiple fractions of very small individual doses. The results established unequivocally that the initial slope of the dose-response curve for life-shortening is linear over a range of low doses. A number of investigators, especially those studying radiation effects on cells in vivo and also those investigating the carcinogenic effects of radon, have reported that fractionation increases the effects of high-LET irradiation. We found that fractionation of the doses of neutrons had no effects on the magnitude of the response. Since the major cause of life-shortening induced by low doses of radiation is the excess cancer rate, our results argue against the claim that low-dose-rate neutron irradiation or fractionation of neutron doses increases the risk of cancer induction. The finding of an initial linear slope for the dose-response of life-shortening after exposure to fission neutrons and our previously reported findings for low-LET radiation substantiate the biophysical model that proposes that at low doses, single-track events predominate and that the effect is proportional to dose.

The collaborative study of the carcinogenic effects of heavy charged particles with colleagues at the Lawrence Berkeley Laboratory is drawing to a close. The data for the induction of tumors of the Harderian gland by heavy ions suggest a somewhat different relationship of Quality Factor to Linear Energy Transfer (LET) of radiations in the high-LET range than that assumed by the International Commission on Radiological Protection. The data from this series of experiments (Alpen et al., Adv. Space Res. 14: 573, 1994) are being used in the development of new approaches to the estimation of the risk of cancer induction by the heavy ions encountered in space.

1. Alpen, E. L., P. Powers-Risius, S. B. Curtis, R. DeGuzman, and R. J. M. Fry. Fluence-based relative biological effectiveness for charged particle carcinogenesis in mouse Harderian gland. Adv. Space Res. 14: 573-581, 1994.

2. Blakeley, E. and R. J. M. Fry. Radiation protection in space. Radiat. Environ. Biophys. (in press). 
3. Boice, J. D., Jr. and R. J. M. Fry. Radiation carcinogenesis in the gut. In: Radiation and Gut, ed. by C. S. Potten and J. H. Hendry. Elsevier Science B. V. Amsterdam, 1995, pp. 291-305.

4. Fry, R. J. M. Radiation protection guidelines for space activities. ACTA Astronaut. 32: 735-737, 1994.

5. Fry, R. J. M. The radiation protection problems of high altitude and space flight. In: Radiation Protection on the Threshold of the 21st Century, Proceedings of an NEA Workshop, Paris, January 11-13, 1993. Nuclear Energy Agency, Paris, 1993, pp. 285-298.

6. Fry, R. J. M. Mice, myths, and men. National Council on Radiation Protection and Measurements, Bethesda (in press).

7. Fry, R. J. M. Effects of low doses of radiation. Health Phys. (in press).

8. Fry, R. J. M. Radiation carcinogenesis. In: Current Radiation Oncology, Vol. II, ed. by J. S. Tobias and P. R. M. Thomas. Edward Arnold, London (in press).

9. Storer, J. B. and R. J. M. Fry. On the shape of neutron dose-effect curves for radiogenic cancers and life shortening in mice. Radiat. Environ. Biophys. 34: 21-27. 1995.

10. Turner, J. E. and R. J. M. Fry. High-LET radiation carcinogenesis: What do we know and what do we need to know? Radiat. Prot. Dosimetry 52: 189-196, 1994.

\title{
NEOPLASTIC PROGRESSION IN RAT TRACHEAL EPITHELIUM
}

\author{
M. Terzaghi-Howe M. E. Overcash ${ }^{3,5}$ \\ G. W. Chang ${ }^{4} \quad$ S. A. Plichta ${ }^{4}$ \\ $\begin{array}{ll}\text { J. R. Ford } & \text { E. B. Wright }\end{array}$
}

In solid cancers there is good evidence that while the initiating events are a prerequisite for carcinogenesis, they do not determine the probability that a cancer develops. This fact makes it imperative to study the factors influencing the expression of initiation or neoplastic transformation. Studies carried out with a combined in vivo and in vitro rat trachea model are designed to evaluate (1) critical target cells for development of respiratory cancers; (2) the influence of direct cell-cell contact on neoplastic development following exposure to highor low-linear energy transfer (LET) radiation; and (3) the influence of cell-cell interactions mediated by diffusible growth factors, such as transforming growth factor type $\beta$, on the evolution of respiratory neoplasias.

In the model system, tracheal cells are isolated, manipulated, and grown in vitro. They can subsequently be used to re-populate denuded tracheas that have been implanted in vivo. A brief summary of specific projects is given below. 
Modulation of Epithelial Cell Growth in the Intact Tissue

During the course of neoplastic progression, rat tracheal epithelial cell lines become less sensitive to growth inhibition by TGF- $\beta$ in culture. For this reason it has been proposed that this loss of sensitivity may be critical to evolution of the neoplastic state. However, the relevance of this observation to tumor development in vivo needs to be confirmed.

In past years we have focused our attention on TGF- $\beta$ and its possible role in the modulation of neoplastic development in vivo. More recently we have identified another factor(s) associated with normal tracheal cells which can modulate growth, differentiation and tumorigenicity of neoplastic cell populations. We are currently attempting to identify and characterize this factor(s).

Changes in gap junction communication between normal and neoplastic cells may be involved in the emergence of neoplastic cells in vivo. In order to test this hypothesis we are in the process of systematically evaluating changes in gap junction communication between normal epithelial cells and epithelial cell lines exhibiting different types of preneoplastic/neoplastic alterations.

\section{Alpha-Particle-Induced Alterations in Exposed Rat Tracheal Mucosa}

Given the well-defined energy spectrum and penetrability of alpha particles in tissues, we are attempting to better define the critical target cells for neoplastic development in irradiated respiratory tissues. Two basic approaches are being utilized. The first involves separation of different subpopulations of tracheal cells prior to irradiation, and the second, irradiation of the intact tissue while systematically varying the distance from the alphaparticle source to different subpopulations within the intact trachea. The parameters of interest are cell survival and the development of preneoplastic or neoplastic lesions in cell populations irradiated under systematically varied conditions. In parallel with experiments designed to evaluate the induction of respiratory neoplasias, we are evaluating the effects of selected experimental variables on the induction of mutations in V79 and derived gpt transfectants. It is proposed that those factors which directly influence the oncogenic potential of alpha-particles may also influence the induction of, for example, mutations. If so, more quantitative experiments can be designed to evaluate basic mechanisms in radiation carcinogenesis.

1. Ford, J. R., and M. Terzaghi-Howe. Effects of ${ }^{210}$ Po alpha-particles on survival and preneoplastic transformation of primary rat tracheal epitheal cells irradiated while in suspension or in the intact tissue. Radiat. Res. 136: 89-96, 1993. 
2. Terzaghi-Howe, M., and J. Ford. Effects of radiation on rat respiratory epithelial cells: Critical target cell populations and the importance of cell-cell interactions. Adv. Space Res. 10: 565-572, 1994.

\section{FUNDAMENTAL AND APPLIED CRYOBIOLOGY}
P. Mazur
T. H. Jackson ${ }^{14,5}$
K. W. Cole
A. E. Jetton ${ }^{15,5}$
J. W. Hall ${ }^{5}$
J. N. Kassis ${ }^{13}$
S. S. Heimansohn ${ }^{14,5}$
P. D. Schreuders ${ }^{1}$

Fundamental Cryobiology of Mouse and Human Sperm

The purpose of our study on the cryobiology of mouse sperm is to devise methods for cryogenically maintaining the rapidly accelerating number of transgenic strains of mice. The cryopreservation of sperm has the potential of being substantially more cost-effective than cryopreservation of embryos. However, until four years ago, in striking contrast to human and bovine sperm, no one had succeeded in obtaining significant survivals of mouse sperm after freezing and thawing. Furthermore, reports of success have been capricious and make little sense in terms of our understanding of basic cryobiology.

Our continuing thesis is that the best, and in some cases only, route to effective cryopreservation is to develop an understanding of the underlying fundamental cryobiological factors. That is the strategy that we have been pursuing for human sperm in collaboration with Dr. John Critser at the Methodist Hospital of Indiana for several years. And it is the strategy that we are now pursuing with mouse sperm in collaboration with that same group. A proposal to that effect was submitted to $\mathrm{NIH}$, and a grant awarded in late spring of FY 1994.

Cryopreservation involves suspending cells in hyperosmotic solutions of appropriate cryoprotective solutes, freezing and thawing them at appropriate rates, and returning them to physiological media. All of these steps subject the cells to marked abnormal osmotic conditions, and whether or not the cells survive depends in part on the magnitude of the osmotic changes, the resulting volume excursions of the cells, and the tolerance of the cells to them. To assess the osmotic volume excursions one must determine the permeability coefficients of the cell to water and the cryoprotectants. And since freezing involves major changes in temperature, one must also determine the temperature coefficients of these permeabilities.

The physical-chemical descriptors of cell osmotic responses are predicated on a cell's behavior as an ideal osmometer. That means that its volume is a linear function of the reciprocal of the external osmolality. We have found that the 
osmotic response of mouse (and human and bovine) sperm is ideal between $~ 100$ and 1000 mosm ( 300 mosm is isotonic). The osmotic response in the anisotonic media has been measured by an electron-spin resonance technique (see next paragraph) and in mouse sperm by electronic cell sizing.

Permeability of cells to water is determined by measuring the rate at which they shrink in nonpermeating hyperosmotic solutions such as $\mathrm{NaCl}$ or sucrose or in hyperosmotic permeating solutes. Permeability to cryoprotective solutes (which, to be protective, usually have to be capable of permeating cells) is assessed by determining the rate at which shrunken cells re-expand to normal volume in those solutions. We have used two methods to determine the kinetics of osmotic volume changes. One method involves measuring the time for cells to swell osmotically to a lytic volume when placed in hypotonic saline with or without cryoprotectant. The second method uses electron spin resonance to follow the rate of increase in the volume of cells, the cytoplasm of which contains the spin label tempone. Both methods have yielded comparable values for the permeability of water $(\mathrm{Lp})$ and glycerol $(\mathrm{Pg})$ in human and bovine sperm. Both are high values, especially Lp. For mouse sperm, we are investigating the feasibility of a third approach, namely, the use of the Coulter electronic cell sizer.

With these permeability coefficients in hand, one can compute the osmotic volume perturbations produced by the addition of glycerol in various concentrations and by various sized steps, and by the manner in which that glycerol is removed. The computer modeling also permits the design of protocols that limit the volume excursions to desired limits. In a recent paper (Gao et al., in press), we have shown that the motility of human sperm is substantially impaired by excessive shrinkage in hypertonic saline and by excessive swelling in hypotonic saline. To obtain motilities of $>90 \%$, the volume excursions have to be kept between 75 and $110 \%$ of the normal isotonic volume. The addition of $1 \mathrm{M}$ glycerol to isotonic saline causes an initial shrinkage and its removal causes swelling above the normal isotonic volume. If the addition and removal are made in one step, the innocuous range of volume excursions is exceeded substantially and only $28 \%$ of the sperm remain motile. However, if the additions and dilutions are made in 4-8 steps of proper size and duration, the volumes will remain in the 0.75 to 1.1 range and over $90 \%$ remain motile. This is important because, generally, the higher the usable concentrations of cryoprotectant, the easier it is to obtain high survivals after freezing and thawing.

We have proposed a similar biophysical approach to developing procedures for the cryopreservation of mouse sperm. But first we wished to investigate whether mouse sperm motility after freezing and thawing is affected by the temperature at which the sperm are collected and, if sperm are collected at $22^{\circ} \mathrm{C}$, whether their motility is affected by the rate at which they are cooled to $0^{\circ} \mathrm{C}$ before the initiation of freezing per se. The reason for the second question is that the sperm of some species (especially porcine and bovine) are killed by rapid 
chilling to $0^{\circ} \mathrm{C}$ (thermal shock). That was thought not to be the case for mouse sperm. But our study (Tao et al., in press) has shown that mouse sperm, in fact, are injured by rapid chilling. Only $30 \%$ to $50 \%$ as many remain motile as when cooling to $0^{\circ} \mathrm{C}$ is slow $\left(1^{\circ} \mathrm{C} / \mathrm{min}\right)$.

The first question, the effect of the collection temperature, arose in part because mouse sperm plasma membranes are especially sensitive to damage from oxygen-derived free radicals. We reasoned that such damage might be reduced if the sperm were never exposed to temperatures above $0^{\circ} \mathrm{C}$ during isolation and subsequent exposure to cryoprotectant. That has proved to be the case. When sperm were frozen and thawed after low temperature isolation and treatment with cryoprotectant, their motilities were some 5 -fold higher $(\sim 50 \%)$ than were the motilities of sperm that had been isolated at room temperature. Another factor affecting post-thaw survival was the warming rate. Very rapid warming $\left(\sim 2000^{\circ} \mathrm{C} / \mathrm{min}\right)$ was substantially more damaging in some cases than warming at $50-1000^{\circ} \mathrm{C} / \mathrm{min}$.

It remains to be seen whether these motile mouse sperm are fully functional; i.e., whether they are capable of fertilizing ova in vitro and whether the resulting embryos develop into normal mouse pups. If so, that would suggest that cryopreservation of sperm will be a feasible approach to maintaining transgenic lines of mice.

\section{Cryobiology of Drosophila Embryos}

Because of its genetic importance, there now exist some 30,000 mutant lines of Drosophila. The maintenance of these lines by standard generational breeding is costly, and it subjects the lines to genetic drift and possible loss by mix-up, disease, or accident. Cryopreservation of embryos would be a clear solution, but it has been a formidable problem, a problem with which we have been involved the past six years with NSF and DOE support. As reported in Science, in 1992, success has been achieved.

A mandatory requirement for the cryopreservation of any cell system is that the cells be permeable to water and cryoprotective solutes. Mammalian cells are permeable to both, but since many non-mammalian systems are not, the development of non-lethal methods to permeabilize them constitutes a formidable challenge to their preservation. Such was the case with Drosophila embryos. However, a chemical method for their permeabilization was developed, a method involving sequential exposure to Clorox, isopropanol, and heptane that contains small amounts of butanol. We have assessed the contributions of these various steps to enhancing permeability to water. The approach was to gravimetrically determine the kinetics of water loss during air drying. The removal of the outer egg shell or chorion by Clorox increases water permeability by about a factor of 6. The exposure to heptane/butanol mixtures increases it further by a factor of 
16. There is evidence that the action of alkane is to remove a $50 \AA$ layer of wax in the inner shell (vitelline membrane). A physical model has been developed to account for the kinetics of dehydration. The model, which is based on Eyring, involves the determination of kinetic constants for efflux and influx of water. The constant for water efflux in heptane-permeabilized embryos is 100 times that of intact embryos. The fit between the model and experiment is good until about $80 \%$ of the intraembryonic water is lost. Manuscripts on the experimental determinations and the model have been recently submitted.

The ability of heptane to permeabilize the vitelline membrane is greatly enhanced by the presence of small amounts $(0.3 \%)$ of butanol. We have compared the effects of substituting methanol, ethanol, or isopropanol for the butanol. As judged by staining with the dye rhodamine $B$, the effectiveness of the first two in permeabilizing the embryos is considerably greater than that of the last two. But the toxicity of the first two is also considerably greater than that of the last two. The polarity of the alcohols also decreases in the order listed. These facts taken together suggest that the wax barrier in the vitelline membrane either consists of mixtures of more polar and less polar molecules or of molecules that have hydrocarbon-like tails and more polar head groups. Consequently, the most effective permeabilizing solvent is one that contains both non-polar molecules (heptane) and moderately polar molecules (alcohols).

\section{Cryobiology of the Anopheles Mosquito Embryo}

A molecular genetic approach is being used increasingly to study and control malaria vectors. One specific approach is to create transgenic strains of mosquitos that are incapable of transmitting the malaria parasite, strains that also have the capacity to introduce this trait into the wild-type anophelian population. This and most other genetic approaches require the acquisition and testing of scores of lines, but the simultaneous maintenance of these many lines is prohibitively difficult with standard breeding and husbandry techniques. It would be greatly facilitated by the ability to cryobiologically preserve the mosquito embryos. Such cryopreservation is currently not possible. In early 1993 Louis Miller, chief of the Laboratory for Malaria Research at NIH, invited us to collaborate to develop a cryopreservation method based on that developed here for Drosophila. The collaboration has proceeded with our contribution supported by OHER and, in FY 1994, by a non-extendable ORNL Seed Money Grant.

There were four formidable obstacles to the cryopreservation of Drosophila embryos. One was that the embryo is highly impermeable to both water and cryoprotective solutes. A mandatory requirement for the cryopreservation of any cell system is that it be permeable to both. The second problem is that the Drosophila embryo is highly chill-sensitive; i.e., it is rapidly killed by exposure to low temperatures in the absence of ice formation. The first problem was solved by the Clorox, alcohol, alkane procedure described above. The second problem 
was solved by using cooling and warming rates that are high enough to outrace the chilling injury. The required rates were on the order of $100,000^{\circ} \mathrm{C} / \mathrm{min}$. But this introduced a third problem. Cooling rates that are higher than a few degrees per minute will ordinarily cause lethal intracellular freezing in objects the size of these embryos. The only way to prevent that is to introduce concentrations of certain solutes that are high enough to induce the water in and around the embryos to form a glass or vitrify rather than freeze. The solute of choice was ethylene glycol. The required concentrations are exceedingly high -- 8.5 molar (55 weight percent). The problem was to avoid lethal toxicity and lethal osmotic consequences from introducing and removing such concentrations. The fourth problem was that these problems were minimized only in a narrow window of developmental stages. Embryos that were too young were unacceptably chill-sensitive and sensitive to the permeabilization and vitrification procedures. Embryos that were slightly older than the "window" were refractory to permeabilization apparently because they have developed a second permeability barrier, chitinized cuticle.

Our research has determined that anophelian embryos are subject to some of these same problems but that there are substantial differences, differences that render the Drosophila procedures ineffective for Anopheles. Like Drosophila, intact and Clorox-dechorionated Anopheles embryos are impermeable to ethylene glycol, but unlike Drosophila they exhibit moderate permeability to water. For example, when held in air, intact Drosophila embryos take $\sim 6 \mathrm{hr}$ to lose half their water whereas young (8-hr) Anopheles embryos dehydrate severely in $3 \mathrm{~min}$. Paradoxically, although permeability to water is essential to cryopreservation, the inherent water permeability of the Anopheles embryo renders the Drosophila permeabilization procedure lethal. Only about half of the former survive the 2.5-min exposure to $50 \%$ Clorox used for dechorionation, and few survive a 3-min exposure. Presumably, because of their permeability to water, the embryonic cells become directly exposed to this strongly oxidizing $\mathrm{pH} 11$ solution. Those that do survive dechorionation are immediately killed by the next step: a 30-sec, or even a 2-sec exposure to isopropanol. The purpose of the isopropanol is to remove surface water and provide a liquid that is miscible with the subsequent alkane. However, in alcohol, the Anopheles embryos undergo severe and lethal dehydration.

Several major modifications the past year have resulted in the development of a procedure that effectively permeabilizes $100 \%$ of 8 -hr embryos and results in the survival (hatching) of $\sim 20-60 \%$. The first modification was to reduce the concentration of Clorox from 50 to $10 \%$, and later to substitute an equivalent concentration of reagent grade hypochlorite. Although these lower concentrations of hypochlorite effectively removed visible indicators of the chorion, they resulted 
in poor permeabilization after subsequent steps unless the exposure time to the reduced hypochlorite was extended from $2.5 \mathrm{~min}$ to $8-10 \mathrm{~min}$ for $10 \%$ Clorox and 20-30 min for $10 \%$ of reagent hypochlorite. Fortunately, these longer exposures were still innocuous.

The second modification was to remove surface water from the dechorionated embryos by brief air-drying rather than by isopropanol. The duration of drying proved critical. If too short $(2 \mathrm{~min})$, enough residual surface water remained to prevent permeabilization by the heptane. If too long ( $3 \mathrm{~min}$ ), the embryos underwent damaging dehydration. There was a narrow window at 2.5 min air drying that sometimes permitted both survival and permeabilization. The problem was that the results were variable. The variability was reduced by basing the appropriate air drying on the morphological appearance of the embryos rather than time; i.e, the embryos were exposed to air while being observed under a microscope, and air-drying was stopped when incipient shrinkage was observed. With this approach and reduced hypochlorite concentrations, all the embryos in most runs are effectively permeabilized, and in those runs, an average of about $30 \%$ survive. Permeability to water is assessed in terms of the time for embryos to initially shrink in $1 \mathrm{M}$ ethylene glycol. Permeability to ethylene glycol is assessed in terms of the time for them to re-expand in that solution. Effective permeabilization means initial shrinkage in less than $5 \mathrm{~min}$ and subsequent expansion in less than $90 \mathrm{~min}$.

Having achieved a degree of success in permeabilizing the embryos without lethality, we turned our attention to the next major question: chill sensitivity in the absence of ice formation. Like Drosophila, 8-hr Anopheles embryos are proving to be highly sensitive, and like Drosophila, anophelian chill injury accelerates rapidly as the temperature is lowered. At $8^{\circ} \mathrm{C}$, no injury occurs in $24 \mathrm{hr}$. But as the temperature is lowered to 5 and $0^{\circ} \mathrm{C}$, half the embryos are killed in $8 \mathrm{hr}$ and $5 \mathrm{hr}$, respectively. Death from chilling continues to accelerate at -5 and $-10^{\circ} \mathrm{C}$, with $50 \%$ of the embryos succumbing in $20 \mathrm{~min}$ and $7 \mathrm{~min}$, respectively. The sub-zero determinations were carried out in a differential scanning calorimeter to ensure that no ice formed during the exposure. The rate of chilling injury increases so rapidly in these young embryos that the only hope of cryopreserving them would be the vitrification route involving very high cooling and warming rates.

We had found that the rate of occurrence of chilling injury in Drosophila embryos decreased sharply as embryos developed from the 3-hr stage to the 12-hr stage. Anopheles embryos were found to behave similarly. Twelve-hour embryos survived at least $48 \mathrm{hrs}$ at $0^{\circ} \mathrm{C}$ and at least $20 \mathrm{~min}$ at $-10^{\circ} \mathrm{C}$, whereas 8-hr embryos succumbed in $5 \mathrm{hr}$ and in $7 \mathrm{~min}$, respectively. But a problem was soon uncovered. Although the older embryos are substantially less sensitive to chilling, they also are proving substantially more refractory to the permeabilization procedure that is effective for the younger embryos. 
This refractoriness led us to initiate preliminary experiments on an alternative way to effect permeabilization, namely, by electroporation. Electroporation is a relatively new method of creating pores in plasma membranes by subjecting cells to pulses of high electrical potential. In the case of Anopheles, the purpose would not be to induce pores in the plasma membranes, but rather would be to porate the non-living vitelline membrane which is the site of the permeability barrier. Our experiments indicated that very high voltage potentials do render a fraction of anophelian embryos permeable to ethylene glycol, but the voltage/ time duration combinations so far tried are lethal. More important, the experiments suggested the idea that perhaps innocuous permeabilization of older embryos can be achieved by a sequential combination of physical and chemical approaches neither of which is effective by themselves. This concept formed a major thrust of a proposal on Anopheles cryobiology submitted to NIH in October 1994. It received a sufficiently high priority score to make funding likely.

1. Cole, K. W., P. D. Schreuders, A. P. Mahowald, and P. Mazur. Procedure for the permeabilization and cryobiological preservation of Drosophila embryos. ORNL/TM-12394, May 6, 1993, Oak Ridge National Laboratory, Oak Ridge, TN.

2. Crabbe, J. C., U. Schneider, J. W. Hall, and P. Mazur. Cryopreservation as a tool for the study of selectively bred lines in rodent behavioral genetics. Behav. Genet. 21: 307-312, 1993.

3. Du, J., F. W. Kleinhans, P. Mazur, and J. K. Critser. Osmotic behavior of human spermatozoa studied by EPR. Cryo Lett. 14: 285-294, 1993.

4. Du, J., J. Tao, F. W. Kleinhans, P. Mazur, and J. K. Critser. Water volume and osmotic behavior of mouse spermatozoa determined by electron paramagnetic resonance. J. Reprod. Fertil. 101: 37-42, 1994.

5. Du, J., F. W. Kleinhans, P. Mazur, and J. K. Critser Human spermatozoa glycerol permeability and activation energy determined by EPR. Biochim. Biophys. Acta 1194: 1-11, 1994.

6. Gao, D. Y., E. Ashworth, P. F. Watson, P. Mazur, and J. K. Critser. Hyperosmotic tolerance of human spermatozoa: Separate effects of glycerol, sodium chloride and sucrose on spermolysis. Biol. Reprod. 49: 112-123, 1993.

7. Gao, D. Y., J. Liu, L. E. McGann, P. F. Watson, F. W. Kleinhaus, P. Mazur, E. S. Critser, and J. K. Critser. Prevention of osmotic injury to human spermatozoa during addition and removal of glycerol. Human Reprod. (in press).

8. Henry, M. E. E. Noiles, D. Gào, P. Mazur, and J. K. Critser. Cryopreservation of human spermatozoa. IV. The effects of cooling rate and warming rate on the maintenance of motility, plasma membrane integrity, and mitochondrial function. Fertil. Steril. 60: 911-918, 1993. 
9. Mazur, P. Principles of medical cryobiology: The freezing of living cells, tissues, and organs. In: Principles of Medical Biology, ed. by E. E. Bittar and N. Bittar. Jai Press (in press).

10. Schreuders, P. D. and P. Mazur. Vitrification-based cryopreservation of Drosophila embryos. Adv. Cryog. Eng. 39: 2031-2038, 1994.

11. Tao, J., J. Du, F. W. Kleinhans, E. S. Critser, P. Mazur, and J. K. Critser. The effect of collection temperature, cooling rate, and warming rate on chilling injury and cryopreservation of mouse spermatozoa. J. Reprod. Fertil. (accepted). 


\title{
Mammalian Genetics and Development Section
}

\author{
Section Overview - R. P. Woychik
}

The Mammalian Genetics and Development Section is one of the world's largest mouse genetics centers with a considerable number of well-characterized mutant stocks. The Section is comprised of eight principal investigators who oversee a number of distinct research programs, all of which involve the utilization of the mouse as a model organism to study gene structure and function and/or mechanisms of mammalian mutagenesis. The core infrastructure, around which all activity within the Section is centered, is the "mousehouse," a 66,000 sq.ft. conventional facility with 66 animal rooms for the maintenance of several hundred thousand mice. This large animal resource has allowed several research programs within the Section to address problems in genetic toxicology, mammalian mutagenesis, and genome analysis that could not be conducted cost-effectively elsewhere.

\section{Genetic Repository for Mutant Mouse Strains}

One of the major assets of the Mammalian Genetics Section is its repository of hundreds of well-characterized mouse mutant lines. The vast majority of these mutant stocks arose over the past 40 years as part of the intense efforts on the part of several investigators within the Section to study mechanisms of radiation/chemical mammalian mutagenesis. Many of these mutations are variable-sized deletions centered around the seven specific loci $(c$, agouti, $b$, brown, $c$, albino, $p$, pink-eye, $d$, dilute, $s$, piebald spotting, and se, short-ear) which comprise the visible specific locus test. Starting in 1987, we expanded our mutant holdings through the generation of insertional mutations in transgenic mice (Insertional Mutagenesis and Transgenic Mouse Group) and through the use of targeted mutagenesis utilizing the embryonic stem cell technology (Targeted Mutagenesis Group). In the past several years, the Genetic Analysis and Mutagenesis Studies Group, Chromosome Damage, and Molecular Genetics Groups have employed chemical mutagenesis with ethylnitrosourea (ENU), chlorambucil $(\mathrm{CHL})$ and other agents for the purpose of saturating specific regions of the mouse genome with point mutations, and to generate large DNA structural rearrangements, like deletions and translocations, throughout the genome. Recent results from the Chromosome Damage Group indicate that chemically-induced translocations are particularly useful for the purpose of identifying mouse mutations with neurologic phenotypes. Efforts are currently under way in the Genetic Analysis and Mutagenesis Studies Group to establish a computerized data base of all of the mutant stocks within the Section. 


\section{Genetic Toxicology and Mechanisms of Mammalian Mutagenesis}

Many of the now classical genetic tests in toxicology were developed in the Mammalian Genetics and Development Section and continue to enable the Genetic Analysis and Mutagenesis Studies, Chromosome Damage, and Organismic Effects Groups to estimate the genetic risk associated with the exposure to specific forms of radiation and chemicals. The visible specific locus test, developed in the Section in the early 1950s, remains the primary test utilized by the Genetic Analysis and Mutagenesis Studies Group. Both the Genetic Analysis and Mutagenesis Studies and Chromosome Damage Groups are applying the results from their testing experiments to study mechanisms of mammalian germ cell mutagenesis. The increased capability for analyzing the nature of mutations, not only by genetic and cytogenetic but also by molecular techniques, has greatly improved the ability to study mechanisms of mutagenesis. These mutagenesis experiments are also contributing significantly to the increase in the mutant resource within the Section. In fact, many of the new translocation mutations being generated by the Chromosome Damage Group were originally derived from experiments utilizing the dominant lethal test to a number of chemical agents.

Information about the nature of mutations induced by different mutagens in different germ-cell stages has formed the basis for a large-scale experiment by the Organismic Effects Group to assess what types of mutations are most likely to produce dominant phenotypes. The Assessment of Dominant Damage (ADD) approach used by this Group combines the study of numerous dominant end points and methods of data analysis.

\section{Analysis of Mouse Mutants to Study Development and Disease}

A major theme of the Section's research is the utilization of mutations in the mouse to study the structure and function of specific genes or genomic regions. Because of the existence of many regions of conserved synteny between the mouse and human genomes, detailed physical/functional analyses, aided by mutation resources in the mouse, can predict functions in a corresponding human genomic segment, can determine the organismal roles played by newly identified DNA sequences, and can identify mouse models for the study of human genetic diseases.

The Molecular Genetics Group works very closely with the Genetic Analysis and Mutagenesis Studies Group on the analysis of genomic regions that are associated with overlapping deletion mutations generated in past and ongoing specific-locus mutagenesis experiments. These regions, in aggregate, cover $2-3 \%$ of the genome. The mapping of DNA clones to, and within, these regions is greatly simplified by the availability of maps generated in earlier and ongoing 
genetic studies (the Genetic Analysis and Mutagenesis Studies Group) that identify functional units in the region surrounding the locus and delineate complementation groups. The Molecular Genetics Group is concentrating its efforts on the molecular characterization of the $c$ (albino) and $p$ (pink-eyed dilution) regions. The Insertional Mutagenesis and Transgenic Mouse Group recently cloned the agouti gene and is working on the analysis of the a (agouti) locus. The regions associated with the other specific loci are being characterized in collaboration with investigators at other institutions around, the world.

With respect to the characterization of mutations outside of the regions surrounding the seven specific loci, the Insertional Mutagenesis and Transgenic Mouse Group is now analyzing a number of insertional mutations throughout the genome that were originally identified as part of a large scale insertional mutagenesis program that was conducted in the Section several years ago. The Targeted Mutagenesis program is concentrating its efforts on the characterization of the c-myc and Evi-1 knockout mutations. The Genome Analysis Group is attempting to clone the genes associated with many of translocation mutants that were originally generated and characterized by the Chromosome Damage Group. Other efforts are under way in the Section to analyze mutations, including Scurfy, which maps to the X-chromosome.

Other experiments within the Section involve the use of transgenic mice to study gene function and to develop models of human disease. An example is the mouse model for sickle-cell anemia that has been constructed by the Mammalian Biochemical Genetics Group. This was accomplished by making appropriate crosses to breed the $\mathrm{Hb} \mathrm{S}$ Antilles transgene into a mutant line that produces high-oxygen-affinity hemoglobins. The red-cell sickling and the secondary organ pathology of this mouse model will facilitate studies on the natural progression of the disease and on possible therapeutic intervention.

\section{Involvement in the Genome Program}

In the last couple of years, the Mammalian Genetics and Development Section has assumed an important role in DOE's Human Genome Program. Now that major portions of the human genome have been mapped and hundreds of human cDNAs have been isolated and sequenced, there is increased recognition in the genome community that physical maps and sequenced segments of DNA have limited value for the purpose of establishing the whole organismic functions and medical relevance of specific genes. Since there is a great deal of homology between the genomes of humans and mice and since many phenotypes in mutant mice closely resemble human diseases, there is now a great interest in generating mutations in the mouse homologues of specific human genes. Given our unique facilities and expertise in mouse mutagenesis, we are well-positioned to address these issues being raised by the genome community. In fact, as part of the recently initiated Genome Mapping Group, we have established a close working 
relationship with the Genome Center at the Lawrence Livermore National Laboratory to map human CDNA clones on the mouse genome. We expect to expand this effort as the number of identified, sequenced genes increases during progression of the Human Genome Initiative.

\section{Scientific Outreach Functions}

In addition to their activities in basic research, several groups within the Section collectively maintain hundreds of mutant stocks (as well as inbred, congenic, and specially constructed strains, and the several very large stocks used for mutagenesis studies). Then mutant stocks are propagated primarily through the efforts of the Genetic Analysis and Mutagenesis Studies Group. Mutations that continue to arise in ongoing mutagenesis studies are tested genetically, analyzed cytogenetically, and assayed with available DNA probes, and are then added to the available mutation resource. An embryo freezing program involving a number of stocks has been operating for several years. Among other resources of the Section are cytogenetic capabilities for conventional mitotic and meiotic preparations (including synaptonemal complex studies, in collaboration with Dr. T. J. Ashley, Yale University), and for fluorescent in situ hybridization (FISH) techniques.

While each group of the Mammalian Genetics and Development Section has its own active program, there are many interactions between groups and with numerous laboratories throughout the world. The multiple interactions enhance the output of individual groups and produce a fine spirit of cooperation. Additionally, as more genes within our Section become cloned and sequenced, we expect to increase our interaction with the Division's Molecular, Cellular, and Cancer Biology Section for the purpose of characterizing the structure and expression of proteins.

\section{GENETIC ANALYSIS AND MUTAGENESIS STUDIES}
L. B. Russell
E. M. Rinchik ${ }^{5}$
P. J. Blair ${ }^{4,5}$
E. D. Griffith ${ }^{12}$
N.L.A. Cacheiro ${ }^{3}$
P. R. Hunsicker
S. P. Shinpock
V. L. Godfrey
D. J. Carpenter
R. E. Olszewski
J. E. Steele ${ }^{5}$
A. S. Arp ${ }^{4}$
K. L. Drake
V. M. Penland ${ }^{3}$
J. W. Bangham
G. M. Guinn ${ }^{5}$
W. L. Russell ${ }^{2}$
J. E. Wilkinson ${ }^{3}$
S. G. Witonsky ${ }^{3}$
B. R. Beatty
T. R. Yoder ${ }^{4}$

Genetic and Functional Analyses of Chromosomal Regions Surrounding Specific Loci: Interactions with Molecular Studies

The products of germ-line mutagenesis studies carried out over several decades include sets of deletion mutations, each centered around one of the 
seven marker loci of the specific-locus test. These regions of the mouse genome are being analyzed genetically and cytogenetically in order to generate functional information, provide the preliminary genetic and complementation maps that form the framework for subsequent intensive physical/functional mapping, and furnish suitable genetic constructs for molecular studies carried out with Division and outside collaborators.

In the period since the last report, much of the effort has been concentrated on regions that encompass the $p$ and a loci, and a collaborative study has been under way on $s$-locus mutations.

(1) The region encompassing pink-eyed dilution $(p)$ in Chromosome 7. We examined the homozygous and heterozygous phenotypes of $45 p$ alleles (most of them radiation-induced) that adversely affect survival at various stages of development. Seven of the new alleles specify pigment phenotypes distinct from that of the standard $p$ (darker fur and/or eyes, or mottling). Cytogenetically detectable aberrations were found in three of the new $p$ mutations, with band $7 C$ involved in each case. The distal breakpoint of an inversion lies in band 7EI, probably within the $c$ region of Chromosome 7 (a region we have characterized in past work). Most of the remaining mutations are probably deletions of various lengths, although a few may be more complex rearrangements.

All of the functional parameters studied in 810 types of compound heterozygotes provided consistent evidence for two types of juvenile lethality (functional units $\mathrm{jls}$ and $\mathrm{j} / \mathrm{m}$ ). Other functional units identified were $\mathrm{pl}-1$ and $\mathrm{pl}-2$ (prenatal lethal), and $\mathrm{nl}$ (neonatal lethal). Deletions of pl-1 and pl-2 were found to be associated with early-post-implantation and preimplantation death, respectively; the $\mathrm{nl}$ function is associated with cleft palate. The functional units can be oriented as follows: centromere, pl-1, jls, jlm, $p, \mathrm{nl}$, and $\mathrm{pl}-2$. In relation to the genetic map, $\mathrm{pl-1}$ is distal to Gas2, $\mathrm{nl}$ is equatable to $\mathrm{cpl}(=$ Gabrb3); and $\mathrm{pl}-2$ probably resides in the $c$-deletion complex. The alleles specifying mottling or darker pigment (generically, $p^{m}$ and $p^{x}$, respectively) probably do not represent deletions of $p$ coding sequences, but could be small rearrangements involving proximal regulatory elements. The complementation map generated is consistent with data from deletion mapping with DNA sequences (see Molecular Genetics and Mouse Genome Studies). The combined genetic and molecular studies serve to identify biological reagents for positional cloning of functionally significant genes within the $p$ region, which has a high degree of synteny with human chromosomal regions associated with a number of disease conditions.

(2) The agouti (a-locus) region of Chromosome 2. We continued complementation and other genetic analyses on a set of induced agouti 
mutations, the deletional nature of several of which has been established by balancing them over $a^{\mid s / G s O}$ and analyzing Southern blots with an appropriate probe. None of the deletions and other rearrangements tested has been found to extend through bp (brachypody), which is thought to lie only $0.3 \mathrm{cM}$ distal to $a$. Tests are under way (but, so far, negative) with $\mathrm{kr}$ (kreis/er), which is also thought to map close to a. A prenatally lethal mutation that we had discovered to have been co-induced but independent of $a^{16 H}$, was found to be $\sim 2 \mathrm{cM}$ from $a^{16 \mathrm{H}}$ but probably not located between $a$ and $b p$.

In ongoing time-of-death studies for prenatally-lethal agouti-locus mutations, we found one of the presumed deletions to kill prior to, and another to be lethal soon after, implantation. Results will further characterize functional units established by the complementation analysis and may serve to subdivide what are presently single units.

The unique structure of the $A^{\gamma}$ allele that was recently demonstrated by R. P. Woychik's group (namely, a 170-kb deletion that removes all but the promoter and noncoding first exon of another gene, Raly, which maps $280 \mathrm{~kb}$ proximal to the $3^{\prime}$ end of the agouti gene) now makes it possible to invoke conventional recombination mechanisms as the explanation for the results of our genetic studies which had shown certain agouti alleles $\left(a^{t}, a\right.$, and $\left.a^{x}\right)$ to recombine with lethal yellow, $A^{y}$, at an estimated frequency of about $0.1 \%$ in each case $1>10,000$ offspring analyzed). While pseudo-allelism between $A^{y}$ and a was originally a possible explanation, the recombination frequencies observed by us are generally compatible with the physical distance of $\sim 105 \mathrm{~kb}$ that separates the $3^{\prime}$ end of the remaining portion of Raly and the region of agouti that is mutated in the $a$ and $a^{t}$ alleles.

Further collaborations involve the radiation-induced prenatally-lethal agoutilocus mutation $a^{2 S A S}$. We have shown that this allele, which is associated with a translocation, $[T(2 ; 13)]$, complements all other a-locus mutations for lethality, suggesting that its lethal phenotype may derive from the Chromosome-13, rather than the Chromosome-2, breakpoint. The extreme obesity of $a^{2 S A S}$ heterozygotes makes this mutation very interesting for expression studies that are in progress in Woychik's lab.

(3) The $s$ region in Chromosome 14. To utilize the Oak Ridge $s$-locus mutations for genetic and molecular analyses, we initiated a collaboration with Dr. Shirley Tilghman (Princeton University). Dr. Tilghman's laboratory was able to localize the $s$ locus to a 2-cM interval defined by the SSLP markers D14Mit38 and D14Mit42. 
We constructed $M$. spretus-balanced hybrids from four recessive-lethal $s$-locus stocks, as well as using $s / s^{\prime}$ mice from 13 different mutant stocks to generate $M$. castaneus-balanced $F_{1}$ 's. By testing for deletion of closely linked microsatellitesequence markers, Tilghman's lab is mapping the region around $s$ and defining the limits of the $s$ locus itself on the physical map. Three of nine of the Oak Ridge mutations exhibited no deletions of the flanking markers, whereas six had deletions of two or more of the markers. The extent of deletions was found to be consistent with the severity of the homozygous phenotype.

Mouse piebald $(s)$ has recently been shown by other investigators to be the endothelin-B (ETB) receptor gene; further, targeted-mutation experiments have indicated that piebald and lethal spotting are probably a receptor-ligand pair. Some of our $s^{\prime \prime}$ (juvenile lethal) and $s^{n l}$ (neonatally lethal) alleles, as well as $s$ (viable) and $s$ (prenatally lethal) are being examined in Dr. Tilghman's laboratory. To date, it has been shown that the ETB gene is completely absent in $s^{\prime}$ and $s^{n l}$, but present in all other alleles tested. Experiments are under way to sequence cDNAs from various juvenile lethals to determine the nature of the mutation.

Complementation and other genetic analyses involving albino $(c)$-, dilute (d)-, short-ear (se)- and brown (b)-locus mutations were completed earlier, but stocks are maintained and supplied for collaborative studies.

\section{Genetic Sterility}

Sterility in the immediate offspring of mutagen-exposed individuals is a type of dominant genetic damage of concern to humans. In an ongoing program, histological and/or cytogenetic analyses of sterile sons of mutagenized mice are performed, and the steadily accumulating results add to the body of information on associations between the nature of the fertility impairment and the chromosomal genotype, and between chromosomal causes of infertility and the common denominators of the mutagenic treatments that produce them. More recently, we have also screened for sterile daughters.

Sterility is quite rare among offspring of mutagenized spermatogonial stem cells, but the accumulation of such probands from numerous separate mutagenesis experiments has brought the study group to over 350. The vast majority $(86 \%)$ are karyotypically normal; about $2 / 3$ of these males exhibit cystic testes and/or blockage of spermatic ducts. About $12 \%$ have numerical sex-chromosome anomalies; and only about $2 \%$ carry reciprocal translocations. This distribution is very similar to that observed among controls, but in strong contrast with that found among the much more numerous sterile sons of males mutagenized in postspermatogonial stages. In the majority of the latter, sterility 
is found associated with reciprocal translocations. The germ-cell stage treated is a much more important determinant of causes of genetic male sterility than is the nature of the mutagen.

Another study under way is the analysis of breakpoint locations in well over $60 \mathrm{~T}(\mathrm{Y} ; \mathrm{A}) \mathrm{s}$ already in our data bank. Currently it appears that autosomal breakpoints in $T(Y ; A) s$ are not restricted to centromeric and/or telomeric regions - as they are in the $T(A ; A) s$ that are associated with male sterility. In the light of what is now known about spermatogenesis-related factors on the $Y$, we will be particularly interested in analyzing the distribution of Y-chromosome breakpoints.

\section{Abnormalities in X-Y Segregation}

From a stock that carries a second copy of the testis-determining factor Sry in the distal portion of the $Y$ (where it undergoes obligatory crossovers with the $X$ chromosome), we derived a line producing exceptional females that we discovered to be $X Y$, and found that an inactivating mutation had probably occurred in the Sry sequence that is located in the proximal part of the $Y$. A cytogenetic study of the progeny of $X Y^{*}$ females (where $Y^{*}$ denotes the $Y$ chromosome with the mutated $S r y)$ has indicated that $X$ and $Y^{*}$ are distributed at random, and that there may thus be no $X-Y^{*}$ pairing at all. In addition, the analyses revealed some unexpected segregation (or, possibly, selection) phenomena. Thus, among daughters that presumably result from normal disjunction events, the ratio of $X X$ to $X Y^{*}$ is about 5:1. Among the nondisjunction progeny that have received maternal contributions of $X Y^{*}$ and 0 , respectively, the ratio is about $9: 1$.

\section{Studies on the Immunogically Defective Mutant, Scurfy}

Scurfy (sf) is an X-linked, recessive mutation that causes a fatal immune-mediated lymphoreticular disease in hemizygous males. Our previous work has shown this disease to be mediated by $\mathrm{CD} 4^{+} \mathrm{T}$ cells via excessive and inappropriate cytokine production. Since the lesions in scurfy mice resemble those seen in tissue graft rejection, we hypothesized that scurfy mice fail to develop self-tolerance as the immune system matures. We have shown that lymph nodes of scurfy mice contain many $T$ cells expressing receptors for endogenous $M l s$ and $I-E$ antigens, T cell clones that are absent from lymph nodes of normal male siblings. Potentially self-reactive T cells are normally controlled by three mechanisms: clonal deletions in the thymus, clonal deletions in the periphery via activation and apoptosis, and clonal anergy in the periphery. Using the autologous mixed lymphocyte assay (AML), we have obtained evidence that mechanisms of clonal deletion in the scurfy thymus are defective or delayed in maturation. In the peripheral lymph nodes, scurfy $T$ cells fail to undergo Fas-mediated apoptosis subsequent to proper activation, indicating a potential 
failure in peripheral tolerance. Scurfy mice are a potential animal model for Wiskott-Aldrich syndrome, an X-linked lethal trait in humans. WAS and scurfy map to homologous portions of the $X$ chromosome, both diseases show severe immunologic disorders, and both diseases result in early death. WAS patients do show additional problems of thrombocytopenia/bleeding disorders and a high incidence of lymphoid malignancies. A candidate gene for WAS called Wiskott-Aldrich syndrome protein (WASP) has been cloned. To determine whether scurfy and WAS are caused by the same gene, we have, in collaboration with the Insertional Mutagenesis and Transgenic Group, initiated phenotyperescue experiments using the murine WASP gene. Experiments that will lead to the knockout of the murine WASP gene are also under way.

\section{Pathology Associated with Selected Genotypes}

Mice of two inbred lines and one mutant stock were found to exhibit severe polyuria/polydipsia starting at about 8 months of age. Affected mice excreted copious amounts of dilute urine with a fixed specific gravity in the range of 1.004-1.006. Water intakes of up to $50 \mathrm{mls} / \mathrm{mouse} /$ day were documented. In a 30-min water deprivation test, affected mice lost up to $5 \%$ of their body weight yet failed to increase the urine specific gravity. Urinalysis was normal and histopathology revealed no gross or microscopic lesions. A preliminary diagnosis of hereditary diabetes insipidus has been made.

The 5772SB strain of mice carries an ENU-induced mutation linked to the albino (c) locus. Mice homozygous for this mutation die suddenly at 12-14 days of age. Histopathology of the affected mice revealed severe vacuolar degeneration of the renal proximal tubular epithelial cells. Electron microscopy showed the vacuoles to be cytosolic accumulation of fluid without limiting membranes suggesting defective ion channels in the plasma membrane.

Specific-locus Tests for Generating Valuable Mutations and Enlarging the Mutagenicity Data Base

Genetic and molecular analyses of mutations recovered in the specific-locus test (see above) have identified numerous mutations that are valuable for dissecting mammmalian development and that provide models for human disorders (e.g., cleft palate associated with a $p$-locus mutation, obesity/diabetes associated with an a-locus mutation - see elsewhere in this Progress Report). In addition to being used for the generation of more mutations, specific-locus experiments are being conducted for enlarging the germ-line mutagenicity data base for all germ-cell stages of males (from spermatogonial stem cells to mature spermatozoa), and, to a more limited extent, for females.

Different chemicals are being used in order to explore whether certain patterns of response might be demonstrable. Our protocol includes procedures 
that also yield accurate comparative productivity results, which can be interpreted with regard to induction of presumed dominant lethals (i.e., major chromosome-breakage and -loss events) and/or germ-cell cytotoxicity, thus adding these outcomes to gene-mutation-rate data.

Expansion of the specific-locus-mutation data base has allowed us to make an examination of the effects of germ-cell stage on both quantity of mutation yield and nature of mutations (for the latter, see below). Many chemicals that are clearly mutagenic in one or more poststem-cell stages give negative results for stem-cell spermatogonia, and no chemical tested to date yields a higher rate from stem-cell spermatogonia than from the most mutable poststem-cell stage. For chemicals mutagenic in poststem-cell stages, three patterns have been identified according to the stages in which they elicit maximum mutation frequencies: (1) spermatozoa and late spermatids; (2) early spermatids; and (3) differentiating spermatogonia.

We have shown two chemicals, chlorambucil (CHL) and melphalan (MLP), to be chemicals that not only are exceptionally mutagenic in specific germ-cell stages but induce mostly deletions and other rearrangements. This makes $\mathrm{CHL}$ and MLP valuable for studies seeking to recover developmentally significant new variants that are amenable to molecular access. In collaboration with Dr. Lorraine Flaherty (Albany), $\mathrm{CHL}$ is being used to generate phenotypically detectable new recessive viable and sublethal mutations throughout the genome.

\section{Factors that Affect the Nature of Induced Mutations}

The knowledge gained from the intensive physical/functional mapping of regions surrounding the marker loci (see above and elsewhere in this Report), including information concerning the phenotype of the ablated condition at each locus, has improved our capability for characterizing the nature of new mutations as well as for making retrospective classifications. Our analyses indicate that, regardless of the nature of the chemical, the proportion of "large" (multigene) lesions is high among mutations induced in postmeiotic stages, but low among mutations induced in either stem-cell or differentiating spermatogonia. These conclusions also apply to specific chemicals (CHL, MLP) that are active in both pre- and postmeiotic stages.

\section{"Sensitized" Spermatogonia}

A comparison (using direct molecular analyses as well as retrospective criteria) between mutations induced in previously undisturbed spermatogonial stem cells and those induced in "sensitized" spermatogonia, i.e., those that received a challenging dose of $X$ rays $24 \mathrm{hr}$ following a priming dose, revealed a marked difference in the nature as well as the frequency of mutations. Mutations induced in "sensitized" spermatogonia included a much higher proportion of large 
lesions than those induced in resting spermatogonia. For the former, the proportion was similar to that found for poststem-cell stages. Earlier studies had shown a major augmentation (above additivity) in mutation frequency to result from 24-hr fractionation treatments. The qualitative difference indicates that the additional mutations are the result of the second (challenging) dose and that the mutation-rate-augmenting effects are not due, merely, to an increase of a normally responsive component of the spermatogonial population.

An experiment is under way in which a small priming dose of $X$ rays ( $1 \mathrm{~Gy}$ ) is followed $24 \mathrm{hr}$ later with a challenging dose of MLP, a chemical that, when used by itself, is mildly mutagenic in spermatogonial stem cells, where it induces primarily intragenic lesions. Results to date indicate that the sensitization may be resulting in a change in the nature of the mutations (more large lesions) without an increase in mutation frequency.

\section{Spontaneous Mutation Rates}

Because specific-locus mutation rates are relatively low, even for moderately good mutagens, it is essential to have a large historical control to provide statistical sensitivity. In the course of conducting experiments with various chemicals, we have augmented the Oak Ridge historical specific-locus control rate for males by over 100,000 offspring and, therefore, no longer have to utilize a historical control rate that includes some data from other laboratories as well.

A historical control rate for females has, in the past, presented problems because one of only three independent spontaneous mutations observed was recovered as a sizable cluster. As a result, for years, alternative spontaneous rates were used in different calculations. Arguing that clusters can arise only from mutation in pre-oocyte stages, we used evidence from visibly mosaic mutants recovered in the FI generation of specific-locus test (SLT) experiments (i.e., the generation that is scored for mutants) to address the question of whether spontaneous mutations occur with equal frequency at each pre-oocyte cell division. This evidence strongly suggests that an appreciable percentage of spontaneous mutations arise preferentially in a single DNA strand in a post-mitotic stage of gametogenesis. The cluster that has complicated the literature probably arose as a single-strand mutation in the gamete of a grandparent of the generation that is being scored for mutations. We therefore concluded that it is appropriate to use only the "single" mutations as control for mutations that are induced in oocytes. For calculations of spontaneous rate, we further added results from several experimental groups that involved treatments proved to be ineffective in females. The lowering of the rate (via removal of the cluster), as well as the augmented sample size, both increase the chance of statistically detecting a mutagenic effect in a given experiment. The newly derived 
spontaneous specific-locus mutation rate for females, $1.6 \times 10^{-6}$ per locus $[6 /(536,207 \times 7)]$, is highly significantly below the spontaneous mutation rate in males [30/(669,765 $\times 7)$ in the Oak Ridge historical control].

\section{Induced Mutations in Females}

Mutagenicity data for female mice, while extensive for radiations, are relatively scant for chemicals. Additionally, prior to our derivation of a new historical control frequency for females (see above), it was dificult to arrive at statistical evaluations of induced-mutation data. We have added results for two chemicals, chlorambucil (CHL) and bleomycin (BLE), to those for only four chemicals available before. Overall, both chemicals were found to be mutagenic in females, but mutagenicity is clearly higher in certain oocyte stages. In the case of $\mathrm{CHL}$, as is true for radiations, this is the group of maturing and mature oocytes (which come to ovulation within 6 weeks after exposure), although a deletion-mutation recovered from immature oocytes was probably also of $\mathrm{CHL}$-induced origin. In the case of BLE, it was possible to further restrict the sensitive stages to weeks 1-4, during which period a high dominant-lethal frequency is also induced (making it difficult to build up numbers).

Although CHL is overall mutagenic in oocytes, the rate is an order of magnitude below that for meiotic and postmeiotic stages of the male, and only $1 / 50$ the rate for early spermatids in particular. It is also noteworthy that BLE, which has been thought of as a radiomimetic chemical, does not affect the survival of immature oocytes at dose levels comparable to radiation doses that cause similar dominant-lethal frequencies (in maturing oocytes) and which wipe out these cell stages. This result also argues against selection being the explanation for the absence of mutation induction in immature oocytes by doses of radiation that are compatible with limited cell survival.

\section{Outreach and Service}

The valuable mutant resource was used to varying extents by most of the other investigators in the Section. In addition, numerous outside laboratories (including several in foreign countries) utilized our mouse stocks for either collaborative or independent research, many of them receiving multiple stocks. Three major categories of stocks are being propagated at ORNL: (1) large stocks used either directly in mutagenesis studies, or employed for the generation of other stocks used in such studies; (2) standard or specially constructed inbred, recombinant-inbred, or congenic strains, or stocks combining specific marker utilized for genetic experiments or molecular studies; (3) hundreds of small stocks propagating mutations that have arisen (and continue to arise) in mutagenesis experiments over the past decades, and whose value for genome analysis is becoming increasingly recognized. An embryo-freezing program involving numerous stocks is under way. 
1. Blair, P. J., S. J. Bultman, J. C. Haas, B. T. Rouse, J. E. Wilkinson, and V. L. Godfrey. $C D 4^{+} \mathrm{CD} 8{ }^{-} \mathrm{T}$ cells are the effector cells in disease pathogenesis in the scurfy (sf) mouse. J. Immunol. 153: 3764-3774, 1994.

2. Blair, P. J., D. A. Carpenter, V. L. Godfrey, L. B. Russell, J. E. Wilkinson, and $E$. M. Rinchik. The mouse scurfy ( $s f$ mutation is tightly linked to Gata 1 and $T f e 3$ on the proximal $X$ chromosome. Mamm. Genome 5: 652-654, 1994.

3. Godfrey, V. L. The scurfy ( $s f$ ) mutation, chromosome X. In: Handbook of Mouse Mutations with Skin and Hair Abnormalities, Animal Models and Biomedical Tools, ed. by J. P. Sundberg. CRC Press, Boca Raton, FL, 1994, pp. 417-422.

4. Godfrey, V. L., B. T. Rouse, and J. E. Wilkinson. Transplantation of T cell-mediated lymphoreticular disease from the scurfy ( $s f$ mouse. Am. J. Pathol. 145: 281-286, 1994.

5. Metallinos, D. L., A. J. Oppenheimer, E. M. Rinchik, L. B. Russell, W. Dietrich, and S. M.Tilghman. Fine structure mapping and deletion analysis of the murine piebald locus. Genetics 136: 217-223, 1994.

6. Rinchik, E. M., L. Flaherty, and L. B. Russell. High-frequency induction of chromosomal rearrangements in mouse germ cells by the chemotherapeutic agent chlorambucil. Bioessays 15: 831-836, 1993.

7. Russell, L. B. Effects of spermatogenic cell type on quantity and quality of mutations. In: Male-Mediated Developmental Toxicity, ed. by. D. R. Mattison, and A. F. Olshan. Plenum Press, New York, 1994, pp. 37-48.

8. Russell, L. B. Role of mouse germ-cell mutagenesis in understanding genetic risk and in generating mutations that are prime tools for studies in modern biology. Environ. Mol. Mutagen. 23 (Supp. 24): 23-29, 1994.

9. Russell, L. B., C. S. Montgomery, N. L. A. Cacheiro, and D. K. Johnson. Complementation analyses for $\mathbf{4 5}$ mutations encompassing the pink-eyed dilution $(p)$ locus of the mouse. Genetics (in press).

10. Russell, L. B. and E. M. Rinchik. Structural differences between specific-locus mutations induced by different exposure regimes in mouse spermatogonial stem cells. Mutat. Res. 288: 187-195, 1993.

11. Shelby, M. D., L. B. Russell, R. P. Woychik, J. W. Allen, L. M. Wiley, and J. B. Favor. Laboratory research methods in male-mediated developmental toxicity. In: Male-Mediated Developmental Toxicity, ed. by D. Mattison, and A. F. Olshan. Plenum Press, New York, 1994, pp. 379-384. 


\section{MOLECULAR GENETICS}
D. K. Johnson
K. J. Houser
E. M. Rinchik ${ }^{2}$
M. D. Potter ${ }^{4,5}$
M. $W u^{4}$
D. A. Carpenter
M. W. Walkowicz ${ }^{4}$
C. M. Withrow ${ }^{14,5}$
T. R. Yoder ${ }^{4}$
C. T. Culiat ${ }^{4}$

The focus of the Molecular Genetics Group is to use both newly-induced and existing mouse mutations, along with modern molecular technology, to identify and characterize genes essential for normal development. Our specific underlying objective is to clone genes that lie within the genome regions associated with three complexes of overlapping, radiation-induced deletions that together encompass nearly $2 \%$ of the whole mouse genome. In the evolution of the Human Genome Program, the mouse has been recognized as the primary model organism for the study of human genetics and human genetic diseases, so that our efforts to understand gene function in the mouse are directly applicable to human health problems.

In the past two years, we have (1) isolated a gene (cp1) responsible for cleft palate, made a transgenic "rescue" of the cleft palate phenotype, and now are studying a second gene that interacts with $c p 1 ;(2)$ identified and characterized the lesion that affects a basic mechanism of gene regulation in a mutation $\left(c^{m}\right)$ that results in coat-color mottling; (3) characterized developmental and clinical abnormalities that result from six alleles of a mutation, fit 1 , that causes anemia; (4) identified and mapped at least eleven loci necessary for normal prenatal development, a new locus that causes abnormal kidneys, and new alleles of a locus responsible in humans for a liver disease (chronic hereditary tyrosinemia); and (5) isolated a candidate gene for a mutation that causes runting, ataxia, and male sterility. We have also opened new and very exciting collaborations with fellow scientists working in several areas. Two of these new collaborations are particularly interesting because they involve attempts to clone and characterize members of groups of interacting genes that control complex behavioral traits. Highlights of some of these studies are given below.

\section{Cleft Palate (cp1)}

One central nervous system regulatory mechanism involves $\boldsymbol{\gamma}$-aminobutyric acid (GABA), an inhibitory neurotransmitter that blocks continued stimulation of neural pathways. Interestingly, our studies have proven that one kind of subunit (B3) of the cellular receptor for GABA (Gabrb3) is necessary for normal development of the palate in mice. We have "cured" cleft palate in mice mutant for $c p 1$ by injecting a normal copy of this Gabrb3 gene from a rat into fertilized mouse eggs that would otherwise grow into pups with cleft palates. In addition, we have isolated a second gene whose expression is lost when Gabrb3 is mutant; this second gene appears to have a role in the normal morphogenesis of the 
tongue, a process that occurs concurrently with palate development. In humans, cleft palate is among the most common birth defects, and is probably caused most often by failure of the tongue to "get out of the way" of the developing palate. Our research data have led us to suggest that human families that include children with cleft palates be studied for defects in these same two genes.

\section{Coat-Color Mottling $\left(c^{m}\right)$}

The albino locus produces tyrosinase, an enyzme in the biochemical pathway that makes skin pigment (melanin). One mutation of the albino locus, $c^{m}$, results in mice with mottled fur; our studies have shown the $c^{m}$ is caused by the insertion of an intracisternal-A particle (IAP), a moveable, repetitive element in the mouse genome, into the regulatory region of the albino gene. This finding is of interest because it adds to our increasing realization that the movement of these repetitive elements within the mouse genome is not only an important source of "spontaneous" mutations, but might in the future be controlled and directed to the production of useful mutations. We have also gained insight into the basic biochemical mechanism that regulates expression of the tyrosinase gene.

\section{fitness 1 (fit 1)}

The fit 1 mutation, near the albino locus, results in abnormal red blood cell production (hematopoiesis), probably associated with dysfunctions in iron storage in the liver. Mice that carry this mutation are runted and anemic, and may show spinal column abnormalities reminiscent of human scoliosis. We have a potential candidate gene for this mutation, and are in the process of analyzing both the structure of the gene and the biochemical pathways controlled by the enzyme it produces. This mutation may well be a model for a group of human genetic hematopoietic diseases called "congenital dyserythropoietic anemias", or perhaps even a model for human scoliosis.

\section{Prenatal-Lethal Phenotypes}

Complementation analyses, involving pairwise crosses of mutation carriers, have identified three new loci within the brown $(b)$ deletion complex (mouse chromosome 4) that are necessary for survival of fetuses past mid-gestation. Ongoing studies will pinpoint the time-of-death and the particular abnormalities associated with each of these loci; our collaborator, Dr. lan Jackson of the MRC in Edinburgh, will participate in the positional cloning of these new genes.

Near the pink-eyed dilution $(p)$ and albino $(c)$ genes in mouse chromosome 7 , we have identified by ENU-mutagenesis at least eight (two near $p$, six near $c$ ) new loci essential for prenatal development; mice mutant for these loci die at various times during gestation. The genomic intervals that contain these genes 
have been defined by mapping within individual deletions, thus making possible the positional cloning of each of these loci.

Two additional loci of particular interest, one near $p$ and one near $c$, are necessary either for successful preimplantation development or successful survival immediately after implantation in the uterine wall. Genes of this nature may well be involved in otherwise unexplained "infertility" in humans; i.e., these "infertile" couples are fertile, but are losing embryos at very early stages of gestation. Each of these genes is also now amenable to positional cloning because we can precisely locate the locus within the regions of overlap of radiation-induced deletions. Each of these two loci is currently under study.

Other ENU-induced new mutations near $c$ include a kidney abnormality that causes sudden morbidity and death in pre-weaning age mice, and two new alleles of a mutation in a liver enzyme known to be involved in the human genetic disease, chronic hereditary tyrosinemia.

Runting, Ataxia and Male Sterility

We have isolated portions of a candidate gene for a mutation near $p$ that results in juvenile lethality in mice that are runted, exhibit severe nervous tremors, and, in the occasional male that survives to reproductive age, abnormal sperm morphology. We know that all three defects result from mutations in a single gene that must play a role in the development or function of widely different body systems.

\section{Quantitative Trait Loci (OTL)}

In recent years molecular biologists have had successes in cloning and analyzing genes that control a particular, easily-distinguished trait such as cleft palate. Geneticists are also turning their attention to the analysis of complex traits that result from the interaction of a number of different genes. These complex traits, called "quantitative trait loci" (QTL) because each gene influences only a portion of the total complex trait, include both behavioral le.g., bipolar disorder) and physical (e.g., hypertension) characteristics. Among our collaborations are studies aimed at analyzing genes that contribute to two such complex traits, alcoholism (or preference for alcohol) and dietary obesity.

One of the eight genes thought to play a role in alcohol-related behavior has been mapped near $c$ by researchers at the University of Colorado at Boulder. This gene plays a role in central nervous system sensitivity to the effects of alcohol, as assayed by measuring the length of time two different strains of mice sleep following injection with ethanol (10 min. vs $2 \mathrm{hr}$ ). By crossing 
these strains of mice with our mice that carry deletions around $c$, we will localize this "sleep time" trait within a genomic interval small enough to make positional cloning possible.

Additionally, collaborators at Lousiana State University have mapped a OTL for dietary obesity near $p$. Although a major "fat gene" that contributes to overall obesity has recently been cloned, other OTL are apparently involved in specific, genetically-controlled body fat deposition patterns. Mice of one strain, created by the Molecular Genetics Group, that are deleted for one particular genome region near $p$ appear to be fatter than non-deleted animals. Our LSU collaborators are analyzing the fat deposition patterns of these mice, and, again, we will localize the genome region that contains this "fat" QTL in preparation for positional cloning.

1. Culiat, C. T., L. J. Stubbs, R. P. Woychik, L. B. Russell, D. K. Johnson, and $E$. M. Rinchik. Deficiency of the $\beta 3$ subunit of the type $A$ $\gamma$-amionbutyric acid receptor causes cleft palate in mice. Nature Genet. (accepted).

2. Johnson, D. K., L. J. Stubbs, C. T. Culiat, C. S. Montgomery, L. B. Russell, and E. M. Rinchik. Molecular analysis of thirty-six mutations at the mouse pink-eyed dilution (p) locus. Genetics (in press).

3. Potter, M. D., M. L. Klebig, D. A. Carpenter, and E. M. Rinchik. Genetic and physical mapping of the fitness1 (fit1) locus within the Fes-Hbb region of mouse chromosome 7. Mamm. Genome 6: 70-75, 1995.

4. Rinchik, E. M. Molecular genetics of the brown(b)-locus region on mouse chromosome 4. II. Complementation analyses of lethal brown deletions. Genetics 137: 855-865, 1994.

5. Rinchik, E. M., J. W. Bangham, P. R. Hunsicker, N. L. A. Cacheiro, B. S. Kwon, I. J. Jackson, and L. B. Russell. Genetic and molecular analysis of chlorambucil-induced germ-line mutations in the mouse. Proc. Natl. Acad. Sci. USA 87: 1416-1420, 1990.

6. Rinchik, E. M., J. Bell, P. R. Hunsicker, J. M. Friedman, I. J. Jackson, and L. B. Russell. Molecular genetics of the brown $(b)$-locus region of mouse chromosome 4. I. Origin and molecular mapping of radiation- and chemical-induced lethal brown deletions. Genetics 137: 845-854, 1994.

7. Rinchik, E. M., and D. A. Carpenter. $N$-ethyl-N-nitrosourea-induced prenatally lethal mutations define at least two complementation groups with the embryonic ectoderm development (eed) locus in mouse chromosome 7. Mamm. Genome 4: 349-353, 1993.

8. Rinchik, E. M., D. A. Carpenter, and M. A. Handel. Pleiotropy in microdeletion syndromes: Neurologic and spermatogenic abnormalities in mice homozygous for the $p^{6 H}$ deletion are likely due to dysfunction of a single gene. Proc. Natl. Acad. Sci. USA (in press). 
9. Rinchik, E. M., D. A. Carpenter, and C. A. Long. Deletion mapping for four loci defined by $N$-ethyl- $N$-nitrosourea-induced postimplantation-lethal mutations within the pid-Hbb region of mouse Chromosome 7. Genetics 135: 1117-1123, 1993.

10. Rinchik, E. M., R. R. Tonjes, D. Paul, and M. D. Potter. Molecular analysis of radiation-induced albino (c)-locus mutations that cause death at preimplantation stages of development. Genetics 135: 1107-1116, 1993.

\section{ORGANISMIC EFFECTS}
P. B. Selby
E. M. Garrison ${ }^{5}$
V. S. Earhart ${ }^{5}$
T. L. Jago ${ }^{3}$
G. D. Raymer ${ }^{5}$
S. T. Kelly $y^{3,5}$
L. A. Smalley ${ }^{10}$
H. A. Sternfels ${ }^{11}$

Assessment of Dominant Damage for Radiation, Chlorambucil (CHL), and Ethylnitrosourea (ENU)

An important gap in knowledge regarding genetic risk estimation for chemicals and radiation is the degree of correlation between specific-locus mutation frequencies and the frequencies of induction of dominant mutations that cause serious organismic damage in first-generation progeny. The first large-scale attempt to provide an understanding of this relationship is under way in experiments in our laboratory using the Assessment of Dominant Damage (ADD) approach. First-generation progeny are being examined for several types of dominant organismic damage following exposure of their fathers to treatments expected to induce either large DNA lesions, such as deletions and other rearrangements (CHL to early spermatids or sperm), small intragenic lesions (ENU to spermatogonial stem cells), or a mixture of lesions (X- or gamma-rays to spermatogonial stem cells). All groups have concurrent controls. The types of dominant organismic effects that are studied in the progeny are skeletal malformations, cataracts in the lens of the eye, stunted growth, dominant visibles, and survival to 11 weeks of age. It is estimated that several thousand genes can mutate to dominants that cause the many types of organismic damage that we observe. Two different dose regimens have been used for ENU; thus far all ENU data analyzed have been for the higher dose.

With analyses now complete on about one-third of the contemplated total sample of 18,500 first-generation offspring, only the ENU treatment shows a significant increase in any of the six types of skeletal analyses thus far applied, and it shows an increase in all six analyses. Also, only the ENU treatment has thus far been shown to induce a significant increase in serious cataracts, and it is also yielding by far the highest specific-locus mutation frequency of the 
treatments under study. Even with ENU, however, the frequency of offspring with anomalies that appear serious is rather low (e.g., 1-2\% for serious skeletal anomalies.) When one considers the large number of recessive mutations that must be induced in the entire genome (based on the very high specific-locus mutation frequencyl, it is obvious that few induced gene mutations are capable of causing serious organismic damage in heterozygotes.

Despite the high frequency of specific-locus (recessive) mutations that has been demonstrated for the same dose of $\mathrm{CHL}$ used in our experiment (Russell et al., PNAS 86: 3704-3708, 1989), none of the six skeletal analyses in the ADD experiments gave any clear suggestion of induction of dominant mutations. It thus appears that specific-locus mutation frequencies are, at best, poorly correlated with dominant organismic damage.

There is thus far no suggestion of any induction of serious dominant mutations by the 6-Gy exposure to protracted gamma radiation. Some of the analyses for the 6-Gy acute radiation exposure group suggest a slight effect. Our large experiment that is using gamma radiation will provide the first data ever available on induced dominant organismic damage for a low dose rate, and it also incorporates many advances over our earlier experiment that has been applied in risk estimation. It thus seems likely that it will provide the basis for a major improvement in genetic risk estimation for radiation. The findings in both radiation experiments already strongly suggest that there is no large error of underestimation in UNSCEAR's (United Nations Scientific Committee on the Effects of Atomic Radiation) direct estimate of genetic risk following paternal irradiation, even if that estimate is applied to all genetic disorders causing serious handicaps by young adulthood, including those of complex etiology.

\section{Development of a More Powerful Test for Mutagenicity}

We are using the data from the ADD experiments to develop a new test for mutagenicity that will have the significant advantages of (1) dealing directly with dominant mutations, (2) requiring production of markedly fewer animals, and (3) having a close relationship with one of the two major methods of genetic risk estimation. The new method, which is called the ADD Index method, makes use of almost all types of information collected in ADD experiments. From our analysis of extensive data already available from our experiment using a large fractionated exposure to ENU, it appears that about two-thirds of the time this new method can demonstrate statistically significant induction of dominant mutations by such a strong mutagenic treatment based on the examination of only 40 first-generation offspring. The ADD Index method has thus far been applied only to the higher ENU dose and to both radiation experiments. The high-dose-rate radiation exposure showed statistically significant induction of dominant mutations, but the 6-Gy low-dose-rate exposure gave no hint of having any effect even with 1,291 offspring examined. 


\section{Organismic Effects of Insertional Mutations}

We examined homozygotes from approximately 200 transgenic lines of mice (generated in the program of R. P. Woychik) for skeletal malformations and cataracts. Several recessive insertional mutations have been found to cause interesting anomalies in the skeleton or eye. One of these, $\mathrm{Tg737}$, causes a large number of skeletal abnormalities. A detailed characterization of this mutation is in progress, with one of the most interesting features being that homozygotes for this mutation often have too many molars if they are on the FVB/N genetic background and too few molars if they are on the C3Hf genetic background.

\section{Studies of Individual Dominant Mutations}

Collaborative mapping and embryological studies are under way with Dr. S. Mundlos (Harvard Medical School, Boston) on the radiation-induced dominant skeletal mutations in mice named cleidocranial dysplasia $(C c d)$ and short digits $(D s h)$. These studies have shown that the $C c d$ mutation is a deletion of 2-3 cM on chromosome 17. This represents the first radiation-induced dominant skeletal mutation for which we have identified the type of lesion at the molecular level. These studies have also shown that the human and mouse $C c d$ mutations, which were already known to be strikingly similar at the phenotypic level, almost certainly involve homologous genes. Subsequently, Dr. Mundlos has shown that the classic example of the Ccd mutation from the huge Arnold family in South Africa maps to the same region of the genome.

These collaborative studies with Dr. Mundlos are also refining the earlier mapping done on Dsh in collaboration with Drs. J. C. Montgomery and Lorraine Flaherty (SUNY, Albany) and Dr. E. M. Rinchik, then of the Biology Division. That earlier mapping effort showed that the Dsh gene is located near the proximal end of chromosome 5. Earlier work in our program showed that Dsh homozygotes exhibit the remarkable feature of completely lacking vertebrae. In spite of this, on at least one genetic background, these short-limbed dwarfs have normal viability until the time of birth.

1. Anderson, D., J. B. Bishop, R. Colin Garner, P. Ostrosky-Wegman, and P. B. Selby. Cyclophosphamide: review of its mutagenicity for an assessment of potential germ cell risks. Mutat. Res. (in press).

2. Cosgrove, G. E., P. B. Selby, A. C. Upton, T. J. Mitchell, M. H. Steele, and W.L. Russell. Lifespan and autopsy findings in the first-generation offspring of X-irradiated male mice. Mutat. Res. 319: 71-79, 1993.

3. Selby, P. B. Risk assessment and risk management. In: Male-Mediated Developmental Toxicity, ed. by D. R. Mattison and A. F. Olshan, Plenum Press, New York, 1994, pp. 389-396. 
4. Selby, P. B., S. N. Bolch, V. S. Mierzejewski, T. W. McKinley, Jr., and G. D. Raymer. Synergistic interactions between two skeletal mutations in mice: Individual and combined effects of the semidominants cleidocranial dysplasia (Ccd) and short digits (Dsh). J. Hered. 84: 466-474, 1993.

\section{CHROMOSOMAL DAMAGE}
W. M. Generoso
L. H. Cacheiro ${ }^{3}$
N.L.A. Cacheiro ${ }^{3}$
K. T. Cain
L. A. Hughes
A. G. Shourbaji ${ }^{3,5}$

Chemical and radiation mutagenesis research in mice has proved to be a driving force in advancing fundamental mammalian biology. Its contribution comes primarily from studies of the underlying mechanisms of mutation induction and from molecular and developmental analyses of chromosomal rearrangement mutants that are generated in mutagenesis experiments under this program. Additionally, by virtue of their chromosomal breakpoints, such mutants promise to be valuable in gene discovery and cloning and in biotechnology. One strength of this program is that studies of germ-cell effects are done in vivo and mutations are detected in descendants. Therefore, the endpoints measured and phenotypes that are observed are potentially those that directly represent human anomalies (e.g., reproductive failure, gestational deaths, congenital anomalies, neurological syndromes, etc.).

Zygote and Pre-gastrulation Embryonic Stages: A Window for Induction of Congenital Anomalies

Progress to be made in the prevention of human birth defects hinges, to a large extent, on understanding the etiologies of a large class of developmental anomalies whose causes are not known. There is strong likelihood that many of these originate from events that occur during the pre-organogenesis stages of embryonic development. Our research group has been the pioneer in exploring developmental toxicity during early embryogenesis. The increasing volume of data being produced under this program points directly to the vulnerability of the zygote and pre-gastrulation embryos to chemical induction of developmental abnormalities, and raises important issues in developmental toxicology, birth defects, and fundamental embryology. We are building the pre-gastrulation database as a continuing process under this project. The spectrum and association of pre-gastrulation-derived defects are being analyzed in detail in order to study the underlying embryological perturbations. We are also conducting a 
molecular study of the hypothesis that, at least in some cases, the primary cause of pre-gastrulation-derived developmental anomalies is direct perturbation of gene expression.

\section{Female-Specific Mutagens}

We have found a number of chemicals to be mutagenic in females, but not in males. In humans and in all mammals, the chromosomes in the majority of oocytes of adult females are arrested in the diplotene stage of meiosis with the chromatin in a diffuse state. In adult males, on the other hand, all stages of spermatogenesis are present simultaneously, and in all cells that are postmeiotic, the chromosomes are relatively more condensed than they are in arrested oocytes. We are determining the classes of chemicals that are female-specific mutagens and we are studying the hypothesis that the female specificity is attributable to the diffuse nature of the oocyte DNA, which allows molecules either to intercalate between base pairs or to bind to specific sequences.

\section{Induced-Translocation Mutant Resource}

The identification and in-depth study of disease-related human genes benefit to a major degree from the discovery of homologous mouse genes. Mouse mutants whose phenotypes are analogous to those of human disease conditions are highly valuable in this regard, especially when the genes involved are readily accessible to molecular cloning. Reciprocal translocations constitute an important class of rearrangement mutants; our past experience has shown that a significant proportion of such mutants that are induced in our radiation and chemical mutagenesis programs are associated with anomalous phenotypes in the heterozygous and/or homozygous state. Because reciprocal translocations have such a high potential for contributing to the progress to be made in molecular developmental biology, for identifying disease-related human genes, and for the development of therapeutics, and because our laboratory is the only one producing this class of mutations in appreciable numbers during the course of large-scale mutagenesis experiments, we have embarked on a long-term systematic search for rearrangements that are associated with potentially useful phenotypes in homozygotes or heterozygotes. A unique repository for such rearrangements has been established.

1. Adler, I. D., M. D. Shelby, J. Bootman, J. Favor, W. Generoso, F. Paccheierotti, T. Shibuya, and N. Tanaka. Summary report of the working group on mammalian germ cell tests. Mutat. Res. 312: 313-318, 1994. 
2. Cacheiro, N. L. A., J. C. Rutledge, K. T. Cain, C. V. Cornett, and W. M. Generoso. Cytogenetic analysis of malformed mouse fetuses derived from balanced translocation heterozygotes. Cytogenet. Cell Genet. 66(2): 139-148, 1994.

3. Generoso, W. M. The rodent dominant-lethal assay. Environ. Mol. Mutagen. 24: 332-333, 1994.

4. Generoso, W. M., and W. W. Piegorsch. Dominant lethal tests in male and female mice. In: Methods in Toxicology, vol. 3A, Methods in Reproductive Toxicology, ed. by R. E. Chapin and J. Heindel. Academic Press, Inc., 1993, pp. 124-141.

5. Kimmel, C. A., W. M. Generoso, R. D. Thomas, and K. S. Bakshi. A new frontier in understanding the mechanisms of developmental abnormalities. Toxicol. Appl. Pharmacol. 119: 159-165, 1993.

6. Natarajan, A. T., R. J. Preston, V. Dellarco, L. Ehrenberg, W. Generoso, S. Lewis, and A. D. Tates. Ethylene oxide: Evaluation of genotoxicity data and an exploratory assessment of genetic risk. Mutat. Res. (in press).

7. Rutledge, J. C., A. G. Shourbaji, L. A. Hughes, J. E. Polifka, Y. P. Cruz, J. B. Bishop, and W. M. Generoso. Limb and lower-body duplications induced by retinoic acid in mice. Proc. Natl. Acad. Sci. USA 91: 5436-5440, 1994.

\section{INSERTIONAL MUTAGENESIS AND TRANSGENIC MICE}
R. P. Woychik
C. M. Foster ${ }^{3}$
J. H. Moyer ${ }^{4,5}$
C. S. Sommardahl ${ }^{1}$
P. E. Barker
M. L. Klebig ${ }^{1,5}$
R. L. Mynatt ${ }^{1}$
L. D. Taylor
S. J. Bultman ${ }^{4,5}$
H. -Y. Kwon ${ }^{1,5}$
W. G. Richards ${ }^{1}$
E. J. Michaud ${ }^{1}$
S. D. Rochat ${ }^{1}$
A. J. Chang
R. J. Miltenberger ${ }^{1}$ J. J. Schrick ${ }^{4,5}$
J. E. Wilkinson ${ }^{3}$
S. G. Witonsky ${ }^{3}$
B. K. Yoder ${ }^{1}$

Molecular analysis of mutations in the mouse is an efficient way of establishing structure/function relationships between individual genes and complex developmental traits in the whole organism. Insertional mutations in transgenic mice are particularly useful for this purpose because the mutant locus is "tagged" with the exogenously added DNA and can be readily characterized at the molecular level. Over the past several years we have identified a number of different insertional mutations with a range of phenotypes that include embryonic lethalities, fertility defects, skeletal deformities, inner ear defects and kidney disease. A considerable effort is currently being devoted to cloning and characterizing the genes associated with these mutations. Additionally, several years ago by utilizing a "tagged" insertional mutation as a molecular access point, we cloned the agouti gene on mouse chromosome 2. Over the past year we have made a lot of progress with respect to characterizing the biological function of the agouti gene. 
Molecular Analysis of Insertional Mutations

In the TgN737Rpw insertional mutant, homozygous animals on the FVB/N inbred background develop a complex phenotype that involves bilateral polycystic kidney disease (PKD). Our analysis of the developmental pathology in this line revealed that the mutant phenotype has a remarkable similarity to autosomal recessive polycystic kidney disease (ARPKD) in humans; hence, we believe that this mutant line will serve as a useful animal model for studying ARPKD in humans. We have now identified, cloned and mapped a cDNA that corresponds to a gene whose expression is interrupted in the TgN737Rpw mutant animals. Moreover, we have utilized the cDNA to "rescue" the mutant kidney trait; this unequivocally establishes the relationship between this gene and the kidney disease in these animals. We have also cloned and sequenced the homologous human gene, which is $>90 \%$ identical with the mouse gene. In collaboration with Dr. Julie Korenberg's lab (Cedars-Sinai Medical Center), we have mapped the human homologue of this gene to the long arm of chromosome 13 in humans. Experiments are currently under way to better understand how this gene functions in kidney development.

In another line, called TgN370Rpw, a recessive insertional mutation causes the development of a characteristic skeletal defect involving an undulation of the distal vertebrae of the spine. We have now cloned and completely characterized the structure of the mutant locus in this line. Additionally, utilizing evolutionarily conserved regions within the sequences flanking the transgene integration, we have cloned a region of the human genome that corresponds to the mutant locus of the TgN370Rpw line. The TgN370Rpw integration site maps to the proximal section of chromosome 5 in the mouse, very close to the dominant Thick-tail (Tht) mutation. We recently determined that the Tht mutation does not complement the TgN370Rpw, which suggests that the TgN370Rpw mutation may be the recessive allele of Tht. Efforts are currently under way to identify the gene associated with this mutation.

We are also characterizing another insertional mutation at the molecular level which may be a model for sensorineural hearing loss in humans. In this line, called TgN2742Rpw, animals develop congenital deafness and a circling behavior in all of the animals homozygous for the transgene. In this case, a vestibular malfunction may be the main cause of circling behavior. Even at an early stage (1 week), homozygotes can be easily identified from their normal littermates because of their noticeable difference in body size and loss of balance during walking. Additionally, the mutant animals are not able to swim. The mutants show no response to metallic clicking sounds, which indicates that they are deaf. In collaboration with Dr. Alexander de Lahunta, from the Department of Anatomy at Cornell University and Dr. Don McGavin, from the University of Tennessee College of Veterinary Medicine, we ruled out any major brain defects by serially sectioning the brain of the mutant animals. Analysis of the inner ear revealed 
defects that are typical of neuroepithelial deafness in humans and mice. Specifically, serial sectioning of the temporal bones of homozygotes revealed that the cochlear duct was intact, but that there was a significant loss of spiral ganglion cell bodies in the modiolus of the cochlea of mutants compared to control mice. More recently, in collaboration with Dr. Gary Wright at the University of Texas, we have determined that at one year of age, the organ of corti is absent for a whole turn of the cochlea. The giant otoconium can be seen at the utricle, the stria vascularis seems to be normal, and the fluid space and Reissner's membrane is intact. We have recently cloned the sequences flanking the transgene insertion site, and efforts are currently under way to further characterize the cloned region.

We have identified one insertional mutation, TgN3261Rpw, where the majority of animals develop tumors before 1 year of age. The predominant tumor type is a reticulum cell sarcoma (RCS) type A which can involve the liver, spleen, pleural cavity, and regional lymph nodes. Histopathology of RCS shows malignant histiocytes in all stages of de-differentiation, which is a characteristic of this type of tumor. Additionally, various ocular abnormalities are also observed in this line. The most severe phenotype is seen in the homozygous mice and includes microophthalmia, microphakia, persistent tunica vasculosa lentis, abnormal primary lens fiber cell differentiation and migration, lack of formation of secondary lens fiber cells and lens bows. Efforts are under way to clone and characterize the gene associated with this mutation.

\section{Characterization of The Mouse Agouti Locus}

We are also using probes derived from transgenic mice for the molecular characterization of other mutations in the mouse. For example, one such mutation, called Is 1 Gso, arose in one of W. M. Generoso's radiation experiments. In this mutation, new alleles of limb deformity $(/ d)$ and agouti (a), two loci normally separated by $20 \mathrm{cM}$ on Chromosome 2, arose simultaneously. Utilizing molecular reagents from the Id insertional mutant, we were able to clone and characterize the structure of the Is $1 \mathrm{Gso}$ mutant; this ultimately allowed us to clone the agouti region on chromosome 2. We are now in the process of studying the structure of the numerous agouti locus mutations that are being maintained within the mutant stocks in the Mammalian Genetics Section. We have also determined that several of the dominant mutations at the agouti locus cause the agouti gene to be ubiquitously over-expressed, which is providing molecular insight into the obesity and type II diabetes traits that are exhibited by these mutant animals. Further analysis of one of these mutations revealed that it is differentially expressed depending upon whether the gene is inherited from the mother or the father. Since we have recently cloned and characterized the human agouti gene, we are currently devoting a considerable effort to understanding the role, if any, of the agouti gene in the development of obesity and the type-ll diabetes in humans. Additionally, reagents from the agouti region 
have been used to clone another gene mapping close to agouti that we believe is directly associated with the preimplantation embryonic lethality of Lethal Yellow, an agouti locus mutation that has been extensively analyzed with embryological techniques. Efforts are currently under way to establish the role of this new gene in preimplantation mouse development.

1. Bultman, S. J., M. L. Klebig, E. J. Michaud, H. O. Sweet, M. T. Davisson, and R. P. Woychik. Molecular analysis of reverse mutations from nonagouti $(a)$ to black-and-tan $\left(a^{t}\right)$ and white-bellied agouti $\left(A^{W}\right)$ reveals alternate forms of agouti transcripts. Genes \& Dev. 8: 481-490, 1994.

2. Doktycz, M. J., G. B. Hurst, S. Habibi-Goudarzi, S. A. McLuckey, C. H. Chen, K. Tang, M. Uziel, K. B. Jacobson, R. P. Woychik, and M. V. Buchanan. Analysis of PCR-amplified DNA products by matrixassisted laser desorption and electrospray ionization mass spectrometry: Current Capabilities and Limitations. Anal. Chem. (in press).

3. Klebig, M. L., J. E. Wilkinson, J. G. Geisler, and R. P. Woychik. Ectopic expression of the agouti gene in transgenic mice causes obesity, features of Type Il diabetes, and yellow fur. Proc. Natl. Acad. Sci. USA 92: 4728$4732,1995$.

4. Klebig, M. L., J. E. Wilkinson, and R. P. Woychik. Molecular Analysis of the Mouse Agouti Gene and the Role of Dominant Agouti-Locus Mutations in Obesity and Insulin Resistance. Proceedings, Molecular Aspects of Obesity Conference, Pennington Biomedical Research Center (in press).

5. Kwon, H. Y., S. J. Bultman, C. Löffler, W. Chen, P. J. Furdon, J. G. Powell, A. Usala, W. Wilkison, I. Hansmann, and R. P. Woychik. Molecular structure and chromosomal mapping of the human homolog of the agouti gene. Proc. Natl. Acad. Sci. USA 91: 9760-9764, 1994.

6. Lu, D., D. Willard, I. R. Patel, S. Kadwell, L. Overton, T. Kost, M. Luther, W. Chen, R. P. Woychik, W. O. Wilkison, and R. D. Cone. Agouti protein is an antagonist of the melanoycte-stimulating-hormone receptor. Nature 371: 799-802, 1994.

7. Michaud, E. J., S. J. Bultman, L. J. Stubbs, and R. P. Woychik. The embryonic lethality of homozygous lethal yellow mice $\left(A^{y} / A^{y}\right)$ is associated with the disruption of a novel RNA-binding protein. Genes \& Dev. 7: 1203-1213, 1993.

8. Michaud, E. J., S. J. Bultman, M. L. Klebig, M. J. van Vugt, L. J. Stubbs, L. B. Russell, and R. P. Woychik. A molecular model for the genetic and phenotypic characteristics of the mouse lethal yellow $\left(A^{v}\right)$ mutation, Proc. Natl. Acad. Sci. USA 91: 2562-2566, 1994.

9. Michaud, E. J., M. J. van Vugt, S. J. Bultman, H. O. Sweet, M. T. Davisson, and R. P. Woychik. Differential methylation of a new dominant agouti allele $\left(A^{\text {iapy }}\right)$ is correlated with methylation state and is influenced by parental lineage. Genes \& Dev. 8: 1463-1472, 1994. 
10. Moyer, J. H., M. J. Lee-Tischler, H.-Y. Kwon, J. J. Schrick, E. D. Avner, W. E. Sweeney, V. L. Godfrey, N. L. A. Cacheiro, J. E. Wilkinson, and R. P. Woychik. Candidate gene associated with a mutation causing recessive polycystic kidney disease in mice. Science 264: 1329-1333, 1994.

11. Schrick, J. J., M. E. Dickinson, B. L. M. Hogan, P. B. Selby, and R. P. Woychik. Molecular and phenotypic characterization of a new mouse insertional mutation that causes a defect in the distal vertebrae of the spine. Genetics (in press).

12. Schrick, J. J., L. Onuchic, S. T. Reeders, J. R. Korenberg, X.-N. Chen, J. H. Moyer, J. E. Wilkinson, and R. P. Woychik. Characterization of the human homologue of the mouse $\mathrm{Tg} 737$ candidate polycystic kidney disease gene. Human Mol. Genet. 4: 559-567, 1995.

13. Woychik, R. P. Transgenic mice in developmental toxicology. In: Male Mediated Developmental Toxicology, ed. by D. R. Mattison, and A. F. Olshan. Plenum Publishing, New York, 1994, pp. 75-79.

14. Woychik, R. P., J. E. Wilkinson, J. H. Moyer, M. J. Lee-Tischler, H.-Y. Kwon, J. J. Schrick, B. Yoder, E. D. Avner, W. E. Sweeney, and V. L. Godfrey. Insertional mutagenesis and PKD. Kidney Int. (in press).

15. Zemel, M. B., J. H. Kim, R. P. Woychik, E. J. Michaud, S. H. Kadwell, I. R. Patel, L. Overton, and W. O. Wilkison. Agouti regulation of intracellular calcium: Role in the insulin resistance of $\left(A^{\text {v/ }}\right)$ viable yellow mice. Proc. Natl. Acad. Sci. USA 92: 4733-4737, 1995.

\section{TARGETED MUTAGENESIS}
M. L. Mucenski
T. A. Banks ${ }^{3,5}$
A. J. Davis ${ }^{17,5}$
J. G. Geisler ${ }^{4}$

P. R. Hoyt ${ }^{1}$

M. K. Kerley

W. H. Lee

H.-H. Lin.

The major focus of the Targeted Mutagenesis Group is to determine the biological function of genes in vitro, using the mouse as a model system. This is accomplished utilizing the embryonic stem (ES) cell technology. Murine ES cells can be manipulated in vitro to disrupt an endogenous gene of interest. ES cells containing the mutant are then introduced back into 3.5 day of gestation embryos, which are then implanted into pseudopregnant female mice to resume normal development. The resulting mice are then tested to determine whether they can pass the mutated gene to their progeny. Through appropriate breeding strategies, mice are generated that are homozygous for the mutation of interest. The characterization of the mutant animals provides important insight into the biological function of the mutated gene in the context of the whole animal 
system. Most importantly, the disruption of genes that are homologous to those associated with diseases in humans can provide murine models for these genetic diseases.

Analysis of mice in which the c-myb proto-oncogene had been disrupted indicates that multiple hematopoietic lineages are. affected by the lack of expression of this gene. These results suggest that this proto-oncogene is essential for the proliferation and/or differentiation of hematopoietic progenitor cells. The c-myb mutant mice have also proven to be a valuable reagent in the identification of novel genes involved in hematopoiesis.

The proto-oncogene Evi-1 and the cytokine gene Iymphotoxin- $\alpha(L T-\alpha)$ have also been disrupted by targeted mutagenesis. Evi-1 mutant mice die approximately mid-way through gestation with multiple organ systems being affected. $L T-\alpha$ mutant mice are born and appear to be phenotypically normal. Histopathological analysis revealed that these mice have no secondary lymphoid organs. Further studies have indicated that the mutant mice are immunocompromised. Overall, the analysis of the mice that have been generated will provide important information as to the normal function of two genes that were initially identified because of their involvement in cancer (c-myb and Evi-1) and one gene that is thought to regulate immune cell interactions through both direct and indirect modes of action $(L T-\alpha)$.

1. Banks, T. A., and M. L. Mucenski. Gene targeting of the immune system: The surprises continue. Curr. Opin. Biotechnol. 5: 604-610, 1994.

\section{MAMMALIAN BIOCHEMICAL GENETICS}
R. A. Popp
T. L. Poole ${ }^{1}$
D. M. Popp
S. G. Shinpock
M. E. Overcash ${ }^{4.5^{\circ}}$
M. Y. Yang ${ }^{4}$

Our group has continued studies on animal models of human diseases that involve abnormal hemoglobins and virus-induced immunodeficiencies. Clinical hematology, biochemical and immunological methods, and molecular biology are being used to characterize induced mutations, altered gene products, and viruses that cause pathophysiological effects in mice. Results of our recent studies are summarized below. 


\section{Development of a Mouse Model of Sickle Cell Disease}

We have continued to develop improved transgenic mouse models of sickle cell disease. In our first model, the $\mathrm{Hb} \mathrm{S}$ Antilles transgenes from Tg58Ru mice were bred onto the genetic background of a line of mice (MHOAH) that produce mutant, high-oxygen-affinity hemoglobins $\left(P_{50}\right.$ of $\left.24.5 \mathrm{~mm} \mathrm{Hg}\right)$ rather than normal mouse hemoglobins $\left(P_{50}\right.$ of $\left.40 \mathrm{~mm} \mathrm{Hg}\right)$. These transgenic $\mathrm{Hb} S$ Antilles mice exhibited many hematological and pathological symptoms commonly found in patients with sickle cell anemia. The peripheral blood contained a higher $(15 \%)$ than normal $(2.5 \%)$ frequency of reticulocytes, and numerous misshapen erythrocytes that resemble irreversibly sickled red cells. Extensive pathology was observed in tissue sections of the spleen, kidneys and lungs of these transgenic sickle cell mice. Several factors may contribute to the red cell sickling and secondary organ pathology. In the venous circulation, the difference between the low-oxygen-affinity of $\mathrm{Hb} \mathrm{S}$ Antilles and the high-oxygen-affinity of the mutant forms of murine hemoglobins favors preferential deoxygenation of $\mathrm{Hb} \mathrm{S}$ Antilles; the deoxygenated form of $\mathrm{Hb} \mathrm{S}$ Antilles polymerizes to cause red cell sickling, red cell membrane damage, water loss and the formation of irreversibly sickled red cells, and the organ pathology observed in these transgenic sickle cell mice. In our second model, an additional $\mathrm{Hb} \mathrm{S}$ Antilles transgene complex (Tg98Ru) has been bred onto the genetic background of the first transgenic sickle cell model. Synthesis of HbS Antilles in these transgenic mice is increased to more than $30 \%$, and more than $30 \%$ of the red cells exhibit sickling properties very similar to that of red cells in human sickle cell patients. The pathology of these mice remains to be examined.

\section{Identification of Retrovirus-Infected Lymphoid Cells in B10.F Mice}

We have extended our studies on the effects of a unique ecotropic murine retrovirus (B1OFV) in B10.F mice. We have shown that a rat-anti-MuLV monoclonal antibody obtained from Dr. Leonard Evans at Rocky Mountain Laboratory will detect MuLV antigen on the surface of B1OFV-infected lymphocytes. A FACStar ${ }^{\text {PLUS }}$ flow cytometer and fluorochrome-conjugated antibodies have been used to show that B1OFV is expressed on the surface of $\mathrm{CD}^{+}, \mathrm{CD}^{+}$, and $\mathrm{CD}^{+} \mathrm{T}$ lymphocytes. ELISA methods have been used to establish that the cytokines produced by T-cell lymphocytes in neonatal B10.F mice switch from primarily IFN-gamma and IL-2 (Th-1) to IL-4 and IL-10 (Th-2) as B10.F mice become more viremic between four- and six-months of age. IFNgamma synthesis has been shown to be an important cytokine to maintain resistance to viral infection. We have initiated studies to evaluate the usefulness of B10.F mice for studies on methods to modify subsets of lymphoid cells, e.g., to enlarge the proportion of IFN-gamma producing lymphocytes, to reduce the risk of retroviral infections in newborn mice, and to increase the resistance to viral replication and the onset of immune deficiency in infected mice. Although cytokine therapy in B10.F mice did modulate the cytokine repertoire of treated 
mice, the treatment regimens used so far have not reduced the incidence of virally infected lymphocytes.

1. Poole, T. L., C. Wang, R. A. Popp, L. N. D. Potgieter, A. Siddiqui, and M. S. Collett. Pestivirus translation occurs by internal ribosome entry. Virology 206: 750-754, 1995.

2. Wang, T. H., W. K. Yang, M. Y. Yang, P. R. Hoyt, D. C. Henley, J. W. Wesley, and D. M. Popp. Thymus involution induced by 5 -azacytidine in the mouse is by selected depletion of immature thymocyte subsets. Toxicology (in press).

\section{GENOME ANALYSIS}
L. J. Stubbs
C. T. Culiat ${ }^{4}$
W. M. Generoso
E. E. Generoso
N. L. A. Cacheiro ${ }^{3}$
M. T. Sobhani ${ }^{3}$
E. A. Carver ${ }^{4}$

\section{Developing Animal Models for the Study of Human Birth Defects}

In recent years, genes responsible for a number of serious human hereditary disorders have been isolated and characterized on the molecular level, opening new avenues of early diagnosis and treatment for each disease. Despite this remarkable progress, the causes of most common human birth defects remain unknown. Although many birth defects are clearly not inherited, most are likely to involve the perturbation of genes or gene products required for the normal progression of specific developmental pathways. One way to gain access to some of these genes is to study animals expressing heritable disorders that closely resemble birth defects commonly seen in human infants, since these related mouse and human disorders are likely to result from disturbance of the same or similar series of morphogenetic events.

Work in our laboratory is focused on the analysis of a collection of mutants that have been generated and maintained exclusively at Oak Ridge. These mutants, which arose as part of an ongoing mutagenesis program conducted by W. M. Generoso, express a wide variety of profound developmental disorders which resemble human birth defects of serious medical consequence. Each of these animals carries a reciprocal chromosome translocation which visibly mark the site of mutation, and greatly simplifies our search for the disrupted genes. As part of Generoso's program, each mutant has been subjected to cytological examination, allowing the breakpoints of each translocation to be assigned to specific chromosomal subregions. These cytological studies represent the first 
crucial step toward the mapping and positional cloning of genes disrupted by each translocation.

Our goal is to isolate the genes disrupted in these mutants, in order to provide access to morphogenetic pathways that are most sensitive to genetic and environmental perturbations in man. To this end, we have developed a general strategy for the localization of genes disrupted by translocation, based upon the use of DNA probes from cytologically-determined breakpoint region in fluorescent in situ hybridization (FISH) analysis of normal and mutant chromosome spreads. Our investment in this project, which began to take on new momentum in the latter part of 1994, is currently focused upon establishment of the technology and resources needed to begin exploiting this collection of mutants on a large and efficient scale. We are concentrating first upon FISH mapping of breakpoints associated with several mutations: (1) $1 \mathrm{Gso}$, a $(2 ; 14)$ translocation which produces a dominant neurological defect and recessive embryonic lethality; (2) $11 \mathrm{Gso}$, a $(5 ; 16)$ translocation, resulting in pronounced hydrocephalus which kills homozygotes before three weeks of age; (3) 13Gso, and 14Gso, two translocations $[(1 ; 15)$ and $(7 ; 10)]$ associated with congenital inner ear defects; and (4) 12Gso, a 4;9 translocation producing severe defects of the lower spine and extremities. As time progresses, we intend to map a large proportion of the mutants in the collection, focusing upon a series of animals expressing disorders of the central nervous system. Two mutations, $1 \mathrm{Gso}$ and $14 \mathrm{Gso}$, have now been mapped to within 1 centimorgan, making breakpoint sequences accessible to molecular mapping and cloning methods. We are cutrently working to isolate the genes disrupted in both of these mutants. The genes that are isolated from these and other mutants in this interesting collection will provide new means of tracing specific factors, both genetic and environmental, that contribute to the development of similar anomalies in human infants. 


\title{
Genome Mapping Program
}

\author{
Overview - L. J. Stubbs
}

Over the past decade, our understanding of the structure and gene content of the mouse and human genomes has increased exponentially. Events of the next few years promise to produce an even more remarkable revolution in the way we view and experiment with the genes of mammalian species, and this information will begin to penetrate fields far beyond the immediate world of genome research. With large scale sequencing projects set to proceed at full pace, the research community will be confronted with a pressing need to develop new ways of handling and processing the enormous volume of DNA sequence information, and bringing it to biological relevance. The expertise and focus of research at ORNL has developed to leave us perfectly poised to serve some of the most urgent upcoming needs of the Human Genome research community. Genome research in the Biology Division focuses upon our strengths in bio-informatics and mouse genetics, with projects organized into two types of programs: (1) an integrated multi-investigator program that is focused upon physical and functional comparative genome mapping; and (2) several smaller, independent programs, each primarily involving a single research group.

A complete DNA sequence of the human genome and sophisticated data analysis tools will provide us with a vast new store of knowledge. However, the link between DNA sequence and biological function will still, for the foreseeable future, hinge on clues derived from living model systems. Housing the world's largest experimental mouse colony, and possessing a long and rich history as a major center of mouse genetics research, the Biology Division is uniquely poised to serve the Human Genome Community at the forefront of this rapidly expanding and increasingly important field. For this reason, a primary focus of Genome research within the Biology Division is developing the methodologies and resources required to exploit the mouse more efficiently as a tool to aid in the discovery and functional analysis of human genes. A large share of this work is being carried out as part of an integrated multi-investigator effort - Mapping Human-Mouse Genomic Homologies. This program is comprised of three distinct, interacting "tasks": (1) man-mouse comparative genome mapping; (2) embryonic stem-cell based functional mapping efforts; and (3) mouse genome informatics support. This larger, integrated program interacts extensively with other Genome-related projects in the Biology Division, in other ORNL Divisions, and in other National Laboratories. For example, the first task of this program has proceeded as part of a strong and very interactive collaboration with researchers in the Human Genome Center at Lawrence Livermore National Laboratory. 
One topic of research which serves as the focus of an. independent program is the critical problem of DNA sequence interpretation (see page 81). As the sequence of each human chromosome emerges, the first effort will be to search for the small, scattered regions of the genome that serve as protein-coding sequences, to predict the structures of the gene products, and to derive basic clues regarding gene family relationships and potential activities. This effort will demand the development of sophisticated computer-based tools, such as GRAIL, a data analysis tool developed by ORNL scientists and now used by researchers world-wide. Extensions of the technology that contributed to GRAlL, and development of new generations of even more sophisticated sequence analysis tools serve as a primary focus of continuing interest to researchers in the Biology Division. A second topic of independent research also involves the development and application of techniques to identify functionally-significant sequences from cloned human DNA (see page 83). This strategy, which allows the rapid isolation of evolutionarily conserved DNA sequences from large cloned genomic segments, is being developed to take advantage of mouse-human genomic homologies and the parallel sets of mouse and human ordered genomic libraries to provide a rapid source of new exons and conserved regulatory elements throughout both genomes.

The shared goal of ORNL's various Genome research programs is thus to capitalize upon the unique history and capabilities of the Laboratory. This will involve the continued development of more efficient tools and strategies for gene discovery and exploitation of the unique mouse genetics resource for analysis of human genome function.

\section{MAPPING HUMAN-MOUSE GENOMIC HOMOLOGIES}
L. J. Stubbs
J. L. Doyle ${ }^{4}$
M. K. Kerley
M. E. Shannon'
D. K. Johnson
W. C. Dunn
W. H. Lee
B. G. Stanford
M. L. Mucenski
C. M. Foster ${ }^{3}$
E. J. Michaud ${ }^{1}$
E. C. Uberbacher ${ }^{6}$
R. J. Mural
E. E. Generoso
C. T. Culiat $^{4}$
L. J. Hauser ${ }^{6}$
S. Petrov ${ }^{6}$
M. Walkowicz ${ }^{4}$

Man-Mouse Comparative Mapping

Comparisons between the genetic maps of mouse and man have revealed striking similarities in the genomes of the two species, despite their obvious biological differences. Mouse and human chromosomes resemble each other closely within large blocks carrying variable numbers of related genes. Although these blocks, or conserved linkage groups, have been scrambled relative to one another during the course of evolution, gene content and order within each block 
is generally very well conserved. Within these homologous segments, mapping data obtained in mouse may often be extrapolated from one species directly to the other; the location of conserved sequences or functional genes in mouse can thus be used to predict the positions of related sequences in man, and vice versa. The large number of existing murine mutants, and our ability to create new mutations by experimental means, make the mouse the most promising assay system for studying the organismal functions of human genes. To aid in the efficient exploitation of mouse as a model genetic system, existing man-mouse comparative maps must be expanded and refined to more clearly reveal the similarities and subtle differences existing between genomes of the two species.

Our group has focused upon generating detailed man-mouse comparative maps in several regions, including a 30 centimorgan (cM) segment extending from the murine pink-eyed dilution ( $p$ ) locus to the centromere of mouse chromosome 7 (Mmu7), and portions of mouse chromosomes 8, 9, 10, and 17 that carry homology to human chromosome $19 p$ (H19p). Proximal Mmu7 was initially targeted for several reasons. First, a number of interesting murine mutations map to this region, including those resulting from overlapping deletions centered at $p$. To generate data and reagents required to precisely locate and isolate genes in this region, we have completed a long-range restriction map spanning more than 3 million basepairs ( $3 \mathrm{Mb}$ ) surrounding $p$, and have isolated most of the $3 \mathrm{Mb}$ region in overlapping yeast artificial chromosome (YAC) and bacteriophage P1 clones. Mapping information obtained to date suggests that this murine region is very similar in gene content and organization to the related region of H15q11-q13, which contains the imprinted genes of the Prader-Willi and Angelman syndrome (PWS/AS) interval. These physical mapping studies have contributed to the identification of Gabrb3, encoding the $\beta-3$ subunit of the type A- $y$-aminobutyric acid receptor, as the gene associated with a cleft palate mutation closely linked to $p$. We are currently working to map a second $p$-linked gene associated with seizures, tremors, runting, and juvenile lethality in affected mice. This and other $p$-linked mutations may point us to new genes surrounding the PWS/AS critical regions.

Proximal Mmu7 also carries homology with two other well-mapped human regions. A segment of homology to H11p15 is located just proximal of $p$; our studies have indicated that this homology segment may be of very limited size, since all of the seven genes that have been mapped to this interval are clustered within a distance of $500 \mathrm{~kb}$. In the past two years, mapping efforts have been focused primarily upon a large region, extending 25 contiguous $\mathrm{cM}$ from the centromere of Mmu7, which carries all known homologs of genes located on $\mathrm{H19q}$. These studies are being conducted in close collaboration with members of the Human Genome Center at the Lawrence Livermore National Laboratory (LLNL), who have generated detailed genetic and physical maps of H19. Our data, resulting from comparative genetic mapping of over 50 conserved markers 
in this region as well as detailed physical mapping in several segments of special interest, has shown that the related mouse and human regions are very similar to one another in gene content and organization. Because of the success of this initial collaborative venture, we have expanded our efforts to include the analysis of all murine regions with significant $\mathrm{H} 19$ homology, with special emphasis on a mutation-rich region of Mmu 8 that is closely related to H19p13.1-p13.2. By coordinating efforts and sharing resources and information with the LLNL team, we are constructing comparative maps that maximize potential for direct interspecies comparisons, and that optimize our ability to exploit the mouse in exploring the functions of the resident human genes.

\section{Embryonic Stem Cell-Based Strategies for Determining Genome Function}

The current focus of the human genome project involves the sequencing of the entire genome. Through this work, a multitude of new genes will be identified, some representing candidate genes for various human diseases. It has been shown that humans and mice show significant homology at the genomic level, with the conservation of a large number of genes between the two species. The recent advancements in embryonic stem (ES) cell technology allow one to disrupt a gene of interest in vitro, and subsequently to generate mice that carry the desired mutation. This makes the mouse an excellent experimental model system for determining the biological function of any gene of interest. Targeted mutagenesis technology is being used to augment the comparative mapping studies between mouse and human homology regions.

A primary aim of this research has been to develop a state-of-the-art facility for the purpose of eventually setting up a large-scale targeted mutagenesis program for the purpose of determining the organismal function of specific human genes. Thus far, we have trained personnel and have optimized protocols for performing targeted mutagenesis experiments using existing standardized procedures. This has included the testing of numerous embryonic stem cell lines for totipotency and efforts to generate new cell lines. Co-cultivation of targeted ES cell with 8-cell embryos has been tried in an effort to generate chimeric animals more efficiently. The mapping of mouse-human homology regions, a collaborative effort between researchers at Lawrence Livermore National Laboratory and the Biology Division has led to the identification and characterization of an evolutionarily conserved cluster of genes that encode transcription factors which contain zinc finger motifs. A targeting vector is being constructed to determine to biological function of one of the genes in the cluster. Collaborations have also been established to determine the biological function of several other genes that are conserved between humans and mice, including DNA repair genes and a candidate gene that may be associated with one or more human neurological disorders. 
A second focus of this project has involved the development of an ES cellbased system for the in vitro generation of germline deletion complexes throughout the mouse genome. The initial focus of this effort was the use of $X$ irradiation to generate deletions at specific chromosomal locations in the genome of ES cells. Preliminary results suggested that this approach may not be feasible; therefore, an alternative approach has been implemented, again focusing on the conserved cluster of zinc finger genes that have recently been identified. It has been reported that deletions of up to $60 \mathrm{~kb}$ can be generated using standard targeting vectors and protocols. How large a deletion can be made using this methodology is not known. To begin to address this question, targeting vectors are being constructed that contain large (up to $100 \mathrm{~kb}$ ) deletions. This ability to make targeted deletions throughout the genome will prove invaluable in the physical mapping of novel genes to test the potential functional redundancy of gene families, and in the generation of models for multi-genic diseases.

\section{Informatics Support for the Mouse-Human Mapping Project}

The informatics portion of the ORNL Mouse-Human Mapping Project is designed to provide informatics support to the other project tasks. This support includes construction of a mapping database for the project, providing tools for managing data in the laboratory, and helping to develop analysis tools for physical and genetic mapping. Recent work has focused on using $A C e D B$, a database system widely used in the genome community, which provides easy access to data through a sophisticated graphical interface. The three main graphical displays of the system (genetic map, physical map, and genomic sequence map) are very well tailored to the needs of the current project. A wide variety of data can be stored, retrieved, and displayed using ACeDB. For instance, in addition to standard mapping and text based data (bibliographic data, for example), we are able to store images of the relevant phenotypes of various mouse mutants.

Our implementation has been modeled, with some modification, on the LBL chromosome $21 \mathrm{ACeDB}$ and is designed to contain genetic and physical mapping data of mouse and the corresponding regions of human chromosomes. Much of the significant backlog of genetic and physical mapping data which existed last year has been incorporated into the current database. We have also been able to include the data from our probe database into the ACeDB model. Within our implementation of $\mathrm{ACeDB}$ we have the ability to transparently move to other information sources that are available over the Internet, such as the Mouse Locus Catalog at Jackson Laboratory. User access to the system is being provided on Sun workstations by forms-based data entry and the ACeDB graphical interface.

1. Culiat, C. T., L. Stubbs, C. Montgomery, L. B. Russell, and E. M. Rinchik. Phenotypic consequences of the deletion of the $\gamma 3, \alpha 5$ or $\beta 3$ subunit of the 
type-A Y-aminobutyric acid receptor in mice. Proc. Natl. Acad. Sci. USA 91: 2815-2818, 1994.

2. Lai, F., L. Stubbs, and K. Artzt. Molecular analysis of mouse Rab11b: A new type of mammalian YPT/Rab protein. Genomics 22: 610-616, 1994.

3. Lai, F., L. Stubbs, H. Lehrach, Y. Huang, Y. Yeom, and K. Artzt. Genomic organization and expressed sequences of the mouse extended $H 2-K$ region. Genomics 23: 338-343, 1994.

4. Stubbs, L. E. Carver, L. Ashworth, and L. Lopez-Molina. Location of the DBP transcription factor gene in man and mouse. Mamm. Genome (in press).

5. Stubbs, L. J., E. M. Rinchik, E. Goldberg, B. Rudy, M. A. Handel, and D. K. Johnson. Clustering of six human $11 \mathrm{p} 15$ genes homologs within a $500-\mathrm{kb}$ interval of proximal mouse chromosome 7. Genomics 24: 324-332, 1994.

\section{AN INTELLIGENT SYSTEM FOR DNA SEQUENCE INTERPRETATION}

\begin{tabular}{|c|c|}
\hline $\begin{array}{l}\text { R. J. Mural } \\
\text { E. C. Uberbacher } \\
\text { M. B. Shah } \\
\text { M. J. Hauser } \\
\text { L. }\end{array}$ & $\begin{array}{l}\text { X. Guan } \\
\text { J. R. Einstein } \\
\text { S. Matis } \\
\text { S. } \mathrm{Xu}^{6}\end{array}$ \\
\hline
\end{tabular}

Computerized nucelotide sequence analysis is rapidly developing as an approach for identifying genes in cloned DNA. During the next 10 to 15 years most, if not all, of the sequence of human DNA $\left(3 \times 10^{9}\right.$ bases) will be known. Understanding the instructions laid out in DNA sequences will require a close interaction between experimental biology and computer analysis. It is already difficult to provide full annotation for the hundreds of thousands of bases of DNA sequence that can be determined each year in a single laboratory. The need for computer tools to locate and characterize biologically important features in DNA sequences will continue to increase as the amount of known sequence increases. As DNA sequencing technology continues to improve, it soon may be that the most efficient way to find genes and other sequences of interest will be though a combination of DNA sequencing and computer analysis.

We are developing an integrated artificial intelligence system to identify and interpret biologically significant features in genomic DNA sequence data. The project combines expertise in molecular biology and genetics in the Biology Division with concurrent-processing and intelligent systems expertise in the Computing and Mathematical Sciences Division. We are focusing on two central areas of DNA sequence analysis: (1) improvement of the basic pattern recognition technology used to locate sequence regions which correspond to genes and other biologically relevant features, and the 
corresponding development and distribution of reliable feature recognition tools to aid experimental activities; (2) development of integrated systems for the intelligent automated assembly of recognized genetic features into hypothetical models for gene structure and function.

GRAIL is a modular system which supports the recognition of gene features and gene modeling for the analysis and characterization of DNA sequences. Overall, about $92 \%$ of exons are found by this system. Using these accurately predicted exons as a starting point, a gene assembly program (GAP) uses heuristic methods and dynamic programming to construct gene models. Genes modeled by this system contain about $94 \%$ of the all true exons, have only $7.4 \%$ false positive information, and $79 \%$ of predicted exons have both edges correctly defined with an additional $19 \%$ having at least one correct edge after gene modeling.

All of this information is presented to the user in graphic form in the $X$-window based client-server system XGRAIL. In addition, the user can view the positions of a number of other features including poly- $A$ addition sites, potential promoters, $\mathrm{CpG}$ islands and repetitive DNA elements using this system. XGRAIL also has a direct link to the genQuest server that allows us characterization of newly obtained sequences by homology based methods through accessing a number of databases. These can be searched using FASTA, BLAST, and a parallel implementation of the Smith-Waterman algorithm that utilizes a specialized computing environment at ORNL. The databases can be searched with the translations of predicted exons or gene models. Following an analysis session, the user can use an annotation tool, which is part of the XGRAIL system, to generate a "feature table" that describes the current sequence and it properties.

Since GRAlL became available as an e-mail server in 1991, it has processed over 200 million bases of DNA sequence (X. Guan and M. Shah, per. comm.) and currently processes 2000 transactions per month. GRAlL can be accessed in a number of different ways: (1) through the e-mail server (grail@ornl.gov); (2) through an X-windows based client-server (the client is available by anonymous ftp from arthur.epm.ornl.gov); and (3) through the World Wide Web (URL http://avalon.epm.ornl.gov/).

1. Gardiner, K. and R. J. Mural. Getting the message - a review of the 4th International Workshop on the Identification of Transcribed Sequences. Trends Genet. 11: 79-81, 1995.

2. Matis, S., M. Shah, R. Mural, and E. Uberbacher. Detection of human RNA polyermase II promoters using artifically intelligent methods. In: Compmed9, ed. by M. Witten. World Scientific (in press). 
3. Matis, S., Y. Xu, M. Shah, D. Buley, X. Guan, J. R. Einstein, R. J. Mural, and $E$. C. Uberbacher. Detection of control regions in human DNA sequence using intelligent systems. Comput. Chem. (in press).

4. Mural, R. J. Finding one's way through DNA. Trends Biotechnol. 12: 393-394, 1994.

5. Uberbacher, E. C., J. R. Einstein, X. Guan, and R. J. Mural. Gene recognition and assembly in the GRAIL system: Progress and challenges. In: Proceedings, The Second International Conference on Bioinformatics, Supercomputing, and Complex Genome Analysis, ed. by, H. A. Lim, J. W. Fickett, C. R. Cantor and R. J. Robbins. World Scientific, 1993, pp. 465-476.

6. Uberbacher, E. C., X. Guan, and R. J. Mural. A practical guide to the GRAlL e-mail server. In: Automated DNA Sequencing and Analysis Techniques, ed. by M. Adams, C. Fields, and C. Venter. Academic Press, 1994, pp. 307-312.

7. Xu, Y., J. R. Einstein, R. J. Mural, M. Shah, and E. C. Uberbacher. An improved system for exon recognition and gene modeling in human DNA sequences. In: Proceedings, Second International Conference on Intelligent Systems for Molecular Biology. AAAI Press (in press).

8. Xu, Y., R. Mural, M. Shah, and E. Uberbacher. Recognizing exons in genomic sequence using GRAIL II. In: Genetic Engineering, Princples and Methods, vol.15, ed. by J. K. Setlow. Plenum Press, 1994, pp. 241-253.

9. Xu, Y., R. J. Mural, and E. C. Uberbacher. Constructing gene models from accurately-predicted exons: An application of dynamic programming. Comp. Appl. Biosci. 10: 613-623, 1994.

10. Xu, Y., R. J. Mural, and E. C. Uberbacher. Correcting sequencing errors in DNA coding regions using a dynamic programming approach. Comp. Appl. Biosci. 11: 117-124, 1995.

\section{STRATEGIES FOR THE IDENTIFICATION OF EVOLUTIONARILY-CONSERVED DNA SEQUENCES}
L. J. Stubbs
K. A. Glantz $z^{3}$
L. R. Chittenden ${ }^{4}$
B. G. Stanford

As part of a distinct but closely related program, we have recently begun to explore new methods to exploit mouse-human genomic relationships for the identification of new genes. This project has been designed to capitalize upon Lawrence Livermore National Laboratory's (LLNL) collection of contiguous cosmid and YAC clones which, with gaps of varying size, span the length of human chromosome 19 (H19). Most cloned H19 genes and DNA markers have been localized to specific cosmid clones, but the known, mapped genes represent only a very small fraction of the total number of transcribed sequences located 
throughout H19. In collaboration with Dr. Elbert Branscomb and other members of the LLNL team, we have recently begun to design and test a novel method for the rapid and efficient identification of genes and other functionally-significant DNA sequences from cloned human DNA.

Our approach relies upon the fact that DNA sequences with important biological functions are most likely to be conserved throughout evolution. Because of this fact, the genes of mouse and man are, on the whole, very similar in DNA sequence; non-gene regions, by contrast, vary greatly between two such highly divergent species. We are currently exploring several different means of selectively cloning the sequences that are most similar in mouse and human DNA. Our approach focuses upon using conserved sequences located in murine genomic clones (YAC, BAC, P1 or cosmid clones) to "trap" similar sequences from overlapping cosmids spanning the homologous human region of interest. Our protocols have been adapted from similar techniques originally developed to select cDNA sequences corresponding to genes located in cloned human regions (developed by Dr. M. Lovett and colleagues at the University of Texas Southwestern Medical Center at Dallas). To test these methods, we have used matched mouse and human cosmids that span the X-ray repair gene, XRCC1, comprised of 17 short exons with widely varying levels of sequence conservation. Since both cosmids have been completely sequenced, we can monitor the success of various modifications to our selected protocols very precisely. Results with this test system have been very promising. The procedure routinely yields $60-65 \%$ exon sequences, with major "contaminants" being restricted to Alu sequences (which are closely related to mouse B1 repeats), and interestingly, non-transcibed conserved sequences most likely representing regulatory elements associated with the $X R C C 1$ gene. Because of these encouraging results, we are now beginning to apply the conserved element mapping (CEM) protocols to larger regions $(\sim 350 \mathrm{~kb})$ of mouse human homology in the search for new genes. Ultimately, we would like to explore the feasibility of applying these and other related methods to aid in the identification of genes along the length of $\mathrm{H} 19$. 


\section{EDUCATIONAL ACTIVITIES}

\section{Doctoral and Postdoctoral Training Programs}

The University of Tennessee-Oak Ridge Graduate School of Biomedical Sciences was established in 1965 through a joint effort of the Biology Division of the Oak Ridge National Laboratory and The University of Tennessee, so that the scientific talents and research facilities of the Laboratory could be utilized more fully in graduate education. The School accepted its first class of seven graduate students in the fall of 1967. Since then it has grown and developed steadily. It now has a graduate enrollment of 18 students and is a recognized center of quality education in the southeast. The University of Tennessee supports 16 students with research assistantships, and 2 students are supported by National Institutes of Health and United States Department of Agriculture predoctoral appointments. As of September 1995, a total of 152 students have been awarded Ph.D. degrees through the Graduate School of Biomedical Sciences. Nearly all continue today in careers in research or research/teaching, and some have won distinction for their research contributions. Although intended primarily for Ph.D. training, the School has awarded a total of 25 M.S. degrees. This component of the program was added to meet the needs of UT and ORNL employees.

The Graduate School offers courses and laboratory experience in many aspects of biomedical science, emphasizing biochemistry and molecular biology, carcinogenesis and radiation biology, mammalian genetics and development, and structural and cellular biology. It has one full-time faculty member from the University of Tennessee (D. E. Olins) and two research professors (A. L. Olins and L. J. Hauser) supported through extramural research funds. An adjunct faculty of 18 members from the Biology Division and other divisions of the Oak Ridge National Laboratory and 2 members each from the Oak Ridge Associated Universities and the University of Tennessee fulfill most of the obligations for teaching and directing thesis research. The Graduate School of Biomedical Sciences is a component of the Graduate School of The University of Tennessee but is housed within the Biology Division of the Oak Ridge National Laboratory. Both classroom teaching and laboratory research training utilize Biology Division facilities. The School's Director reports jointly to the Dean of the Graduate School at the University, the Biology Division Director, and the Associate Director for Life Sciences and Environmental Technologies at the Laboratory. 
The overall objective of the Graduate School of Biomedical Sciences is to develop a high quality, multidisciplinary graduate training program in the Biomedical Sciences. The program begins with a core curriculum that emphasizes the multidisciplinary and quantitative aspects of modern biology while providing a diversity of laboratory research experiences. Advanced students take courses and tutorials in specialized areas, participate in research seminars, and pursue dissertation research under the direction of a faculty preceptor.

The students form a very active group of investigators as reflected by 17 coauthorships, 9 as first authors, during the last 20 months. This represents a significant contribution to the productivity and excellence of ORNL's Biology Division. In return, the students receive superb guidance and training by staff members of the Biology Division.

Postdoctoral training is another important activity of the Biology.Division. The program is administered by The University of Tennessee and by Oak Ridge Associated Universities. Support for 4 postdoctoral fellows was provided by a Postdoctoral Training Grant in Carcinogenesis Research from the National Cancer Institute, and 9 postdoctoral fellows were supported by research grants and contracts secured by individual principal investigators. After a two- or three-year period of research in the Biology Division, trainees obtained positions in universities, industries or other government laboratories.

\section{Undergraduate Training Programs}

The Biology Division participated in three undergraduate training programs: (i) Great Lakes Colleges Association/Associated Colleges of the Midwest (GLCA/ACM Science Semester), (ii) Oak Ridge Associated Universities Student Research Participation (SRP), and (iii) Science Engineering Research Semester (SERS). Under the auspices of these organizations and in cooperation with Oak Ridge National Laboratory, outstanding college juniors and seniors are offered opportunities for independent research in the life sciences. In the past 24 months, there were 13 students, possessing the educational qualifications and the potential for a successful scientific career, who spent several weeks performing research under the guidance of Biology Division staff members.

Although the principal purpose of the programs is to provide training experience for the students, it often allows Division staff members an opportunity to broaden their areas of research. Upon completion of their research activities in the laboratory, students prepare a formal scientific paper and present a talk on their work. The programs, in which over 586 students have participated during the past 29 years, have received the enthusiastic endorsement of the students, their colleges, and the members of the Biology Division. 
APPENDICES 


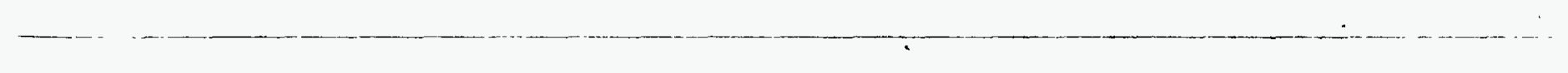




\section{Advisory Committee}

Dr. Irwin Fridovich

James B. Duke Professor

Department of Biochemistry

Duke University Medical Center

Durham, North Carolina 27710

Dr. David E. Housman

Professor of Biology

Center for Cancer Research, E17-543

Massachusetts Institute of Technology

77 Massachusetts Avenue

Cambridge, Massachusetts 02139

Dr. H. Ronald Kaback

Howard Hughes Medical Institute Professor, Department of Physiology University of California at Los Angeles 5-748 McDonald Research Laboratories 10833 LeConte Avenue Los Angeles, California 90024-1662

Dr. Gail R. Martin

Professor, Department of Anatomy University of California at San Francisco 513 Parnassus Street, S-1457

San Francisco, California 94143-0452 


\section{Extramural Activities}

Society Committees

G. J. Bunick

Special Interest Committee on Small-Angle Scattering, American Crystallographic Association (1991-1994); chair (1993)

R. J. M. Fry

History Committee, Radiation Research Society (1982-); Finance Committee (1990-); Council (1988-)

F. C. Hartman

Awards Committee, American Society for Biochemistry and Molecular Biology (1992-1994)

P. Mazur

Chairman, Publications Committee, Society for Cryobiology (1974-)

Board of Governors, Society for Cryobiology (1967-)

D. M. Skinner

Board of Governors, The Crustacean Society (1987-)

Selection Committee, Miller Research Fellows, Miller Institute for Basic Research in Science, University of California, Berkeley (1987-)

Chair, Membership Recruitment (National), Association for Women in Science (1992)

\section{Advisory Committees}

G. J. Bunick

Applications Software Working Group, National Energy Research Supercomputer User Group (1991-1994)

J. S. Cook

Member of the Corporation, Mount Desert Island Biological Laboratory (1962-)

R. J. M. Fry

Scientific Committee 40, National Council on Radiation Protection and Measurements (1977-) Honorary Member, National Council on Radiation Protection and Measurements (1993-) 
R. J. M. Fry (continued)

W. M. Generoso

P. Mazur

R. J. Mural
Scientific Committee 75 (Chairman), National Council on Radiation Protection and Measurements (1983-)

Scientific Committee 1, National Council on Radiation Protection and Measurements (1992-1

Committee 1, International Commission on Radiological Protection (1985-)

Member, Subcommission on Radiobiology, National Aeronautics and Space Administration (1990-1994)

Chairman, Radiation Discipline Working Group, National Aeronautics and Space Administration (1992-1996)

Chairman, Subcommission on Radiation Biology, Committee on Space Research (1990-1994)

Visiting Committee, Medical Department, Brookhaven National Laboratory (1991-1995)

Scientific Advisory Committee for Radiobiology, Brookhaven National Laboratory (1995-)

Advisory Committee for NASA's Radiation Health Center for Research and Training (Chairman), Lawrence Berkeley Laboratory (1992-)

Advisory Committee, National Radiobiology Archives, Department of Energy (1993-)

Advisory Committee, Armed Forces Radiation Research Institute (1992-1995)

Institute of Medicine Committee to Study the Mortality of Military Personnel Present at Atmospheric Tests of Nuclear Weapons, National Academy of Sciences (1994-)

Committee on Toxicology, National Research Council (National Academy of Sciences) (1993-1996)

Advisory Board, Second International Conference on Environmental Mutagens in Human Populations at Risk (1993-1995)

Special Grants Review Committee, NIEHS (1994)

Scientific Advisory Board, Cryobiology Research Institute, Methodist Hospital of Indiana (1993-)

Member, Project Advisory Committee, The Biological Sciences Curriculum Study, Colorado Springs, CO (1993-1994)

Member, Human Genome Organization (1994-) 
S. K. Niyogi

A. L. Olins

D. E. Olins

R. A. Popp

L. B. Russell

P. B. Selby

D. M. Skinner

A. L. Stevens
Scientific Expert, United Nations Industrial Development Organization (1989-1

External Advisor to Indian Jute Industries Research Association, Government of India (1989-)

Advisor to Indian Institute of Chemical Biology, India (1986-)

Member of the Corporation, Marine Biological Laboratory, Woods Holes (1983-)

National Science Foundation, Cell Biology Program, Review Panel (1990-1993)

Member, Scanning Transmission Electron Microscope Advisory Committee, Brookhaven National Laboratory (1995-2001)

Member of the Corporation, Marine Biological Laboratory, Woods Holes (1983-)

Mouse Hemoglobin Nomenclature Committee (1984-)

Member, Advisory Committee, Sickle Cell Center, University of California, San Francisco (1994-)

Environmental Health Institute, Fellow (1987-); Awards Nomination Committee (1991-)

External Advisory Committee, University of Cincinnati NIH Center for Environmental Genetics (1991-)

Scientific Advisor and Member of the United States Delegation of UNSCEAR (United National Scientific Committee on the Effects of Atomic Radiation) (1984, 1986-)

Member, Technical Committee, Environmental Mutagen Society (1992-)

Member of the Corporation, Marine Biological Laboratory, Woods Holes (1971-)

Biomedical Sciences Study Section, National Institutes of Health (1985-) 


\section{Editorial Boards}

J. S. Cook

R. J. M. Fry

W. M. Generoso

F. C. Hartman

P. Mazur

D. E. Olins

L. B. Russell

D. M. Skinner

M. Terzaghi-Howe
American Journal of Physiology (1987-1996)

Current Topics in Membranes and Transport, Advisory Board (1983-1995)

News in Physiological Sciences, Associate Editor (1986-1995)

Radiation Research, Editor-in-Chief (1988-)

Advances in Radiation Biology (1990-1993)

Teratogenesis, Carcinogenesis, and Mutagenesis (1979-)

Mutation Research (1985-)

Environmental and Molecular Mutagenesis (1994-1997)

Journal of Protein Chemistry (1982-)

Journal of Biological Chemistry (1991-1995)

Cryobiology (1967-)

Chromosoma (1990-)

Mutation Research (1976-)

Gene (1986-)

Physiological Zoology (1989-)

American Journal of Physiology - Lung Cellular and Molecular Physiology (1994-)

Radiation Research (1995-)

Awards, Honors

K. T. Cain

Martin Marietta Energy Systems, Inc., Technical Support Award (1995)

K. W. Cole

Martin Marietta Energy Systems, Inc., Technical Support Award (1994) 
R. J. M. Fry

W. M. Generoso

F. C. Hartman

M. R. Harpel

H. G. Hodge

P. Mazur

K. W. Cole

J. W. Hall

A. J. Mahowald

P. D. Schreuders

R. J. Mural

L. B. Russell

D. M. Skinner

A. Stevens

M. Terzaghi-Howe
Radiation Research Soceity, Thirty-Second Failla Memorial Lecturer (1995)

Radiology-Centennial Hartman Medal (1994)

Martin Marietta Energy Systems, Inc., R\&D Accomplishment Award (1995)

Martin Marietta Energy Systems, Inc., Publication Award (1995)

Martin Marietta Energy Systems, Inc., ORNL Bargaining Unit Support Award (1995)

Martin Marietta Energy Systems, Inc., Publication Award (1994)

Martin Marietta Energy Systems, Inc., R\&D Accomplishment Award (1994) (with E. C. Uberbacher and $X$. Guan, Computing and Mathematical Sciences Division)

Enrico Fermi Award (1994)

Crustacean Society, Award for Research Excellence (1993)

Tufts University Distinguished Alumna Award (1994)

Martin Marietta Energy Systems, Inc., R\&D Accomplishment Award (1995)

Association for Women in Science Award (1995) 


\section{Invited Presentations at Major Conferences October 1, 1993 - September 30, 1995}

Fry, R. J. M.

"Relative biological effectiveness of high-LET radiations." Symposium on Radiobiology of Labeled Nuclides, Richland, WA, November 9-10, 1993.

"Mice, myths, and men." 18th Lauriston Taylor Lecture. National Council on Radiation Protection and Measurements Annual Meeting, Bethesda, MD, April 6, 1994.

"Radiation protection in space." Radiation Research Society, 42nd Annual Meeting, Nashville, TN, May 30-June 3, 1994.

"The NCRP and radiobiology, epidemiology, risk and basic radiation protection criteria." 39th Annual Meeting of Health Physics Society, San Francisco, CA, June 26-30, 1994.

"Skin deep." 32nd Failla Memorial Lecture. 43rd Annual Meeting of the Radiation Research Society, San Jose, CA, April 1-6, 1995.

Hartman, F. C.

"Site-directed mutants of ribulose-1,5-bisphosphate carboxylase/oxygenase (Rubisco) as mechanistic probes." Canadian Federation of Biological Societies, Saskatoon, Saskatchewan, Canada, June 14-18, 1995.

"Catalytic roles of flexible regions at the active site of ribulosebisphosphate carboxylase/oxygenase (Rubisco)." 10th International Photosynthesis Congress, Montpellier, France, August 20-25, 1995.

"Interaction of thioredoxin $f$ with target proteins." 4th International Conference on Thioredoxins and Related Proteins, Witzenhausen, Germany, August 27-31, 1995.

S. K. Niyogi

"Engineering of human EGF: Functional analysis of specific aromatic and ionic residues." Symposium on Protein, Structure, Function and Engineering, Calcutta, India, September 16-17, 1994. 
"Structure-function analysis of EGF-receptor interaction by protein engineering" and "Mutational analysis of leucine 15 of human epidermal growth factor (hEGF)." 16th International Congress of Biochemistry and Molecular Biology, New Delhi, India, September 19-22, 1994.

Olins, A. L.

"The 3-D architecture of RNA in the Balbiani ring granule (hnRNP)." International Congress on Electron Microscopy 13, Paris, France, July 17-22, 1994.

Russell, L. B.

"Germ-cell stage as a determinant of mutation rate and quality." Germ Line Conference, National Institutes of Health, Bethesda, MD, November 16-18, 1994.

Woychik, R. P.

"Understanding the genetic complexity of the agouti locus." Cold Spring Harbor Meeting on Mouse Molecular Genetics, Cold Spring Harbor, NY, August 31-September 4, 1994.

"Cloning of the gene associated with the yellow obese agouti mutation." Molecular and Genetic Aspects of Obesity Symposium, Baton Route, LA, February 20-23, 1994.

"Mouse genome studies aimed at deciphering gene function." Human Genome Workshop, Santa Fe, NM, November 13-17, 1994. 


\section{Abstracts for Technical Meetings October 1, 1993 - September 30, 1995}

Affholter, K. A., S. J. Henderson, G. D. Wignall, G. J. Bunick, R. E. Haufler, R. N. Compton, E. T. Samulski, J. Disimone, and M. O. Hunt. Structural characterization of $\mathrm{C}_{60}$ and $\mathrm{C}_{70}$ fullerenes by small-angle scattering. American Crystallography Association, Atlanta, GA, June 28-July 1, 1994.

Aguinaga, M. d. P., P. Kopsombut, M. J. Koury, P. D. Roa, A. Rivers, F. Eason, E. A. Turner, and R. A. Popp. Decreased hemoglobin S levels during folate deficiency in the sickle cell transgenic mice. 20th Annual Meeting on Sickle Cell Disease, Boston, MA, March 18-21, 1995.

Aguinaga, M. d. P., P. Kopsombut, M. J. Koury, P. D. Roa, E. A. Turner, and R. A. Popp. Effect of folate deficiency on hemoglobin $S$ in sickle cell transgenic mice. American Society of Hematology, Nashville, TN, December 2-6, 1994.

Aguinaga, M. d. P., P. Kopsombut, M. J. Koury, E. A. Turner, and R. A. Popp. Methotrexate treatment decreases $\mathrm{Hb} S$ levels in the sickle cell transgenic mouse model. 20th Annual Meeting on Sickle Cell Disease, Boston, MA, March 18-21, 1995.

Bishop, J. B., W. M. Generoso, J. E. Polifka, and J. C. Rutledge. Effects of retinoic acid upon pregastrulation mouse embryos. Environmental Mutagen Society 25th Annual Meeting, Portland, OR, May 7-12, 1994.

Bishop, J. B., L. A. Hughes, J. C. Seely, and W. M. Generoso. Differential response of male and female mice to the reproductive and developmental effects of actinomycin-D. Environmental Mutagen Society Annual Meeting, St. Louis, MO, March 12-16, 1995.

Bishop, J. B., A. Shourbaji, L. A. Hughes, and W. M. Generoso. Malformations induced in pregastrulation mouse embryos by 9-cis and 4-oxo retinoic acid. 35th Annual Teratology Society Meeting, Newport Beach, CA, June 24-29, 1995.

Blair, P. J., S. B. Bultman, J. C. Haas, B. T. Rouse, J. E. Wilkinson, and V. L. Godfrey. $C D 4^{+} 8^{-} T$ cells are the effector cells in disease pathogenesis in the scurfy ( $s$ ) mouse. Experimental Biology 94, Anaheim, CA, April 24-28, 1994. 
Blair, P., J. Haas, B. Rouse, E. Wilkinson, and V. Godfrey. CD4 T cells are critical mediators of disease in the scurfy ( $s f$ mouse. Annual Meeting of the American College of Veterinary Pathologists, San Antonio, TX, December 5-10, 1993.

Brandes, H. K., M. K. Geck, F. W. Larimer, and F. C. Hartman. Interaction of thioredoxin $f$ with target proteins. 4th International Conference on Thioredoxins and Related Proteins, Witzenhausen, Germany, August 27-31, 1995.

Brandes, H. K., F. C. Hartman, and F. W. Larimer. Characterization of spinach phosphoribulokinase over expressed in Pichia pastoris. Ninth Symposium of the Protein Society, Boston, MA, July 8-12, 1995.

Brandes, H. K., F. C. Hartman, and F. W. Larimer. Overexpression of the gene for spinach phosphoribulokinase (PRK) in Pichia pastoris. 1995 American Society for Biochemistry and Molecular Biology Annual Meeting, San Francisco, CA, May 21-25, 1995.

Brandes, H. K., F. W. Larimer, and F. C. Hartman. Exploration of covalent complex formation between phosphoribulokinase (PRK) and thioredoxin $f$ (Trx). 4th International Thioredoxin Conference, Kassel, Germany, August 27-31, 1995.

Brandes, H. K., F. W. Larimer, and F. C. Hartman. The $\mathrm{N}$-terminus of thioredoxin $f$ (Trx f). American Association of Plant Physiologists, Portland, OR, July 30-August 3, 1994.

Bunick, G. J. Structural biology at the high flux isotope reactor. Biotechnology Colloquium at Pacific Northwest National Laboratory, Hanford, WA, March 15, 1994.

Chen, Y.-R., and F. C. Hartman. A signature of the oxygenase intermediate of Rubisco catalysis as provided by a novel product formed with a sitedirected mutant. 14th Enzyme Mechanism Conference, Scottsdale, AZ, January 4-8, 1995.

Chen, Y.-R., and F. C. Hartman. A signature of the oxygenase intermediate of Rubisco catalysis as provided by a novel product formed with a sitedirected mutant. 1995th American Society for Biochemistry and Molecular Biology Annual Meeting, San Francisco, CA, May 21-25, 1995. 
Colitz, C. M. H., J. E. Wilkinson, V. Godfrey, and R. P. Woychik. Characterization of the ocular phenotype of transgenic line TGN3261RPW. Annual Meeting of The Association for Research in Vision and Opthalmology, Ft. Lauderdale, FL, May 14-19, 1995.

Colitz, C. M. H., J. E. Wilkinson, V. Godfrey, and R. P. Woychik. Characterization of tumor phenotype in transgenic line TGN3261RPW. Experimental Biology 95, Atlanta, GA, April 9-13, 1995.

Culiat, C. T., D. K. Johnson, R. P. Woychik, L. J. Stubbs, and E. M. Rinchik. Deficiency of the $\beta 3$ subunit of a type-A $Y$-aminobutyric acid receptor is associated with cleft palate in mice. 17th Annual Meeting of the Southern Genetics Group, Pawley's Island, SC, July 6-9, 1994.

Culiat, C. T., E. M. Rinchik, R. P. Woychik, L. J. Stubbs, L. B. Russell, C. S. Montgomery, and D. K. Johnson. The $\beta 3$ subunit of the $G_{A B A_{A}}$ receptor appears to be necessary to normal palate development in the mouse. 8th Mouse Genome Workshop, London, England, November 5-10, 1994.

Dellarco, V. L., J. C. Rutledge, and W. M. Generoso. Genetic anomalies in germ cells, zygote, or pregastrulation stages and their implications for human reproductive and developmental risk.. Teratology Society 34th Annual Meeting, San Juan, PR, June 25-30, 1994.

Dellarco, V. L., A. G. Shourbaji, G. L. Kimmel, J. C. Rutledge, and W. M. Generoso. Exposure of mouse zygotic or pregastrulation stages to 5-azacytidine produced embryonic death and fetal anomalies. International Congress of Toxicology, Seattle, WA, July, 1995.

Dellarco, V. L., A. G. Shourbaji, G. L. Kimmel, J. C. Rutledge, and W. M. Generoso. Treatment of mouse zygotic or pregastrulation stages to 5-azacytidine produced embryonic death and fetal anomalies. Environmental Mutagen Society 25th Annual Meeting, Portland, Oregon, May 7-12, 1994.

Doktycz, M. J., R. S. Foote, K. L. Beattie, and K. B. Jacobson. Evaluation of base sequence and position dependent effects on the hybridization of short DNA oligomers. International Workshop on Sequencing by Hybridization, The Woodlands, TX, October 29-30, 1993.

Doktycz, M. J., M. D. Morris, K. B. Jacobson, K. L. Beattie, and R. S. Foote. Positional effects of nearest-neighbor base pairs and mismatched base pairs in short DNA duplexes. Human Genome Workshop, Santa Fe, NM, November 13-17, 1994. 
Doyle, J., E. Generoso, W. Dunn, B. Stanford, E. Carver, E. Rinchik, S. Watt, W. Zimmerman, L. Ashworth, G. Lennon, A. Olsen, S. Tsujimoto, H. Mohrenweiser, B. Brandriff, and L. Stubbs. Detailed man-mouse comparative maps of human chromosome 19. Human Genome Workshop, Santa Fe, NM, November 13-17, 1994.

Firestone, L. L., J. J. Quinlan, G. Homanics, S. Firestone, P. M. Winter, L. B. Russell, and E. M. Rinchik. Halothane responses in mice with deletion of the genes encoding for $\mathrm{GAGA}_{A}$ receptor subunits $\alpha_{5}$ and $Y_{3}$. American Society of Anesthesiologists Annual Meeting, San Francisco, CA, October 15-19, 1994.

Foote, R. S., S. C. Jacobson, M. J. Doktycz, K. B. Jacobson, and J. M. Ramsey. Microfabricated devices for medical diagnostics. Biochip Array Technologies, Washington, DC, May 10, 1995.

Fry, R. J. M. Skin deep. 43rd Annual Meeting of the Radiation Research Society, San Jose, CA, April 1-6, 1995.

Fry, R. J. M. Radiation protection in space. Radiation Research Society, 42ṇd Annual Meeting, Nashville, TN, May 30-June 3, 1994.

Fry, R. J. M. Relative biological effectiveness of high-LET radiations. Symposium on Radiobiology of Labeled Nuclides, Richland, WA, November 9-10, 1993.

Fry, R. J. M. The NCRP and radiobiology, epidemiology, risk and basic radiation protection criteria. 39th Annual Meeting of Health Physics Society, San Francisco, CA, June 26-30, 1994.

Gao, D. Y. , C. Liu, P. Mazur, E. S. Critser, and J. K. Critser. Effects of supercooling and potential intracellular ice formation on cryosurvival of human spermatozoa. American Society of Andrology, 1994 Annual Meeting, Springfield, IL, March 4-7, 1994.

Geck, M. K., F. W. Larimer, and F. C. Hartman. Exploration of interactions of thioredoxin $f$ with target proteins by site-directed mutagenesis. 1995 American Society for Biochemistry and Molecular Biology Annual Meeting, San Francisco, CA, May 21-25, 1995.

Geck, M. K., F. W. Larimer, and F. C. Hartman. Identification of residues of spinach thioredoxin $f$ involved in interactions with target proteins. 4th International Thioredoxin Conference, Kassel, Germany, August 27-31, 1995. 
Generoso, W. M., J. B. Bishop, and J. C. Rutledge. Developmental toxicities in mice from exposure of zygotes and pregastrulation embryos. Teratology Society 34th Annual Meeting, San Juan, PR, June 24-30, 1994.

Harpel, M. R., Y.-R. Chen, and F. C. Hartman. Stabilization and partitioning of the ribulose 1,5-bisphosphate (RuBP) carboxylase/oxygenase (Rubisco) oxygenation intermediate and related side products. 1995 American Society for Biochemistry and Molecular Biology Annual Meeting, San Francisco, CA, May 21-25, 1995.

Harpel, M. R., Y.-R. Chen, and F. C. Hartman. The nature and alternative fates of the ribulose 1,5-bisphosphate (RuBP) carboxylase/oxygenase (Rubisco) oxygenation intermediate. 10th International Photosynthesis Congress, Montpellier, France, August 20-25, 1995.

Harpel, M. R., E. H. Serpersu, S. Habibi-Goudarzi, S. A. McLuckey, Z.-H. Huang, D. A. Gage, and F. C. Hartman. A novel oxygenase-related side product generated by a mutant of ribulose-bisphosphate carboxylase/oxygenase (Rubisco). 1994 Gordon Research Conference, Meriden, NH, July 17-22, 1994.

Harpel, M. R., E. H. Serpersu, S. Habibi-Goudarzi, S. A. McLuckey, Z.-H. Huang, D. A. Gage, and F. C. Hartman. A novel oxygenase-related side product generated by a mutant of ribulose-bisphosphate (RuBP) carboxylase/oxygenase. Eighth Symposium of the Protein Society, San Diego, CA, July 9-13, 1994.

Harpel, M. R., E. H. Serpersu, S. Habibi-Goudarzi, S. A. McLuckey, Z.-H. Huang, D. A. Gage, and F. C. Hartman. Destabilization of reaction intermediates by the K329A mutant of ribulose-bisphosphate (RuBP) carboxylase/oxygenase (Rubisco). 1994 American Society for Biochemistry and Molecular Biology Annual Meeting, Washington, DC, May 21-25, 1994.

Harpel, M. R., E. H. Serpersu, J. A. Lamerdin, and F. C. Hartman. A novel oxygenase-related side product generated by a mutant of ribulosebisphosphate (RuBP) carboxylase/oxygenase (Rubisco). 14th Enzyme Mechanisms Conference, Scottsdale, AZ, January 4-8, 1995.

Hartman, F. C., M. R. Harpel, Y.-R. Chen, E. M. Larson, and F. W. Larimer. Catalytic roles of flexible regions at the active site of ribulose-bisphosphate carboxylase/oxygenase (Rubisco). 10th International Photosynthesis Congress, Montpellier, France, August 20-25, 1995. 
Hartman, F. C., M. R. Harpel, Y.-R. Chen, E. M. Larson, and F. W. Larimer. Sitedirected mutants of ribulose-1,5-bisphosphate carboxylase/oxygenase (Rubisco) as mechanistic probes. Canadian Federation of Biological Societies, Saskatoon, Saskatchewan, Canada, June 14-18, 1995.

Henderson, S. J., and G. J. Bunick. Comparison of window materials for smallangle $X$-ray scattering: $A$ better beryllium window. American Crystallography Association, Atlanta, GA, June 28-July 1, 1994.

Henry, M. A., P. Mazur, and J. K. Critser. Sperm cell concentration following cryopreservation using various cooling and warming rates. American Society of Andrology, 1994 Annual Meeting, Springfield, IL, March 4-7, 1994.

Hoyt, P."R., T. A. Banks, C. Bartholomew, P. J. Blair, V. L. Godfrey, M. K. Kerley, W. H. Lee, B. L. M. Hogan, B. T. Rouse, J. N. Ihle, S. S. Potter, and M. L. Mucenski. Functional analysis of genes using the mouse as a model system. Human Genome Workshop, Santa Fe, NM, November 13-17, 1994.

Johnson, D. K., and L. J. Stubbs. Mouse RNAs for the determination of stageand tissue-specific expression profiles for human genes throughout development. Human Genome Workshop, Santa Fe, NM, November 13-17, 1994.

Kim, J. H., R. P. Woychik, W. O. Wilkison, D. Willard, S. Blanchard, and M. B. Zemel. Agouti gene regulation of intracellular free calcium $\left(\left[\mathrm{Ca}^{2+}\right] l\right)$ : Role in obesity and insulin resistance. Experimental Biology 95, Atlanta, GA, April 9-13, 1995.

Klebig, M. L., J. E. Wilkinson, and R. P. Woychik. Ectopic expression of the agouti gene in transgenic mice causes obesity, hyperinsulinemia, and yellow coat color. Cold Spring Harbor Meeting on Mouse Molecular Genetics, Cold Spring Harbor, NY, August 31-September 4, 1994.

Kleinhans, F. W., J. Du, J. Tao, L. Horstman, V. S. Travis, K. E. Colvin, P. Mazur, and J. K. Critser. EPR studies of mammalian sperm. In Vivo EPR and EPR Studies of Viable Biological Systems, Hanover, NH, October 1722, 1993.

Larimer, F. W., T.-Y. S. Lu, and D. M. Buley. Sequence and expression of the form II ribulose-bisphosphate carboxylase/oxygenase (Rubisco) gene from Rhodobacter capsulatus. 1995 American Society for Biochemistry and Molecular Biology Annual Meeting, San Francisco, CA, May 21-25, 1995. 
Lin, H.-H., and M. L. Mucenski. Differential gene expression in C-MYB mutant mice. Cold Spring Harbor Meeting on Mouse Molecular Genetics, Cold Spring Harbor, NY, August 31-September 4, 1994.

Lin, H.-H., S. G. Shinpock, M. K. Kerley, D. M. Popp, R. A. Popp, and M. L. Mucenski. Hematopoietic analyses of c-myb mutant mice. 23rd Annual Meeting of the International Society for Experimental Hematology, Minneapolis, MN, August 21-25, 1994.

Lin, H.-H., D. C. Sternfeld, and M. L. Mucenski. Functional analysis of the c-myb proto-oncogene. Workshop on the Molecular Aspects of Myeloid Stem Cell Development, Annapolis, MD, April 30-May 3, 1995.

Mazur, P. Acute chilling injury in non-mammalian embryos. Society for Cryobiology Annual Meeting, Madison, WI, July 6-11, 1995.

Mazur, P., K. W. Cole, P. D. Schreuders, S. Heimansohn, and M. d. P. Valencia. Chill sensitivity of embryos of the malaria mosquito Anopheles gambiae: A comparison with Drosophila. 31st Annual Meeting of the Society for Cryobiology, Kyoto, Japan, August 20-26, 1994.

Mazur, P., K. Cole, P. Schreuders, M.-d.-P. Valencia, and L. Miller. Challenges in the cryobiological preservation of Anopheles gambiae embryos. MacArthur Foundation, 1995 Vector Biology, Network Scientific Institute, Denver, CO, June 15-18, 1995.

Michaud, E. J., M. J. van Vugt, S. J. Bultman, H. O. Sweet, M. T. Davisson, and R. P. Woychik. Differential expression of a new dominant agouti allele $\left(A^{\text {iapy }}\right)$ is correlated with methylation state and is influenced by parental lineage. Cold Spring Harbor Meeting on Mouse Molecular Genetics, Cold Spring Harbor, NY, August 31-September 4, 1994.

Minks, C. E., A. T. Peter, P. Mazur, F. W. Kleinhans, and J. K. Critser. Osmotic behavior of mouse spermatozoa. American Society of Andrology, 1995 Annual Meeting, Raleigh, NC, March 31-April 4, 1995.

Murray, M. B., and S. K. Niyogi. Mutational analysis of histidine 10 of human epidermal growth factor (hEGF). 1995 American Society for Biochemistry and Molecular Biology Annual Meeting, San Francisco, CA, May 21-25, 1995.

Mynatt, R. L., M. L. Klebig, J. E. Wilkinson, and R. P. Woychik. Ectopic expression of the agouti gene in transgenic mice as a model for obesity and non-insulin dependent diabetes mellitus. Experimental Biology 95, Atlanta, GA, April 9-13, 1995. 
Mynatt, R. L., M. L. Klebig, J. E. Wilkinson, and R. P. Woychik. Obesity and a form of non-insulin dependent diabetes mellitus result from the ectopic expression of the agouti gene in transgenic mice. OBESITY Advances in Understanding and Treatment, Washington, DC, February 27-March 1, 1995.

Nandagopal, K., and S. K. Niyogi. Functional analysis of histidine 16 of human epidermal growth factor by site-directed mutagenesis. 1995 American Society for Biochemistry and Molecular Biology Annual Meeting, San Francisco, CA, May 21-25, 1995.

Nandagopal, K., D. K. Tadaki, and S. K. Niyogi. Mutational analysis of leucine 15 of human epidermal growth factor (hEGF). American Societies for Biochemistry and Molecular Biology, Washington, DC, May 21-25, 1994.

Nandagopal, K., D. K. Tadaki, and S. K. Niyogi. Mutational analysis of leucine 15 of human epidermal growth factor (hEGF). 16th International Congress of Biochemistry and Molecular Biology, New Delhi, India, September 19-22, 1994.

Nicholls, R. D., C. C. Glenn, M. T. C. Jong, S. Saitoh, E. M. Rinchik, H. Cedar, and D. J. Driscoll. Complexities of genomic imprinting in Prader-Willi and Angelman syndromes. American Society for Biochemistry and Molecular Biology, Keystone, CO, October 22-25, 1993.

Nicholls, R. D., M. T. C. Jong, C. C. Glenn, A. H. Carey, S. Saitoh, K. A. Porter, H. Cedar, L. Stubbs, M. H. Lau, C. Stewart, E. M. Rinchik, and D. J. Driscoll. Complex molecular mechanisms and multiple genes are involved in imprinting in Prader-Willi and Angelman syndromes. Keystone Symposia on Molecular and Cellular Biology, Copper Mountain, CO, January 15-22, 1994.

Niyogi, S. K., S. R. Campion, and D. K. Tadaki. Engineering of human EGF: Functional analysis of specific aromatic and ionic residues. Symposium on Protein, Structure, Function and Engineering, Calcutta, India, September 16-17, 1994.

Niyogi, S. K., S. R. Campion, D. K. Tadaki, M. R. Hauser, and J. S. Cook. Mapping the receptor binding/activation residues of human EGF by protein engineering. 1993 American Physiological Society Conference: Signal Transduction and Gene Regulation, San Francisco, CA, November 17-20, 1993. 
Niyogi, S. K., D. K. Tadaki, and S. R. Campion. Structure-function analysis of EGF-receptor interaction by site-directed mutagenesis. Keystone Symposium on Breast \& Prostate Cancer, Lake Tahoe, CA, March 14-21, 1994.

Niyogi, S. K., D. K. Tadaki, K. Nandagopal, and S. R. Campion. Structurefunction analysis of EGF-receptor interaction by protein engineering. 16th International Congress of Biochemistry and Molecular Biology, New Delhi, India, September 19-22, 1994.

Olins, A. L., D. E. Olins, V. Olman, H. A. Levy, and D. P. Bazett-Jones. The 3-D architecture of RNA in the Balbiani ring granule (hnRNP) International Congress on Electron Microscopy 13, Paris, France, July 17-22, 1994.

Popp, D. M., S. G. Shinpock, R. A. Popp, and M. L. Mucenski. Flow cytometric analysis of murine fetal liver hemopoietic stem cells. Hematopoietic Stem Cell Conference, Seattle, WA, June 10-15, 1994.

Popp, D. M., M. Y. Yang, T. Poole, and R. A. Popp. Quantitation and characterization of MuLV infected lymphoid cells using flow cytometry. International Cytometry Symposium, San Francisco, CA, January 18-21, 1994.

Popp, R. A., D. M. Popp, M. Y. Yang, M. E. Overcash, and S. G. Shinpock. Flow cytometric and immunological studies on animal models of human diseases. South Central Flow Cytometry Association Annual Meeting, Little Rock, AR, May 4-6, 1995.

Popp, R., S. Shinpock, D. Popp, and T. Poole. An improved transgenic mouse model of sickle cell disease. 19th Sickle Cell Program, New York, NY, March 23-26, 1994.

Popp, R. A., S. G. Shinpock, D. M. Popp, T. Poole, and E. Rubin. Combined expression of two HbS Antilles transgenes in $\mathrm{MHOAH}$ mice. IX Hemoglobin Switching Conference, Seattle, WA, June 10-15, 1994.

Richards, W. G., B. K. Yoder, P. G. Detilleux, R. J. Isfort, C. Foster, N. Neilsen, J. E. Wilkinson, and R. P. Woychik. Isolation and characterization of putative oval cells from livers of $\mathrm{Tg} 737$ mice. FASEB Summer Research Conference, Saxtons River, VT, August 7-12, 1994.

Richards, W. G., B. K. Yoder, P. G. Detilleux, R. J. Isfort, J. H. Moyer, J. J. Schrick, C. Foster, N. Neilsen, J. E. Wilkinson, and R. P. Woychik. Biliary hyperplasia associated with the murine insertional mutation TgN737Rpw. Experimental Biology 95, Atlanta, GA, April 9-13, 1995. 
Russell, L. B. Germ-cell stage as a determinant of mutation rate and quality. Germ Line Conference, Bethesda, MD, November 16-18, 1994.

Rutledge, J. C., W. M. Generoso, J. E. Polika, and J. B. Bishop. Homeotic malformations induced by retinoic acid exposure of mice blastocysts. Teratology Society 34th Annual Meeting, San Juan, PR, June 24-30, 1994.

Schreuders, P. D., J. Kassis, and P. Mazur. A model describing the kinetics of water loss in Drosophila melanogaster embryos. 31st Annual Meeting of the Society for Cryobiology, Kyoto, Japan, August 20-26, 1994.

Schreuders, P. D., P. Mazur, J. N. Kassis, U. Schneider, and A. P. Mahowald. Effect of dechorionation and permeabilization on the rate of dehydration in Drosophila melanogaster embryos in air at $22^{\circ} \mathrm{C}$. 31 st Annual Meeting of the Society for Cryobiology, Kyoto, Japan, August 20-26, 1994.

Schrick, J. J., L. Onuchic, S. T. Reeders, J. R. Korenberg, X.-N. Chen, J. H. Moyer, and R. P. Woychik. Characterization of the homologous human gene for the mouse TG737 candidate polycystic kidney gene. Cold Spring Harbor Meeting on Mouse Molecular Genetics, Cold Spring Harbor, NY, August 31-September 4, 1994.

Shannon, M., M. L. Mucenski, L. Ashworth, and L. Stubbs. Comparative mapping of a conserved zinc-finger gene cluster in man and mouse. Human Genome Workshop, Santa Fe, NM, November 13-17, 1994.

Shelby, M. D., L. B. Russell, and W. M. Generoso. AZT, germ cell mutagenicity and reproductive toxicity tests. Environmental Mutagen Society Annual Meeting, St. Louis, MO, March 12-16, 1995.

Stevens, A., S. K. Niyogi, and K. Nandagopal. 5'-3' exonuclease-2 of Saccharomyces cerevisiae. RNA Processing Meeting of The RNA Society, Madison, WI, May 24-29, 1994.

Strouse, C. E., G. J. Bunick, M. N. Burnett, and C. K. Johnson. ORNL 4-circle neutron diffractometer. American Crystallography Association, Atlanta, GA, June 28-July 1, 1994.

Stubbs, L., K. Glantz, and E. Branscomb. Development and testing of a method for the purification of evolutionary conserved sequences from cloned human DNA. Human Genome Workshop, Santa Fe, NM, November 13-17, 1994. 
Tadaki, D. K., S. R. Campion, and S. K. Niyogi. Analysis of the tyrosine residues at positions 22 and 29 of human epidermal growth factor (hEGF) by sitedirected mutagenesis. American Societies for Biochemistry and Molecular Biology, Washington, DC, May 21-25, 1994.

Tao, J., J. Du, F. W. Kleinhans, E. S. Critser, P. Mazur, and J. K. Critser. Cryopreservation of mouse spermatozoa l: The effect of collection temperature on freezing survival of mouse spermatozoa after cooling and warming. American Society of Andrology, 1994 Annual Meeting, Springfield, IL, March 4-7, 1994.

Valencia, M. d. P., L. H. Miller, and P. Mazur. Permeabilization of embryos of Anopheles mosquitos. 31st Annual Meeting of the Society for Cryobiology, Kyoto, Japan, August 20-26, 1994.

Valencia, M. d. P., L. H. Miller, and P. Mazur. Water permeability of intact and dechorionated embryos of Anopheles mosquitos: Comparison with Drosophila. 31st Annual Meeting of the Society for Cryobiology, Kyoto, Japan, August 20-26, 1994.

Witonsky, S., C. Foster, J. Bowen, N. Neilsen, C. Sommardahl, U. Siebenlist, R. P. Woychik, and J. E. Wilkinson. Pathobiology of NF-KB transgenic mice. FASEB Meeting: Experimental Biology 95, Atlanta, GA, April 9-13, 1995.

Woychik, R. P., S. J. Bultman, E. J. Michaud, S. Hope, and M. Davisson. Understanding the genetic complexity of the agouti locus. Cold Spring Harbor Meeting on Mouse Molecular Genetics, Cold Spring Harbor, NY, August 31-September 4, 1994.

Woychik, R. P., S. J. Bultman, E. J. Michaud, H. Y. Kwon, M. L. Klebig, J. E. Wilkinson, I. Patel, and W. Wilkinson. Cloning of the gene associated with the yellow obese agouti mutation. Molecular and Genetic Aspects of Obesity. Symposium, Baton Route, LA, February 20-23, 1994.

Woychik, R., L. Russell, L. Stubbs, D. Johnson, W. Generoso, M. Mucenski, E. Michaud, and E. Wilkinson. Genome-wide mouse mutagenesis and the functional analysis of genes in humans and mice. Seventh International Genome Sequencing and Analysis Conference, Hilton Head, SC, September 16-20, 1995.

Woychik, R. P., L. Stubbs, M. L. Mucenski, J. Moyer, H. Kwon, W. G. Richards, B. Yoder, and J. E. Wilkinson. Mouse genome studies aimed at deciphering gene function. Human Genome Workshop, Santa Fe, NM, November 13-17, 1994. 
Yang, M.-Y., D. M. Popp, and R. A. Popp. The route of retroviral transmission in B10.F mice identified by flow cytometric methods that detect cell surface MuLV antigen expression. Southern States Flow Cytometry Meeting, Nashville, TN, May 20-21, 1994.

Yoder, B. K., W. G. Richards, J. H. Moyer, J. J. Schrick, E. Wilkinson, and R. P. Woychik. Analysis of a candidate gene (Tg737) involved in the development of autosomal recessive polycystic kidney disease in mice. Cold Spring Harbor Meeting on Mouse Molecular Genetics, Cold Spring Harbor, NY, August 31-September 4, 1994.

Zimmerman, W., B. Fischer, M. Weiss, A. Olsen, L. Stubbs, and N. Beauchemin. Mapping of the murine CEA/PSG gene family region. CEA/PSG Gene Workshop, Freiburg, Germany, July 18-20, 1994. 


\section{Grants}

\begin{tabular}{|c|c|c|}
\hline $\begin{array}{l}\text { Principal } \\
\text { Investigator }\end{array}$ & Title & $\begin{array}{l}\text { Inclusive } \\
\text { Dates }\end{array}$ \\
\hline G. J. Bunick & $\begin{array}{l}\text { Structural Studies of Nucleosomes } \\
\text { (NIH) }\end{array}$ & $01 / 91-12 / 95$ \\
\hline V. L. Godfrey & $\begin{array}{l}\text { Immunobiology of Scurfy Mouse } \\
\text { (NIH) }\end{array}$ & $09 / 92-05 / 95$ \\
\hline F. C. Hartman & $\begin{array}{l}\text { Characterization of } \\
\text { Phosphoribulokinase (USDA) }\end{array}$ & $10 / 86-09 / 96$ \\
\hline D. K. Johnson & $\begin{array}{l}\text { Molecular Genetics of Palate } \\
\text { Development in Mice (NIH) }\end{array}$ & $04 / 94-04 / 97$ \\
\hline P. Mazur & $\begin{array}{l}\text { Cryobiological Preservation of } \\
\text { Anopheles Embryos (NIH) }\end{array}$ & $08 / 95-07 / 98$ \\
\hline A. L. Olins & Chromatin Structure (NIH) & $11 / 90-03 / 94$ \\
\hline \multirow[t]{2}{*}{ D. E. Olins } & $\begin{array}{l}\text { Development of Electron } \\
\text { Microscope Tomography (NIH) }\end{array}$ & $05 / 91-01 / 96$ \\
\hline & $\begin{array}{l}\text { Structure and Function of the } \\
\text { Replication Band (NSF) }\end{array}$ & $01 / 89-12 / 95$ \\
\hline D. M. Skinner & Crustacean Proteins (NSF) & $09 / 89-12 / 95$ \\
\hline M. Terzaghi-Howe & $\begin{array}{l}\text { Cell Interactions: Expression of } \\
\text { Preneoplastic Markers (NIH) }\end{array}$ & $05 / 83-06 / 96$ \\
\hline
\end{tabular}


Contracts

\begin{tabular}{|c|c|c|}
\hline $\begin{array}{l}\text { Principal } \\
\text { Investigator }\end{array}$ & Title & $\begin{array}{l}\text { Inclusive } \\
\text { Dates }\end{array}$ \\
\hline \multirow[t]{2}{*}{ W. M. Generoso } & Translocation Tests in Mice (NIEHS) & $06 / 82-09 / 95$ \\
\hline & $\begin{array}{l}\text { Identification of Genes Affecting the } \\
\text { Immune System (Darwin Molecular) }\end{array}$ & $05 / 95-11 / 98$ \\
\hline \multirow[t]{3}{*}{ P. Mazur } & $\begin{array}{l}\text { Cryopreservation of Mouse Embryos } \\
\text { (OHSU) }\end{array}$ & $06 / 88-05 / 95$ \\
\hline & Frozen Embryos (NSF) & $07 / 93-03 / 94$ \\
\hline & Cryobiology of Mouse Sperm (NIH) & $05 / 94-04 / 97$ \\
\hline R. A. Popp & $\begin{array}{l}\text { Mutant Hemoglobins that Allow } \\
\text { Hb S to Sickle (NIH) }\end{array}$ & $07 / 89-04 / 96$ \\
\hline L. B. Russell & $\begin{array}{l}\text { Chemical Mutagenicity Studies in } \\
\text { Mice (NIEHS) }\end{array}$ & $05 / 81-09 / 95$ \\
\hline P. B. Selby & $\begin{array}{l}\text { Assessment of Dominant Damage } \\
\text { (Westlakes Research [Trading] Ltd.) }\end{array}$ & $09 / 94-09 / 95$ \\
\hline \multirow[t]{4}{*}{ R. P. Woychik } & $\begin{array}{l}\text { Epithelial Cells within the Liver of } \\
\text { Mutant Mice (P\&G) }\end{array}$ & $03 / 93-03 / 96$ \\
\hline & Agouti Gene (Glaxo) & $01 / 94-12 / 96$ \\
\hline & TG737 Mouse (NIH) & $08 / 93-09 / 95$ \\
\hline & Transmit Gene Mutations (NIEHS) & $05 / 81-09 / 95$ \\
\hline
\end{tabular}




\section{Financial Summary and Personnel Distribution}

Total Biology Division

FY 1994

\begin{tabular}{|c|c|c|c|}
\hline Funding Source & $\begin{array}{l}\text { Funding in } \\
\text { Thousands }\end{array}$ & $\begin{array}{c}\text { Percent of } \\
\text { Total } \\
\text { Budget }\end{array}$ & $\begin{array}{c}\text { Scientific } \\
\text { Technical } \\
\text { Person- } \\
\text { Years* } \\
\end{array}$ \\
\hline Department of Energy & 10,205 & 82.4 & 38.8 \\
\hline National Cancer Institute & 211 & 1.7 & 0.7 \\
\hline $\begin{array}{l}\text { National Institute of Child Health and } \\
\text { Human Development }\end{array}$ & 134 & 1.1 & 0.9 \\
\hline $\begin{array}{l}\text { National Institute of Environmental } \\
\text { Health Sciences }\end{array}$ & 1,164 & 9.4 & 7.1 \\
\hline National Institute of Dental Research & 67 & 0.5 . & 0.6 \\
\hline University of Tennessee & 477 & 3.8 & 1.8 \\
\hline Oregon Health Sciences University & 27 & 0.2 & 0.2 \\
\hline Procter and Gamble Company & 44 & 0.4 & 0.3 \\
\hline \multirow[t]{2}{*}{ University of Texas } & 61 & 0.5 & 0.3 \\
\hline & 12,390 & 100.0 & 50.7 \\
\hline
\end{tabular}

*Does not include $\sim 41.8$ person years: 40.5 PY Distributed (administration and clerical, animal caretakers, histology, and kitchen); 1.3 PY supported by other divisions and ORNL seed money. 


\section{Financial Summary and Personnel Distribution}

Total Biology Division

FY 1995

\begin{tabular}{|c|c|c|c|}
\hline Funding Source & $\begin{array}{l}\text { Funding in } \\
\text { Thousands }\end{array}$ & $\begin{array}{c}\text { Percent of } \\
\text { Total } \\
\text { Budget }\end{array}$ & $\begin{array}{c}\text { Scientific/ } \\
\text { Technical } \\
\text { Person- } \\
\text { Years* } \\
\end{array}$ \\
\hline Department of Energy & 10,676 & 81.4 & 31.9 \\
\hline National Cancer Institute & 282 & 2.1 & 0.4 \\
\hline $\begin{array}{l}\text { National Institute of Child Health } \\
\text { and Human Development }\end{array}$ & 227 & 1.7 & 0.8 \\
\hline $\begin{array}{l}\text { National Institute of Environmental } \\
\text { Health Sciences }\end{array}$ & 1,281 & 9.8 & 8.6 \\
\hline National Institute of Dental Research & 243 & 1.9 & 1.8 \\
\hline University of Tennessee & 176 & 1.3 & 0.1 \\
\hline Oregon Health Sciences University & 23 & 0.2 & 0.1 \\
\hline PharMingen & 4 & 0.0 & 0.0 \\
\hline Westlakes Research Ltd. & 40 & $0.3^{\prime}$ & 0.0 \\
\hline Procter and Gamble Company & 52 & 0.4 & 0.2 \\
\hline \multirow[t]{2}{*}{ Darwin Molecular Corporation } & 123 & 0.9 & 0.6 \\
\hline & 13,127 & 100.0 & 44.2 \\
\hline
\end{tabular}

*Does not include $~ 46.8$ person years: 42.1 PY Distributed (administration and clerical, animal caretakers, histology, and kitchen); 4.6 PY supported by other divisions and ORNL seed money. 


\section{AUTHOR INDEX}

Arlinghaus, H. 22

Chen, C.H. 22

Arp, A. S. 48

Chen, Y.R. 7

Bangham, J.W. 48

Chittenden, L. R. 83

Banks, T.A. 71

Cole, K.W. 37

Barker, P.E. 67

Colitz, C.M. 67

Beatty, B.R. 48

Culiat, C.T. 58, 74, 77

Blair, P.J. 48

Davis, A.J. 71

Boroughs, J.B. 31

Dhar, M.S. 28

Brandes, H. 7

Do, M.T. 19

Bultman, S.J. 67

Doktycz, M.J. 22

Bunick, G.J. 19

Doyle, J.L. 77

Cacheiro, L.H. 28, 65

Drake, K.L. 48

Cacheiro, N.L.A. $48,65,74$

Dunn, W.C. 77

Cain, K.T. 65

Earhart, V.S. 62

Campion, S.R. 7

Einstein, J.R. 81

Carpenter, D.A. 58

Foote, L.J. 31

Carpenter, D.J. 48

Foote, R.S. 22

Carver, E.A. 74

Ford, J.R., Jr. 35

Chang, A.J. 67

Ford, V.A. 31

Chang, G.W. 35

Foster, C.M. 67, 77 
Fry, R.J.M. 33

Garrison, E.M. 62

Geck, M.K. 7

Geisler, J.G. 71

Generoso, E.E. 74, 77

Generoso, W.M. 65, 74

Gewiess, A. 19

Glantz, K.A. 83

Godfrey, V.L. 48

Griffith, E.D. 48

Guan, X. 81

Guinn, G.M. 48

Hall, J.W. 37

Hardigree, A.A. 7

Harp, J.M. 19

Harpel, M.R. 7

Hartman, F.C. ix, 7

Hasan, A. 22

Hauser, L.J. 28, 77, 81

Heimansohn, S.S. 37

Henderson, S.J. 19

Herrmann, A.L. .28
Houser, K.J. 58

Hoyt, P.R. 71

Hughes, L.A. 65

Hunsicker, P.R. 48

Jackson, T.H. 37

Jacobson, K.B. 22

Jago, T.L. 62

Jetton, A.E. 37

Johnson, D.K. 58,77

Kassis, J.N. 37

Kelly, S.T. 62

Kennel, S.J. 31

Kerley, M.K. 71, 77

Klebig, M.L. 67

Kumari, S.S. 25

Kwon, H-Y. 67

Lankford, P.K. 31

Larimer, F.W. 7, 22

Larson, E. 7

Lee, W.H. 71, 77

Levy, H.A. 28

Lin, H-H. 71 
Lu, T-Y.S. 7

Matis, S. 81

Mazur, P. 37

Michaud, E.J. 67,77

Miltenberger, R.J. 67

Moyer, J.H. 67

Mucenski, M.L. 71, 77

Mural, R.J. 77,81

Murray, M.B. 7

Mynatt, R.L. 67

Nandagopal, K. 7

Niyogi, S.K. 7

Olins, A.L. 28

Olins, D.E. 28

OIman, V.N. 28

Olszewski, R.E. 48

Overcash, M.E. 35,72

Palmer, E.L. 19

Penland, V.M. 48

Petrov, S. 77

Plichta, S.A. 19, 35

Poole, T.L. 17, 72
Popp, D.M. 72

Popp, R.A. 72

Potter, M.D. 58

Ramsey, J.M. 22

Raymer, G.D. 62

Richards, W.G. 67

Rinchik, E.M. 48, 58

Rochat, S.D. 67

Robertson, S.D. 31

Russell, L.B. 48

Russell, W.L. 48

Schreuders, P. 37

Schrick, J.J. 67

Selby, P.B. 62

Shah, M.B. 77,81

Shannon, M.E. 77

Shinpock, S.G. 48,72

Shourbaji, A. 65

Skinner, D.M. 25

Sloop, F.V. 22

Smalley, L.A. 62

Sommardahl, C.S. 67 
Sobhani, M.T. 74

Stanford, B.G. 77,83

Steele, J.E. 48

Stengele, K.P. 22

Sternfels, H.A. 62

Stevens, A. 17

Stringer, C.D. 7

Stubbs, L.J. $74,76,77,83$

Tadaki, D.K. 7

Taylor, L.D. 67

Terzaghi-Howe, M. 35

Uberbacher, E.C. 77,81

Varadaraj, K. 25

Walkowicz, M.J. 58, 77

Warmack, R.J. 22

Wilkinson, J.E. 48,67

Withrow, C.M. 58

Witonsky, S.G. 48,67

Woychik, R.P. $22,45,67$

Wright, E.B. 35

Wu, M. 58

$\mathrm{Xu}, \mathrm{Y} .81$
Yang, M.Y. 72

Yette, M.L. 7

Yoder, T.R. $48,58,67$

York, M.L. 19 
ORNL 6875

Distribution Category UC-408

\section{INTERNAL DISTRIBUTION}

1. B. A. Berven

2. J. W. Culver

3. C. W. Gehrs

4. J. M. Gilbert

5-230. F. C. Hartman

231. S. G. Hildebrand

232. E. H. Krieg, Jr.

233. C. Krause

234. B. K. Mansfield

235. S. K. Niyogi

236. M. L. Poutsma

237-238. D. E. Reichle

239. M. J. Saltmarsh
240. R. F. Sincovec

241. D. A. Waters

242. R. P. Woychik

243. Biology Library

244. Biomedical Graduate School

245. Central Research Library

246. ORNL-Y-12 Technical Library Document Reference Section

247-248. Laboratory Records Department

249. Laboratory Records, ORNL, PC

250. ORNL Patent Office

251. Technical Publications

\section{EXTERNAL DISTRIBUTION}

252. Robert T. Acuff, Associate Dean for Research, James H. Quillen College of Medicine, East Tennessee State University, Johnson City, TN 37614-0414

253. Robert R. Appleson, Director, Division of Sponsored Research, 416 Kirkland Hall, Vanderbilt University, Nashville, TN 37240

254. Robert Barker, 295 Sudden Valley, Billingham, WA 98226

255. Benjamin J. Barnhart, Health Effects Research Division, ER-72, Office of Health and Environmental Research, DOE, Germantown, MD 20874-1290

256. Kathryn A. Bayne, American Association for Accreditation of Laboratory Animal Care, 11300 Rockville Pike, Suite 1211, Rockville, MD 20852-3035

257. James R. Beall, Health Effects Research Division, ER-72, Office of Health and Environmental Research, DOE, Germantown, MD 20874-1290

258. Elbert Branscomb, Human Genome Center, L-452, Lawrence Livermore National Laboratory, P. O. Box 5507, Livermore, CA 94551 
259. Anthony Carrano, Director, Human Genome Center, L-452, Lawrence Livermore National Laboratory, P. O. Box 5507, Livermore, CA 94551

260. Thomas Caskey, Institute for Molecular Genetics, Baylor College of Medicine, T809, One Baylor Plaza, Houston, TX 77030

261. Verne M. Chapman, Chairman, Department of Molecular Biology, and Associate Director-for Scientific Affairs, Roswell Park Memorial Institute, Buffalo, NY 14263

262. George Church, Department of Genetics, Harvard Medical School, 20 Shattuck Street, Boston, MA 02115

263. Mary E. Clutter, Assistant Director for Biological Sciences, National Science Foundation, 4201 Wilson Blvd., Arlington, VA 22230

264. Francis Collins, Director, National Center for Human Genome Research, 9000 Rockville Pike, Bldg. 38A, Bethesda, MD 20892

265. Frank Costantini, Department of Genetics and Development, Columbia University, Hammer Health Science Bldg., New York, NY 10032

266. F. L. Culler, Electric Power Research Institute, 3412 Hillview Avenue, P.O. Box 10412, Palo Alto, CA 94303

267. J. Glen Davis, Director, Medical Sciences Division, Oak Ridge Associated Universities, P.O. Box 117, Oak Ridge, TN 37830

268. Larry Deaven, Los Alamos National Laboratory, LS-4, MS-M888, Los Alamos, NM 87545

269. F. J. de Serres, Environmental Toxicology Program, NIEHS, MD 19-02, P.O. Box 12233, Research Triangle Park, NC 27709

270. A. Paul Duhamel, Physical and Technological Research Division, ER-74, Office of Health and Environmental Research, DOE, Germantown, MD 20874-1290

271. Lorraine Flaherty, Chief, Laboratory of Immunology, Wadsworth Center for Laboratories and Research, State of New York Department of Health, Albany, NY 12201

272. Marvin E. Frazier, Office of Health and Environmental Research, ER-72, DOE, Germantown, MD 20874-1290

273. Irwin Fridovich, Department of Biochemistry, Duke University Medical Center, Durham, NC 27710

274. David Friedman, Office of Solid Waste, U.S. Environmental Protection Agency, 2108 Waterslide Mall, Washington, DC 20460

275. William Frietsch, III, Deputy Director, Energy and Air Division, U.S. Environmental Protection Agency, Health Effects Research Laboratory, 26 West St. Clair, Cincinnati, OH 45268

276. David J. Galas, Vice President, R\&D, 22025 20th Avenue SE, Suite 1000, Bothell, WA 98021

277. Roger E. Ganschow, Division of Basic Science Research, Children's Hospital Research Foundation, IDR 721, Elland and Bethesda Avenues, Cincinnati, OH 45229 
278. Gerald Goldstein, Medical Applications and Biophysical Research Division, ER-73, Office of Health and Environmental Research, DOE, Germantown, MD 20874-1290

279. Judith H. Greenberg, Director, Genetics Program Branch, National Institute of General Medical Sciences, NIH, Westwood Bldg., Room 910, Bethesda, MD 20892

280. R. A. Griesemer, Deputy Director, National Institute of Environmental Health Sciences, P. O. Box 12233, Research Triangle Park, NC 27709-2233

281. F. Harris, Director, Biological Sciences Division, The University of Tennessee, Andy Holt Tower, Knoxville, TN 37996

282. Ronald W. Hart, Director, National Center for Toxicological Research, Jefferson, AR 72079

283. William C. Hilles, Office of the Administrator, The Johns Hopkins Oncology Center, 600 North Wolfe Street, Baltimore, MD 21205

284. David G. Hoel, Associate Director for Risk Assessment, National Institute of Environmental Health Sciences, Research Triangle Park, NC 27709

285. William A. Hoffman, Jr., Director, Oak Ridge Science Semester, GLCA, Denison University, Main Street, Granville, $\mathrm{OH} 43023$

286. Leroy E. Hood, Department of Molecular Biotechnology, University of Washington, FJ-20, Seattle, WA 98195

287. David Housman, Center for Cancer Research, Massachusetts Institute of Technology, E17-543, 77 Massachusetts Avenue, Cambridge, MA 02139

288. E. Huberman, Director, Biological and Medical Research, Argonne National Laboratory, 9700 South Cass Avenue, Argonne, IL 60439

289. Beth Jinkerson, University Programs Division, Oak Ridge Associated Universities, Oak Ridge, TN 37830

290. Barry L. Johnson, Associate Administrator, Agency for Toxic Substances and Disease Registry, Atlanta, GA 30333

291. Charles W. Johnson, Vice President for Academic Affairs, Meharry Medical College, Nashville, TN 37208

292. H. Ronald Kaback, Howard Hughes Medical Institute, Professor, Department of Physiology, University of California at Los Angeles, 5-748 McDonald Research Laboratories, 10833 LeConte Avenue, Los Angeles, CA 90024

293. Ruth L. Kirschstein, Director, National Institute of General Medical Sciences, NIH, Westwood Bldg., Room 926, Bethesda, MD 20892

294. Hans Lehrach, Imperial Cancer Research Labs, Lincoln's Inn Fields, London, WC2A 3P, England

295. David C. Longfellow, Chief, Chemical and Physical Carcinogenesis Branch, Division of Cancer Etiology, National Cancer Institute, Executive Plaza North, Suite 700, Bethesda, MD 20892 
296. Gail R. Martin, Department of Anatomy, University of California at San Francisco, 513 Parnassus Street, S-1457, San Francisco, CA 94143-0452

297. Mortimer L. Mendelsohn, Biomedical Sciences Division, Lawrence Livermore National Laboratory, P. O. Box 5507, L-452, Livermore, CA 94551

298. C. W. Minkel, Associate Vice Chancellor for Graduate Programs, The University of Tennessee, 404 Andy Holt Tower, Knoxville, Tf' 37996

299. Robert K. Moyzis, CHGS-MS M885, Los Alamos National Laboratory, Los Alamos, NM 87545

300. Albert E. New, American Association for Accreditation of Laboratory Care, 11300 Rockville Pike, Suite 1211, Rockville, MD 20852-3035

301. W. R. Ney, Executive Director, National Council on Radiation Protection and Measurements, 7910 Woodmont Avenue, Suite 1016, Washington, DC 20014

302. Heather Nicholls, Program Manager, Colorado Bio/Medical Venture Center, 1610 Pierce, Lakewood, CO 80214

303. Kenneth Olden, Director, National Institute of Environmental Health Sciences, P. O. Box 12233, Research Triangle Park, NC 27709

304. Aristides Patrinos, Associate Director, Office of Health and Environmental Research, Office of Energy Research, ER-70, DOE, Germantown, MD 20874-1290

305. Henry C. Pitot, Director, McArdle Laboratory for Cancer Research, University of Wisconsin, Madison, WI 53706

306. Michael J. Prival, Genetic Toxicology Branch, Food and Drug Administration, 200 C Street, SW, Washington, DC 20204

307. C. A. Reilly, Division of Biological and Medical Research, Argonne National Laboratory, 9700 S. Cass Avenue, Argonne, IL 60439

308. Lee L. Riedinger, Associate Vice Chancellor for Research Administration, The University of Tennessee, 404 Andy Holt Tower, Knoxville, TN 37996

309. Jasper Rine, Director, Human Genome Center, Lawrence Berkeley Laboratory, 459 Donner Laboratory, 1 Cyclotron Road, Berkeley, CA 94720

310. William J. Rutter, Department of Biochemistry and Biophysics, University of California, San Francisco, 964 Medical Science Bldg., San Francisco, CA 94143

311. William J. Schull, Director, Center for Demographic \& Population Genetics, The University of Texas Health Science Center, P.O. Box 20334, Houston, TX 77225

312. James K. Selkirk, Laboratory of Molecular Carcinogenesis Branch, National Institute of Environmental Health Sciences, 111 Alexander Drive, D4-03, Research Triangle Park, NC 27709

313. Richard B. Setlow, Associate Director for Life Sciences, Brookhaven National Laboratory, 50 Bell Avenue, Upton, Long Island, NY 11973 
314. K. Sexton, Director, Office of Health Research, RD 683, U.S. Environmental Protection Agency, Washington, DC 20460

315. M. D. Shelby, National Toxicology Program, National Institute of Environmental Health Sciences, P.O. Box 12233, Research Triangle Park, NC 27709

316. Sydney Siegel, National Library of Medicine, 8600 Rockville Pike, Bethesda, MD 20209

317. W. K. Sinclair, National Council on Radiation Protection and Measurements, 7910 Woodmont Avenue, Suite 1016, Bethesda, MD 20814-3095

318. David A. Smith, Director, Health Effects Research Division, ER-72, Office of Health and Environmental Research, DOE, Germantown, MD 20874-1290

319. W. T. Snyder, Chancellor, The University of Tennessee, 527 Andy Holt Tower, Knoxville, TN 37996

320. Sylvia Spengler, Human Genome Center, Lawrence Berkeley Laboratory, 1 Cyclotron Road, Berkeley, CA 94720

321. John Stewart, Consortium for Research Institutes, 830 Corridor Park Blvd., Suite 200, Knoxville, TN 37932

322. Marvin Stodolsky, Health Effects Research Division, ER-72, Office of Health and Environmental Research, DOE, Washington, DC 20585

323. John B. Storer, 592 Eagle Point Road, Rockwood, TN 37854

324. R. W. Tennant, Chief, Cellular Genetic Toxicology Branch, National Institute of Environmental Health Sciences, P. O. Box 12233, Research Triangle Park, NC 27709

325. P. Floyd Thomas, Manager, Lockheed Martin Energy Systems, Inc., Oak Ridge National Laboratory, 600 Maryland Avenue S.W., Suite 306W, Washington, DC 20024

326. Robert Thomas, Health Effects Research Division, ER-72, Office of Health and Environmental Research, DOE, Germantown, MD 20874-1290

327. Shirley M. Tilghman, Department of Molecular Genetics, Princeton University, Princeton, NJ 08544

328. M. N. Varma, Physical and Technological Research Division, ER-74, Office of Health and Environmental Research, DOE, Germantown, MD 20874-1290

329. Jon M. Veigel, President, Oak Ridge Institute for Science Education, P.O. Box 117, Oak Ridge, TN 37830

330. Candace C. Vessella, Director, Washington Operations, Lockheed Martin Corporation, 499 S Capitol Street, Crystal City, VA

331. Joseph J. Villafranca, Professor, Department of Chemistry, 152 Davey Laboratory, Pennsylvania State University, University Park, PA 16802

332. Bruce Walcholz, Low Level Radiation Effects Branch, National Cancer Institute, 6130 Executive Blvd. N., Bethesda, MD 20205 
333. Michael D. Waters, PhD., Assistant Laboratory Director, MD-51A, National Health and Environmental Effects Research Laboratory, U.S. Environmental Protection Agency, Research Triangle Park, NC 27711

334. Brandon H. Weirs, Procter \& Gamble Company, Miami Valley Laboratories, P.O. Box 398707, Cincinnati, OH 45239-8707

335. Arthur Weissbach, P.O. Box 168, Sanibel, FL 33957

336. A. Wohlpart, Division Director and Vice President, Science/Engineering Education Division, Oak Ridge Institute for Science and Education, Oak Ridge, TN 37831-0117

337. John C. Wooley, Deputy Associate Director, Office of Health and Environmental Research, Office of Energy Research, ER-70, DOE, Germantown, MD 20874-1290

338. Alvin L. Young, Scientific Director, Office of Agricultural Biotechnology, U.S. Department of Agriculture, Room 321-A, Administration Building, 14th \& Independence Avenue, S.W., Washington, DC 20250

339. S. Ziegeler, Darwin Molecular Corporation, 22025 20th Avenue SE, Bothell, WA 98021

340. Assistant Administrator for Research and Development, U.S. Environmental Protection Agency, Office of Research and Development, RD672, Washington, DC 20460

341. Biochemistry Department Head, The University of Tennessee, M407 Walter Life Sciences, Knoxville, TN 37996-0840

342. Biology Department Head, The University of Tennessee, M303 Walter Life Sciences, Knoxville, TN 37996-1110

343. Botany Department Head., The University of Tennessee, 437 Hesler Biology Bldg., Knoxville, TN 37996-1100

344. Director, National Cancer Institute, National Cancer Program, 9000 Rockville Pike, Bethesda, MD 20892

345. Director, National Institutes of Health, Bldg. 1, Room 126, 9000 Rockville Pike, Bethesda, MD 20892

346. Director, Office of Energy Research, DOE, 1000 Independence Avenue SW, Washington, DC 20585

347. Microbiology Department Head., The University of Tennessee, M409 Walter Life Sciences, Knoxville, TN 37996-0845

348. National Library of Medicine, Serial Records Section, 8600 Rockville Pike, Bethesda, MD 20209

349. National Radiological Protection Board, Librarian, Chilton Didcot, Oxfordshire OXII ORO, England

350. Oak Ridge Institute for Science and Education, H. T. Burn, Librarian, Information Center/EES, P.O. Box 117, Oak Ridge, TN 37831-0117

351. Office of Assistant Manager for Energy Research and Development, Department of Energy, Oak Ridge Operations, P.O. Box 2001, Oak Ridge, TN 37831-8600 
352. Zoology Department Head, The University of Tennessee, M313 Walter Life Sciences, Knoxville, TN 37996-0810

353-397. Given distribution as shown in DOE/TIC-4500 under Biology and Medicine category, UC-408 